Florida International University FIU Digital Commons

10-11-1991

\title{
The effect of direct instruction in story grammar using deep processing on the reading and writing achievement of second graders
}

Joyce Caplan Fine

Florida International University

DOI: $10.25148 /$ etd.FI15101399

Follow this and additional works at: https:// digitalcommons.fiu.edu/etd

Part of the Curriculum and Instruction Commons

\section{Recommended Citation}

Fine, Joyce Caplan, "The effect of direct instruction in story grammar using deep processing on the reading and writing achievement of second graders" (1991). FIU Electronic Theses and Dissertations. 3323.

https://digitalcommons.fiu.edu/etd/3323 
ABSTRACT OF THE DISSERTATION

The Effect of Direct Instruction in Story Grammar Using Deep Processing on the Reading and Writing Achievement of Second Graders

by

Joyce Caplan Fine

Florida International University, 1991

Miami, Florida

Professor Sharon W. Kossack, Major Professor Professor Lynne D. Miller, Major Professor

The purpose of this study was to investigate the effects of direct instruction in story grammar on the reading and writing achievement of second graders. Three aspects of story grammar (character, setting, and plot) were taught with direct instruction using the concept development technique of deep processing. Deep processing which included (a) visualization (the drawing of pictures), (b) verbalization (the writing of sentences), (c) the attachment of physical sensations, and (d) the attachment of emotions to concepts was used to help students make mental connections necessary for recall and application of character, setting, and plot when constructing meaning in reading and writing. 
Four existing classrooms consisting of seventy-seven second-grade students were randomly assigned to two treatments, experimental and comparison. Both groups were pretested and posttested for reading achievement using the Gates-MacGinitie Reading Tests. Pretest and posttest writing samples were collected and evaluated. Writing achievement was measured using (a) a primary trait scoring scale (an adapted version of the Glazer Narrative Composition Scale) and (b) an holistic scoring scale by R. J. Pritchard. ANCOVAs were performed on the posttests adjusted for the pretests to determine whether or not the methods differed. There was no significant improvement in reading after the eleven-day experimental period for either group; nor did the two groups differ. There was significant improvement in writing for the experimental group over the comparison group. Pretreatment and posttreatment interviews were selectively collected to evaluate qualitatively if the students were able to identify and manipulate elements of story grammar and to determine patterns in metacognitive processing. Interviews provided evidence that most students in the experimental group gained while most students in the comparison group did not gain in their ability to manipulate, with understanding, the concepts of character, setting, and plot. 
FLORIDA INTERNATIONAL UNIVERSITY

Miami, Florida

The Effect of Direct Instruction in Story Grammar Using Deep Processing on the Reading and Writing Achievement of Second Graders

A dissertation submitted in partial satisfaction of the requirements for the degree of Doctor of Education in curriculum and Instruction

by

Joyce Caplan Fine 
- copyright by

Joyce Caplan Fine 1991 
To Professors: Sharon W. Kossack, Lynne D. Miller, and Paulette M. Johnson.

This dissertation, having been approved in respect of form and mechanical execution, is referred to you for judgement upon its substantial merit.

Dean I. Ira Goldenberg

College of Education

The dissertation of Joyce Caplan Fine is approved.

Paulette M. Johnson

Lynne D. Miller, Major Professor

Sharon w. Kossack, Major Professor October 11, 1991

Dean Richard L. Campbell

Division of Graduate studies

Florida International University, 1991 


\section{DEDICATION}

To my husband, Roger Fine, my children, Andrew Fine,

Laura Fine Freedman, and Seth Freedman, and my parents, Ruth and Daniel Caplan 


\section{ACKNOWLEDGMENTS}

I wish to express my appreciation to Drs. Sharon Kossack, Lynne Miller, and Paulette Johnson for their guidance, encouragement, and the benefit of their insight and wisdom.

Next, I wish to thank the principal, Trudy Edelman, the teachers, Debbie Ring, Amy Sakowitz, Lisa Brown, and Lillian Marrero, and the students for their efforts in teaching and learning.

Many thanks also go to Risa Adler and Kathy Klein for their help in data collection, and Dr. Janice Sandiford, Ruth Cirone, and Virginia Miller for their technical support.

Finally, I wish to extend my sincere gratitude to my family, friends, and colleagues who have been a source of strength in helping me to complete this dissertation, especially. .

To my husband, Dr. Roger Fine, my children, Andrew Fine, Laura Fine Freedman, and Seth Freedman, from whom I have learned so much, for their love, support, patience, and understanding.

To Dr. Sharon Kossack for her friendship, encouragement, and unselfish support since the beginning of my graduate career.

To Dr. Lynne Miller for her friendship, patience, and gentle push to excellence. 
To Trudy Edelman for her faith, support, and encouragement.

To Bonnie Perry for her love, friendship, and encouragement for many years.

To my parents, Ruth and Daniel Caplan for their love, encouragement, and support.

THANK YOU! 
July 4,1945

1967, B.A.

1983, M.S.

1968

$1973-1979$

$1979-1990$

$1983-1989$

$1984-1989$

$1986-1987$

1990

$1990-1991$

1991
Born, Baltimore, Maryland

Education

Goucher College

Towson, Maryland

Reading Education

Florida International

University

Miami, Florida

Adult Education Teacher

English to Speakers of other Languages

Los Angeles, California

Elementary School Teacher Dade county, Florida

Tutoring Practice

Adjunct Professor

Florida International

University

Educational consultant MacMillan Publishing Company

Laboratory Facilitator

Sabal Palm Elementary School

Dade county, Florida

Educational consultant

Harcourt Brace Jovanovich

Visiting Professor

Florida International

University

Instructor

Florida International

University 


\section{PUBLICATIONS AND PRESENTATIONS}

Fine, J. C., Kossack, S.W., \& Johnson, P. (1986, December). Learning bridges falling down: Basal progression and transfer called to question. Paper presented at the meeting of the American Reading Forum, Sarasota, FL.

Kossack, S., Kane, S., \& Fine, J. (1987). The readingwriting connection. Journal of Reading, 30, 730-732.

Newspaper in Education (NIE) (1984-1988). A series of workshops in reading and writing. The Miami Herald, Dade and Broward counties. 
Page

DEDICATION

ACKNOWLEDGEMENTS

VITA

TABLE OF CONTENTS

viii

LIST OF FIGURES

xii

LIST OF TABLES

xiii

CHAPTER ONE Introduction ............ 1

Background of the Problem . . . . . . . . . . 1

Sociological Issues . . . . . . . . . . . . 1

Theoretical Issues... . . . . . . . . . . 2

Pedagogical Issues... . . . . . . . . . . . 4

Statement of the Problem . . . . . . . . . 6

The Purpose of the study . . . . . . . . . . 6

Questions to be Answered . . . . . . . . . 7

Quantitative.............. . . . 7

Qualitative . . . . . . . . . . . 8

Significance ................. . . . 8

Assumptions . . . . . . . . . . . . . . . 8

Limitations . . . . . . . . . . . . . . . 9

Definition of Terms............. . 10

CHAPTER TWO Review of the Literature . . . . . . 13

A Process Approach to Reading and Writing . . . 13

The Relationship Between Reading and

Writing .................. 18

A Child's Sense of story . . . . . . . . . 23

Direct Instruction in story Grammar . . . . . . . 25

Deep Processing... . . . . . . . . . . . 28

Visualization . . . . . . . . . . . . 29

The Attachment of Emotions . . . . . . . . 33

The Attachment of Physical Sensations . . . . 34

Summary of Literature Review . . . . . . . . 35

CHAPTER THREE Design of the Study . . . . . . . 36

Description of Research Methodology . . . . . 36

Research Design and Hypotheses . . . . . . . 36

Quantitative Phase... . . . . . . . 37

Hypotheses . . . . . . . . . . 38 
Page

Reading . . . . . . . . . . . 38

Writing . . . . . . . . . . . 38

Qualitative Phase . . . . . . . . . . . 38

procedures and Methods . . . . . . . . . . . 39

Pilot studies . . . . . . . . . . . . . 39

Sample Population . . . . . . . . . . 39

Quantitative Phase . . . . . . . . . . . 41

Reading achievement: Instrument. . . . . . 41

Reading and writing achievement: Training of teachers ........... . . . . 41

Writing achievement: Samples . . . . . . 42

Writing achievement: Assessment

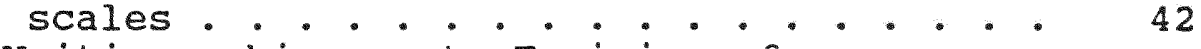

Writing achievement: Training of
raters.......... . . . . . . . . . 43

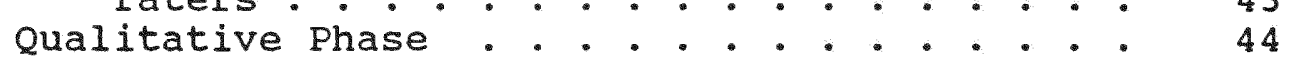

Metacognitive assessment: Instrument . . . 44

Metacognitive assessment: Training
and administration....... . . . . . . 47

Classroom Treatments . . . . . . . . . . . 47

Experimental group materials: stories . . . 47

Experimental group materials: Lessons . . 48

Experimental group: Teacher training . . . 49

Experimental group: Application . . . . . 51

Comparison group materials: Stories . . . . 52

Comparison group materials: Lessons . . . 53

Comparison group: Teacher training . . . . 53

Comparison group: Application ... . . . . 54

Data Collection and Analysis . . . . . . . . 55

Quantitative Phase... . . . . . . . . 55

Gathering data . . . . . . . . . . 55

Scoring. . . . . . . . . . . . . . 55

Analysis . . . . . . . . . . . . 56

Qualitative Phase . . . . . . . . . . 58

Gathering data ........... . . 58

Analysis ................ . 58

Summary . . . . . . . . . . . . . . . . 58

CHAPTER FOUR Results and Discussion . . . . . . 60

Results Related to the Improvement in Reading Achievement .................... 60

Discussion . . . . . . . . . . . . . . 64

Results Related to the Improvement in Writing Achievement . . . . . . . . . . . . . 68

Discussion . . . . . . . . . . . . . 74 
Results Related to Comparing the Primary Trait scoring scale and the Holistic scoring

Scale . . . . . . . . . . . . . . . . 77

Discussion . . . . . . . . . . . . . 78

Results Related to the Qualitative Analysis of

the Interviews for the Experimental Group . .

Reading Tables: Explanation of Terms and

Symbols . . . . . . . . . . . . . 79

Character............... 80

Setting . . . . . . . . . . . . 83

Plot . . . . . . . . . . . . . 83

Metacognitive Patterns . . . . . . . 88

Discussion . . . . . . . . . . . . . . 90

Results Related to the Qualitative Analysis of

the Comparison Group . . . . . . . . . . . 91

character . . . . . . . . . . . . . 92

Setting . . . . . . . . . . . . . . . . 92

Plot . . . . . . . . . . . . . . . . 97

Metacognitive Patterns . . . . . . . . 97

Discussion . . . . . . . . . . . . . 100

Summary of the Findings ............ 101

Discussion of the Findings . . . . . . . . . 102

An Individual Case ............ . 102

CHAPTER FIVE Summary, Conclusions, and

Recommendations . . . . . . . . . . . . 104

Restatement of the Problem . . . . . . . . 104

Related Research . . . . . . . . . . . . 104

Design and Procedures... . . . . . . . . 105

Findings of the study . . . . . . . . . . . . 107

Quantitative............... 107

Qualitative ...... . . . . . . . 108

Conclusions . . . . . . . . . . . . . . 109

Implications . . . . . . . . . . . . . . 109

Recommendations for Future Research . . . . . . 110

Discussion . . . . . . . . . . . . . . . 111

BIBLIOGRAPHY . . . . . . . . . . . 113

APPENDICES

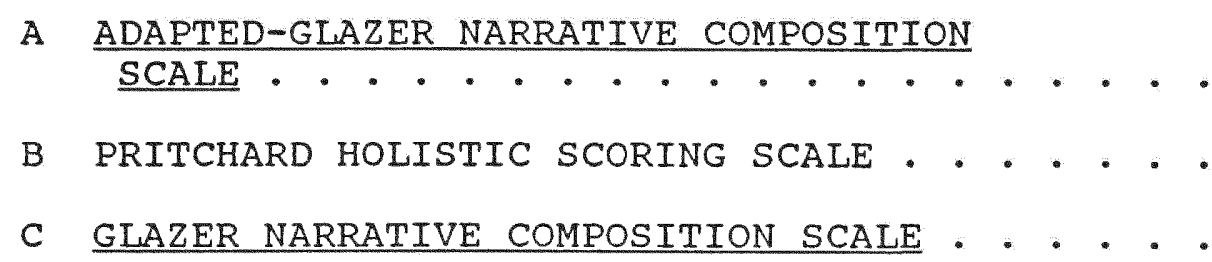


D DIRECT INSTRUCTION LESSONS DEEP PROCESSING STORY GRAMMAR: EXPERIMENTAL GROUP . . . . . 137

E MODIFIED DIRECTED READING LESSON: COMPARISON GROUP . . . . . . . . . . . 155

F QUALITATIVE ANALYSIS FORM . . . . . . . . 165 
Figure

1 Pretest and posttest writing means for story grammar on the adapted-Glazer Narrative Composition Scale . . . . . . . . . . . .

2 Pretest and posttest adjusted writing means on the adapted-Glazer Narrative Composition

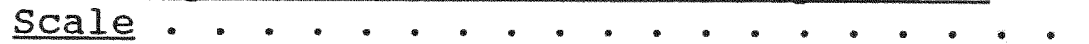

3 The differences between pretest and posttest means for story grammar, style, and total on the adapted-Glazer Narrative composition

Scale . . . . . . . . . . . . . . . 
Table

Page

1 Pretest Means by Treatment Group: Reading

Measure Scores . . . . . . . . . . . . .

2 Pretest, Posttest, and Adjusted Posttest Means by Treatment Group: Reading Measure

Scores .......................

3 Differences Between Pretest and Posttest for Each Group: Reading Measure Scores . . . .

4 Pretest Means by Treatment Group: Writing Measure Scores

5 Pretest, Posttest, and Adjusted Means by Treatment Group: Writing Measure Scores . .

6 Differences Between Pretest and Posttest for Each Group: Writing Measure Scores . . . .

7 Correlations of Primary-Trait scale with Holistic scale ....... . . . . . . .

8 Number of students Who Attained Acquisition of a Level for the Concept of Character: Experimental Group ..... . . . . . . . . .

9 Acquisition Level for the concept of Character: Experimental Group . . . . . . . . . . .

10 Number of students Who Attained Acquisition of a Level for the Concept of Setting: Experimental Group ............. . . . .

11 Acquisition Level for the concept of setting: Experimental Group . . . . . . . . . . .

12 Number of students Who Attained Acquisition of a Level for the concept of Plot: Experimental Group . . . . . . . . . . . . . . .

13 Acquisition Level for the concept of Plot: Experimental Group . . . . . . . . . . .

14 Metacognitive Patterns: Experimental Group 
15 Number of students Who Attained Acquisition of a Level for the concept of Character: Comparison Group . . . . . . . . . . . .

16 Acquisition Level for the concept of character: Comparison Group . . . . . . . . . . .

17 Number of students who Attained Acquisition of a Level for the concept of setting: Comparison Group . . . . . . . . . . . . . . . . .

18 Acquisition Level for the concept of setting: Comparison Group ...............

19 Number of students Who Attained Acquisition of a Level for the concept of Plot: Comparison Group . . . . . . . . . . . . . . .

20 Acquisition Level for the concept of Plot: Comparison Group . . . . . . . . . . . .

21 Metacognitive Patterns: Comparison Group . . . 100 


\section{CHAPTER ONE}

\section{Introduction}

The purpose of this chapter is to present the (a) background of the problem, (b) statement of the problem, (c) purpose of the study, (d) questions to be answered, (e) significance, (f) assumptions, (g) Iimitations, and (h) definitions of terms.

\section{Background of the Problem}

\section{Sociological Issues}

During the 1980 s several educational reports focused the nation's attention on the problem of the rising number of Americans who were unable to read and write sufficient1y. In one report, A Nation at Risk (1983), members of the National Commission on Excellence in Education stated that 23 million Americans were functionally illiterate and that our country's national security was at risk as a result. The Commission indicated that the low level of performance resulted in citizens who were disenfranchised, perhaps unmotivated to achieve, and disinterested in participating in national affairs. John Goodlad, in A Place Called School (1984), also reported problems related to a sterile, emotionally-neutral curriculum in which students were required to give low-level cognitive responses and seldom were asked to create their own products. In another report, Becoming a Nation of Readers (1985), the 
Presidential commission stated that to correct the problem of rising numbers of Americans who cannot read or write, students must have more opportunity to read. The Presidential commission also suggested that educators integrate reading and writing in the school curriculum instead of separating instruction as had been the case in most classrooms. This report underscored the need for a strategic approach to reading and writing which emphasizes process over product. These three reports heralded to educators the necessity of changing instruction if schools were to educate literate, involved citizens.

Theoretical Issues

The theoretical framework for this study was predicated on two changes in practices concerning the teaching of reading and writing that were widely observed in education. The first change involved a shift from a skills to a process focus. Educators should no longer teach as if reading and writing were the sum total of mastering isolated, sequential skills. This change resulted from a shift in a theoretical paradigm. Researchers moved from the framework of behaviorism to the framework of cognitive psychology to understand the acts of reading and writing. Within behaviorism's stimulus-response framework, teaching reading or writing was teaching a series of sequential skills that focused on products. In classroom teaching, 
reading or writing was often a sequence of assigning pages or topics, students reading or writing, and teachers rewarding with grades. These external rewards worked with some, but such rewards had complex consequences. Sometimes they resulted in mitigating learning by demotivating students (Deci \& Ryan, 1987). Within the framework of cognitive psychology, however, teaching reading and writing were facilitated with a process approach in a social environment where students were engaged in the use of strategies to construct meaning and to communicate. The social setting included students' inner meanings (prior knowledge and experience) and the outer realities (interpersonal relationships).

The second change involved the symbiotic nature of reading and writing. Reading should no longer be taught separately from writing. The integration of reading and writing instruction resulted from investigations into the relationship between these two forms of communication, even though the exact nature of the relationship has not been established (Stotsky, 1983). Educators have differing views of how this might be done. Jagger (1986) said that the nature of the relationship is unclear because most research has ignored the instructional context. Tierney and Leys (1984) said reading and writing are two sides to the same coin. Loban (cited in Stotsky, 1983) investigated the correlation of reading scores and writing 
scores, and Woodward and Phillips (cited in Stotsky, 1983) researched the effects of one on the other. Woodward and Phillips found that better writers tended to be better readers and that writing activities improved reading comprehension in instructional materials. They also found that more reading was better than grammar study (parts of speech) for improving writing. Stotsky (1983) also reported in her synthesis of research that the nature of the reading experience was as critical as giving writing instruction because using literary models led to significant gains in writing. Other researchers (Ballard, 1988; Zarnowski, 1990) reported improved writing in classrooms where reading and writing were integrated using literature. These researchers used techniques that included mapping story grammar, visualizing, and generating sentences with intermediate and middle school students.

\section{Pedagogical Issues}

Prior to entering school, not all children live in a print-rich environment where adult models cultivate motivation to become literate. Society then expects the teacher to establish an environment that helps to maximize the use of students' natural abilities with nurturing in the classroom. While this seems a monumental task, various educators have proposed possible ways of establishing such an environment. 
Suggestions for ways to better educate students were made by educational researchers such as calkins (1986), Goodman (1986), Graves (1983), Holdaway (1979), Smith (1973), and Wells (1981). They advocated changing instructional methodology to an holistic approach. This approach is based on a shift in emphasis from a product to a process focus using purposeful activities to develop reading and writing in social contexts. The methods they suggested emphasize students' intrinsic motivation when they are in an environment that encourages them to make sense of their world (Holdaway, 1979).

In an holistic classroom, the teachers' role has changed. Newman (1985) suggested teachers "lead from behind" by supporting students' initiatives (p. 5). This is similar to the way a parent encourages speech when a child is learning to communicate (Wells, 1981). Teachers need to provide activities through which students can discover meaning. Pearson (1985) suggested teachers be like good coaches, there at the right moment with the needed direction, encouraging students to take the next step.

In classrooms in which teachers use direct instruction methodology, it has been found that direct instruction on story grammar improved achievement in reading and writing for older students (Ballard, 1988; Gordon 1988, 1989). Additionally, there were a variety of other 
factors that impact on learning in the classroom. Paris, Lipson, and wixson (1983) describe the factors necessary for success as having the knowledge and the motivation to use it. Raphael (1984) identified teaching and learning environmental factors such as the students' psychological dispositions and social interactions as being important determinants.

\section{Statement of the Problem}

The sociological, theoretical, and pedagogical background of the problem suggested areas that needed to be addressed:

1. Reading and writing achievement need to be improved.

2. Educators need to find a way to teach reading and writing that is consistent with the nature of the processes.

3. Students need to be cognitively involved in their own learning.

\section{The Purpose of the study}

The purpose of the study was to investigate the effect of teaching aspects of story grammar (specifically, character, setting, and plot) with direct instruction in combination with deep processing (a concept development technique) on the reading and writing achievement of second graders. 
This study investigated whether second graders taught with direct instruction and deep processing improved in reading and writing more than students taught with modified directed reading lessons featuring vocabulary instruction and written multi-level comprehension questions. Through interviews, the researcher examined if secondgrade students grasped the concepts of character, setting, and plot to the degree that they were able to verbalize about the use of these concepts to write and revise their own narratives. Additionally, students' metacognitive patterns for writing were identified.

\section{Questions to be Answered}

Specific research questions asked were as follows:

\section{Quantitative}

1. Is direct instruction in three aspects of story grammar (character, setting, and plot) using deep processing better for improving reading achievement scores than modified directed reading lessons?

2. Is direct instruction in three aspects of story grammar (character, setting, and plot) using deep processing better for improving writing achievement scores than writing linked to modified directed reading lessons? 


\section{Qualitative}

3. Can students identify and manipulate the concepts of story grammar (character, setting, and plot) in their own narratives?

4. What metacognitive patterns do the students use in writing narratives?

\section{Significance}

By investigating the use of techniques for deep processing ideas, a thinking skill, educators may come closer to understanding processes involved with cognitive growth and human creativity. The inclusion of the elements of deep processing (visualization, verbalization, the attachment of physical sensations, and emotion) may enable teachers to create task environments that help students develop and use concepts related to story grammar. Gains in achievement will suggest that teachers can construct and deliver lessons which stimulate young students to manage the tasks of comprehending and composing more easily.

\section{Assumptions}

The study is based on the following assumptions:

1. Reading and writing are related processes.

2. Constructing meaning in reading and writing is reflective of the thinking processes in the mind. 
3. Story grammar is a viable means of developing and measuring the reader's organization of narrative information.

4. Story gramar is a viable means of developing and measuring the writer's organization of narrative information.

5. The introspective self-reports of second graders accurately reflect their thinking.

\section{Limitations}

The study has the following limitations:

1. The fact that all the parents of the students gave permission for participation so easily may indicate that the sample population comes from home environments that are positively biased toward attaining literacy. 2. The Glazer Narrative Composition Scale was normed with fourth through sixth graders. The scale was, however, recommended as a writing assessment instrument for primary grades by the National Council of Teachers of English.

3. The generalizability of the findings may be Iimited due to the size of the sample which was decreased from the original size due to school absences because of chicken pox and other illnesses.

4. Studying students in pre-assigned classrooms may have affected the broader generalizability of the findings. 
5. The brief time allowed for the implementation of the treatments may have hindered obtaining positive results.

6. Measured changes in student behavior may not be long lasting.

\section{Definition of Terms}

For the purpose of this study these terms were defined as follows:

ATTACHMENT OF EMOTIONS: thinking about the internal, affective responses a character would feel

ATTACHMENT OF PHYSICAL SENSATIONS: thinking about the reaction (e.g., feel, taste, smell, hear) to external stimulation one feels while doing an activity

DEEP PROCESSING: a strategic thinking process which included verbalization, visualization, the attachment of physical sensations, and the attachment of emotion (Marzano \& Arredondo, 1986)

DIRECT INSTRUCTION: a process in which the teacher clearly showed, demonstrated, or modeled for students what was to be learned; provided opportunities for students to use what was learned; provided corrective feedback, and monitored as students learned (Duffy \& Roehler, 1989) INTEGRATED INSTRUCTION: instruction using meaningful, purposeful activities to build competence in both reading and writing where each was important within the same lesson context 
INTERVIEWER: the researcher or one of two elementary education major seniors who asked questions on a one-toone basis to students for an introspective, self-report METACOGNITION: ability to think about one's own thinking as evidenced through self reports

MODIFIED DIRECTED READING LESSON: a planned reading activity in which the teacher provided needed background information, instruction in critical vocabulary, an oral reading of the story followed by students rereading, discussing, and participating in a follow-up activity

PLOT: the part of story that was divided into (a) the problem or goal, (b) the response or feeling, (c) the action attempt, and (d) the outcome or ending

RESEARCHER: author of the study

STORY GRAMMAR: the parts of story limited to characters, setting, and plot

SCAFFOLDING: mediating learning from one level to the next highest level

STYLE: characteristics of writing including such aspects as the match of title to content, sentence structure, word usage, dialogue, emotional quality, unusual literary elements, and the use of theme

TEACHER: person responsible for instruction in an individual classroom

VERBALIZATION: putting thoughts into written sentences 
VISUALIZATION: mental imaging represented by the pictures the students drew of the aspects of story grammar 


\section{Review of the Literature}

It is the purpose of this chapter to review literature which is relevant to the following areas: (a) a process approach to reading and writing, (b) the relationship between reading and writing, (c) a child's sense of story, (d) direct instruction in story grammar, and (e) deep processing.

\section{A Process Approach to Reading and Writing}

For many years, the emphasis in both reading and writing instruction has been on product, not process. This product orientation resulted in an emphasis on the mechanical surface elements in reading and writing: Reading instruction focused on precise reader application with phonics and question drills; writing instruction centered around grammar and punctuation study. Over the years, despite various obstacles, reading and writing instruction has continued to evolve toward a meaning-first, process orientation.

Early pioneers of reading instruction advocated process and meaning. In 1908, Huey wrote that reading instruction that develops meaning was more beneficial than skills instruction (Pearson, 1985). Such meaning-based reading curriculum, with the additional element of a social environment, was endorsed by Kilpatrick in 1918 in 
the form of the "Project Method" which later became an experience curriculum (cited in Kliebard, 1982). There was much support for this meaning-based method at first, but it lost popularity for several reasons. One reason was flawed curriculum in which the activities became more important than the knowledge learned. A second reason was societal influences such as the acceptance of principles of scientific management and industrialization. A third reason was the attempt to establish psychology as a scientific field of study requiring research on observable, measurable aspects of reading. Replacing the early meaning-based orientation was a stimulus-response orientation which has formed the basis of reading instruction for the past seventy years (Goodman, Shannon, Freeman, \& Murphy 1988).

During the seventy years of product oriented instruction, classroom teachers emphasized word recognition and comprehension skills. This practice led to problems. First, teachers believed that the basal readers included everything all students needed to learn to be literate (Goodman, Shannon, Freeman, \& Murphy, 1988). Second, students were saturated with skill practice. Third, students were often routinely moved through basal series without necessarily being able to comprehend sufficiently. Many teachers assumed that when students had progressed through the skills of one level of the basal, they were definitely 
ready for the next. A closer look at this assumption, even in an advantaged school, showed that less than $1 \%$ of the student population were functioning on an independent level on the reader they had just completed (Fine, Kossack, \& Johnson, 1986).

Other evidence suggesting that the stimulus-response product orientation might not be working was the high number of dropouts and the identification of a large atrisk student population. Because of increasing problems, educational change agents began to look for ways to improve instructional approaches so more students would be successful (Routman, 1988). Researchers (Cooper \& Petrosky, 1976; Goodman cited in Samuels \& Kamil, 1984; Smith, 1973) from the field of psycholinguistics, the science that combines cognitive psychology and linguistics, questioned the "skills first" approach. They argued that readers seek meaning first and that skills were useful only in so far as they contributed to meaning. Such a shift in the theoretical perspective produced a redefinition of the act of reading. Reading was now seen as a constructive process in which the reader interacts with the text to build meaning. To facilitate learning, the teacher needed to be concerned with the mental processes of the reader. Instead of the "stimulus-response" framework, more attention was directed to the thought processes involved. What had only been represented by the hyphen in 
the term stimulus-response (thinking) had been neglected completely or left to the student to do independently. Processing had become the focus of instruction under a cognitive psychology perspective (Goodman et al., 1988).

One of the earliest advocates of process writing instruction was the National Council of Teachers of English (NCTE). This professional group endorsed the "experience curriculum" for teaching writing. The NCTE recognized writing as recursive in nature, an important communication tool having social relevance and requiring social interaction with real purposes for writing to real and varied audiences. With the advent of World War II, attention turned to a technical and functional curriculum. Even though the NCTE promoted process, much of the writing in school was taught in a lock-step method: The teacher assigned, the student wrote, and the teacher corrected the product (Anderson \& Lapp, 1988).

Ethnographic researchers in the field of writing have documented concerns relevant to the teaching of writing with the product approach. For example, Britton, Burgess, Martin, McLeod, and Rosen (1975) reported from research with adolescents that writing was transactional in nature. By "transactional" they specifically meant the function of writing was to transmit information to an audience of one (the teacher) in a first-draft-as-final-version, test-like situation. There was little chance to write and almost no 
time to write to any audience other than the teacher. Even when given the chance to write stories, other ethnographic researchers (Freeman, Samuelson, \& Sanders, 1986; Goodlad, 1984) confirmed that teachers and students were "repetitively preoccupied with the mechanics of usage" (Goodlad, 1984, p. 243).

Some of the research analyzed what the writer must bring to the task of writing. According to Hillocks (1987), researchers found there are four different types of knowledge needed to write: (a) knowledge of content, (b) knowledge of the process to manipulate the content, (c) knowledge of text structures, and (d) knowledge of the process to manipulate text structures to produce writing. This information continued to shift interest in instructional methods to a process approach.

In the field of elementary education, Graves (1981) has been a strong advocate of a process approach to writing instruction. He documented the relationship of talking, drawing, reading, and writing in the writing process. He found that writers discover their meaning while they write and that they may lose control over some aspect of writing which they had been able to control (Newman, 1985).

In summary, the emphasis in instruction of reading and writing has been changing from product to process. While this movement has roots in the past, this change is 
a redirection from what has been uniformly accepted for the greater part of this century.

The Relationship Between Reading and Writing

For most of this century, teachers taught reading and writing separately. The processes were viewed as complementary sides of a coin: Reading was receptive and imitative, and writing expressive and generative (Durkin, 1989; Wittrock, 1983). Then Smith (1983) explained that the amount of specialized knowledge needed to write cannot come from lectures, textbooks, or drills. Instead, it must come from reading like a writer. Even though he believed that fluent readers do not pay attention to spelling and punctuation, he recognized that they do learn intuitively, from reading, much of the knowledge needed to write. He further explained that if teachers have provided opportunities for students to see themselves as writers of text, they will begin to pay attention to conventions that writers use. It is now thought that readers and writers may use different thought processes and behaviors, even though they both use generative processes for constructing meaning (Wittrock, 1983).

Four tasks or phases common to both reading and writing processes were described by Tierney and Pearson (1983). In the first phase, they viewed the student as a planner. The reader planned a purpose for reading, and the writer planned a purpose for writing. In the second 
phase, the student was a composer. The reader read and composed a meaning of the author's message, and the writer composed his or her own meaning. In the third phase, the student was an editor. The reader reread, reflected, and revised meaning, and the writer revised the text with intended meaning. In the fourth phase, the student was a monitor. The reader finalized meaning, and the writer finalized message. Tierney and Pearson (1983) also saw a similarity in the "tug of war" between authors and their readers and the internal struggle to compose meaning as one reads (p. 569).

wittrock (1983) pointed out similarities in the psychological aspects of ownership and choice in reading and writing. He argued that ownership (a sense of empowerment to create one's own meaning either from text or with text) and choice (the right to select personally meaningful topics to read or to write) were imperative to the reading and writing processes. Calkins (1986) insisted teachers must not impose their own agendas on students. students' own lives and their own personal concerns are appropriate topics. When given choice, the students were more likely to be motivated by their own interests and intentions. Atwell (1987) said that a first step to motivating students to read and write was to allow them to "exert ownership and choose the literature that they will read" (p. 161). 
What impact has reading on writing and vice versa? With the shift to an emphasis on process over product, educators began to suggest that instruction should be integrated. Newman (1985) advocated, "Reading is an inextricable part of the writing process. Children learn a great deal about reading while writing; they learn about writing while reading" (p. 27). Bromley (1988) supported the notion of integrated instruction from a language acquisition point of view by pointing out that since both reading and writing share the same symbol system and require thinking, learning one reinforces the other. In contrast, sommers (1988) suggested that ability in one area may not necessarily transfer to the other because both require different thinking strategies.

Given these contrasting beliefs, researchers continued to show an interest in the reading-writing relationship. If the processes underlying reading and writing were similar, one would expect there would be a high statistical correlation between achievement scores. Yet, Tierney and Leys (1984) found there was only a modest correlation between overall reading and writing achievement with some fluctuation due to age and the measures used. They observed that not all good readers were good writers, and, conversely, not all good writers were good readers. They did, however, find that process-oriented writing influences students to read text like a writer, 
using the structure of the text to help them comprehend the author's message.

While Tierney and Leys looked at the correlation in general and noted that what students read influences how they write, other researchers looked at specific aspects of transfer in the relationship. Devries (cited in Eckhoff, 1983) found that increased reading practice improved writing. Chomsky (cited in Eckhoff, 1983) suggested that students learned complex language patterns from reading. Eckhoff (1983) compared the writing of students who had read original stories with the writing of students who had read rewritten versions of stories and found that the students wrote at the same level of complexity as the stories they had read. Taylor and Beach (1984) were able to improve middle-school students' reading and writing of expository text by asking them to write paragraphs using the same structure patterns as the expository text used in the study. Meyers (cited in stotsky, 1983) also found support for the idea that readers tend to use authors' organizational plans.

Has the notion of transfer of strategies from reading to writing or vice versa been investigated as it applies to primary students? Westbrooks (1987) found that second graders who wrote basal summaries after reading basal stories did not read significantly better but improved their writing of basal summaries. Tompkins and McGee 
(1989) described in their work with kindergartners and first graders a methodology that models repetitive stories. They recommended using the predictable nature of these stories to help children use parallel ideas to write stories as a total class and then to write their own versions.

A review of the professional literature revealed that the relationship between reading and writing is not completely known. Nonetheless, Shanahan (1988) has summarized several principles that capsulize the application of reading-writing research as it relates to the classroom. These are the following:

1. Both reading and writing need to be taught.

2. Both should be taught from the earliest grades.

3. Instruction in reading and writing should be taught differently at different developmental stages.

4. The connections between reading and writing should be made explicit to the students.

5. Instruction must include both product and process knowledge.

6. The communication aspect of reading and writing should be emphasized.

7. Both should be taught in meaningful contexts. Furthermore, it seems that lessons that include built-in transfer between the reading and writing processes may be 
necessary for effective, integrated instruction (Sommers, 1988).

\section{A Child's Sense of story}

A child's sense of story is a concept that may develop from an early age. Vygotsky (1962) explored concept development, in general, and described stages of progressive complexity. All the basic intellectual functions take part in the formation of a concept, a process that cannot be reduced to association, attention, imagery, or inference (Marzano \& Arredondo, 1986: Vygotsky, 1962). Concept formation requires a problem that needs to be solved (such as making communication meaningful).

Vygotsky also warned that researchers must understand the bonds between the external task and the total social and cultural situation as it impacts thinking. The stages Vygotsky named and described in general concept development were used by Applebee (1978) to identify the development of a child's sense of story (concept of story). Applebee found that most children have a sense of story by the time they are starting school and are able to tell a story orally.

Stages in the development of a concept of story led people, regardless of culture, to tell and create (Stein \& Glenn, 1979) stories which included the same elements (e.g., character, setting, and plot) in a similar pattern. The pattern is referred to as story grammar, i.e., the way 
narrative information is stored in the mind (Golden, 1984; Marshall, 1984).

Research has supported that children have an intuitive sense of story. Applebee (1978) found that kindergarten students used their sense of story to guide their responses to questions about stories or to tell their own oral stories. Stein's research (cited in Squire, 1983) suggested that children who knew how to read before coming to school had internalized the basic story grammar and had prepared themselves to understand the basic patterns. Barnes (1987) found that three-, four-, and five-year-olds could understand stories with story grammar parts as stories more often than those without story grammar parts. Way (1988) found that first- and second-grade children preferred stories that had been rewritten with explicit story grammar, over stories without it, which suggested that young children had a sense of what makes a story. Feldmen (1983) found that it was easier for children to read and comprehend text that followed story grammar format.

Yet another researcher investigated the impact of story grammar on reading comprehension. Rose (1983) found that, in order of importance, knowledge of concept of story came after grade, intelligence, and previous reading achievement when determining the difference in comprehension. In her study of third and sixth graders, there was 
a positive correlation between comprehension of narrative text and concept of story, but there was no positive correlation between concept of story and writing stories.

Even though there is evidence supporting the intuitive nature of story grammar, there appear to be developmental differences in the use and understanding of story grammar (Mandler \& Johnson, 1977; Taylor, 1980). Mandler and Johnson (1977) found differences between children's and adults' use of story grammar concepts. In Taylor's (1980) study, sixth graders were more likely to use story grammar in their recalls than children in lower grades. Besides differences between age groups, Marzano and Arredondo (1986) stated that any individual's concepts may be developed to different degrees. The first level is attainment, having surface knowledge such as a label or mental image, and the second is development, knowing examples or attributes.

In summary, research has shown the following:

1. The development of a sense of story follows the same stages of development as concept development in young children in general.

2. Knowledge of story grammar makes a difference in comprehension.

\section{Direct Instruction in Story Grammar}

Direct instruction is an instructional process in which the teacher uses various combinations of the 
following: telling why something is important to learn, modeling how to apply it, giving examples, giving guided practice, and providing the opportunity for independent student application. A number of researchers showed that the mean improvement in reading comprehension for groups getting direct instruction was statistically significant. Specifically, singer and Donlan (1982) taught averageability students for one week using direct instruction in story grammar and were able to improve reading comprehension. Gurney (cited in Gersten, 1989) taught story grammar to mildly-handicapped high school students who were three to six years below grade level. They improved in their ability to answer comprehension questions. Carnine and Kinder (1985) and Idol and Croll (1987) investigated teaching story grammar using direct instruction, including using as subjects low-performing fourth- to sixth-grade students. Idol and croll also added the dimension of story maps, graphic representations of the parts, and the relationships of story grammar (cited in Davis \& McPherson, 1990). Idol and Croll (1987) showed that by combining direct instruction in story grammar with an instructional technique that included a visual component with verbal input, comprehension improved. Ballard (1988) also used direct instruction in story grammar using mapping to improve comprehension. She extended the scope of 
the study to investigate the effect on original composition as well as on reading, and found that eighth-grade students improved. Fitzgerald and spiegel (1983) and Spiegel and Fitzgerald (1986) used direct instruction in story grammar elements, taught one at a time, when teaching 20 fourth graders who had been identified as deficient in this area of knowledge. These students improved in both their literal and inferential comprehension and also produced stories including more elements of story grammar. Subjects in these studies were intermediate-aged students or older.

In studies using story grammar with very young students, Ratliff (1986) found preschoolers' listening comprehension improved after direct instruction in story grammar. Similarly, Smith (1986) worked with first graders using wordless picture books. The experimental group was given instruction in story grammar. The control group illustrated the stories. The results showed an improvement in only one area, the number of propositions included in the retelling. A possible factor contributing to the lack of significant differences may have been the control group's illustration activity, a process activity involving drawing parts of the story.

Further contributing to the importance of process is the sense of ownership from creating something. In a 
study using story grammar, Johnson (1987) found a difference in the reading comprehension of fourth-grade students. The experimental group constructed their own story maps. The control group used a cloze paragraph provided by the teacher. This suggested that, perhaps, ownership and the physical involvement contributed to the success of this personal story-mapping technique.

In summary, direct instruction in story grammar seems to improve reading ability. Other factors that contribute seem to be ownership and physical involvement which may include drawing and mapping.

\section{Deep Processing}

Marzano and Arredondo (1986) explained there were four parts to a concept: (a) Iinguistic information, mental pictures, (c) physical sensations, and (d) emotions. They said that well-known concepts are known linguistically and non-linguistically. Deep processing is a concept development procedure to help students acquire and/or develop the Iinguistic and non-linguistic aspects of concepts. Deep processing is the conscious generation of parts of a concept.

Marzano and Arredondo (1986) gave several advantages for teaching this learning strategy. First, as a memory device, it is useful when studying factual information. Second, it helps students elaborate on information; and, third, it stimulates creative thinking. Marzano and 
Arredondo stated that: in schools, little effort has been made to help students develop the non-linguistic parts of concepts and that deep processing should be added to instructional methodology.

Research in each aspect of deep processing will be presented in the following sections: (a) visualization, (b) attaching emotional meaning to the concepts to be learned, and (c) attaching meaning via physical sensations.

\section{Visualization}

A search of the literature revealed that visualization can be equated with drawing and with mental imagery. Throughout the ages, drawn images have been a form of communication. Before there were written languages, there were pictures on cave walls throughout the world, regardless of culture. From the Middle Ages when artists painted scenes to tell religious stories, to the present when governments provide international pictographs to communicate important information, drawn images have been important. Likewise in education, drawing has been recognized as an aid in the development of another form of communication, composition (Calkins, 1986). Therefore, a closer look at the theoretical underpinnings of visualization (drawing and mental images), a major aspect of deep processing, is appropriate. 
Bruner's (1975) theory of cognitive growth explains that children go through three stages. The first is the enactive stage in which a child learns from interacting with his or her environment. The next level of cognitive growth is the iconic stage in which information is carried by images, but decisions are still made on the basis of sensory perception. The third stage is the symbolic stage in which the child mediates learning with language. Visual and sensory cues are needed prior to the use of language. If teachers are to help children advance from their current level of development to the next highest level, while working within their zone of proximal development (Vygotsky, 1978), they need to provide children with opportunities that provide a scaffold for cognitive growth (Bruner, 1975; Palinscar, 1986).

Consistent with Bruner's ideas of cognitive growth, Calkins (1986) observed possible stages related to the emergence of writing ability. She encouraged the drawing of images as a form of rehearsal or prewriting for young children. She explained that very young children draw first and then name what they have drawn. Next, they name while drawing. Lastly, they decide before drawing. She said that the act of drawing and the actual picture provides mental scaffolding, an instructional process that bridges learning from one level of functioning to the next. This use of visualization exemplifies a gradual 
increase in control over the writing process, with picture drawing being a prewriting stage. Turnbill (1984) attempted to extend to older children the use of drawing to help sort ideas before writing. Siegel (cited in Goodman, Watson, \& Burke, 1987) suggested that older students do "sketch-to-stretch" activities to enable them to take a different perspective and to get meaning they might have missed (p. 49). However, Calkins cautioned that a child may only write about what he or she can draw. While drawing is one aspect of visualization, mental imagery is an equally important aspect. Research has been conducted in the area of mental imagery since the beginning of experimental psychology (Richardson, 1969). Although there was little interest during the period of stimulus-response learning theory, with the shift to cognitive psychology, more studies were conducted involving mental imaging. Levin (cited in Gage \& Berliner, 1988) found that until children were about seven, they were unable to make mental images from verbal suggestions. They needed to draw what they were told to visualize. Alvermann and Boothby (1982) reported that making pictures helped fourth graders to understand what they had read. These researchers suggested teachers help children to use visualization (mental imagery) to improve comprehension of expository as well as narrative texts. 
Winzenz (1988) studied the relationship of mental images and reading comprehension. All the college undergraduates who comprised the population in the study reported the use of mental images. Also, the number of images was significantly related to the degree of literal comprehension. Through a qualitative review of data, Winzenz determined that there was a difference in the types of images made by college students reading on different levels. The better readers were able to use their images to make inferences, draw conclusions, and make judgments. This study showed that the existence, frequency, quality, and use of visualizations contributed to comprehension. In contrast, stoll (1983) tried to use imagery training in a game format to affect comprehension and creativity. The students, however, did no creative production in the training, and results were not significant.

Bryant (1986) studied the effects of visualization, verbalization, or no given study strategy on retention of social studies concepts for sixth-graders. One experimental group was taught to answer embedded questions in a social studies expository text by drawing answers. A second experimental group was taught to answer with short essays. The control group read the same text without embedded questions. Bryant's results showed no difference in retention of concepts from expository texts among the 
groups. Each of these groups used only one aspect or none of the aspects identified by Marzano and Arredondo as being central to the development of a concept.

The Attachment of Emotions

The attachment of emotions appears to be key in reading comprehension in several ways. Emotions seem to be closely linked to aesthetic reading (reading to live or feel the experience). According to Rosenblatt (1976): Through the medium of words, the text brings into the reader's consciousness certain concepts, certain sensuous experiences, certain images of things, people, actions, scenes. The special meanings and, more particularly, the submerged associations that these words and images have for the individual reader will largely determine what the work communicates to him. The reader brings to the work personality traits, memories of past events, present needs and preoccupations, a particular mood of the moment, and a particular physical condition. These and many other elements in a never-to-be-duplicated combination determine his response to the peculiar contribution of the text. (p. 30-31)

Franklin (1988) supported Rosenblatt's belief when he reported results from his study showing that students, when asked to draw a picture and write what they liked about a story, drew and wrote very personal meanings. 
Emotions help students comprehend by facilitating the storage and retrieval of information. Piaget (cited in Marzano, 1991) said that everything is both cognitive and affective. Halgren, Wilson, Squires, Engel, Walter, and Crandall (cited in Caine \& Caine, 1990) found that cognition and emotions could not be separated. The first step in responding to literature may be to become aware of emotional responses and to label them by name (Marzano, 1991). Additionally, emotion may be a bridging device which helps students to comprehend by relating prior emotional experience to text (Norton, 1991).

\section{The Attachment of Physical sensations}

Kinesthetic modes of teaching have been recognized as a means of keeping students actively involved in the learning process. Active learning (motor involvement) during or after instruction is more likely to result in longer and greater retention (Hovland, Lumsdaine, \& Sheffield, cited in Gage \& Berliner, 1988). According to Gage and Berliner (1988), active learning and the use of imagery result in better learning. Varley, Levin, Severson, and Wolff (cited in Gage \& Berliner, 1988) said they believe learning could be facilitated with motor involvement, pictorial representations, and verbal coding by getting students to draw. It may be that the time to do these activities gives students time to think through ideas. This thinking through has been referred to as 
"ideating" by Smith, Goodman, and Meredith (cited in Goodman, Watson, \& Burke, 1987, p. 44) who asserted that the reading process involves (a) perceiving meaning and relating it to what is known; (b) "ideating," or working through meaning; and (c) presenting meaning through some means such as drawing.

\section{Summary of Literature Review}

Research seems to suggest the following:

1. Educators are encouraged in elementary school to use a process approach to instruction in reading and writing.

2. Reading and writing seem to be related and may be best taught in an integrated manner.

3. Reading literature seems to promote writing.

4. Story grammar represents the organization of narrative text structure in the mind.

5. Scaffolded instruction (moving from a student's level of proximal development to the next level) optimizes learning.

6. Children have an intuitive sense of story.

7. Drawing enhances writing for young children.

8. Direct instruction in story grammar helps make students aware of story grammar concepts.

9. Direct instruction in story grammar improves students' achievement in reading and writing.

10. Deep processing helps students learn concepts. 
Design of the Study

The purpose of this chapter is to present: (a) a description of the research methodology; (b) the research design and hypotheses: (c) procedures and methods including pilot studies, the population, instruments, and classroom treatments; and (d) data collection and analysis.

\section{Description of Research Methodology}

Both quantitative and qualitative research methods were applied. The quantitative measures were used to assess gains in achievement in reading and writing. Both t-tests and analysis of covariance (ANCOVA) were performed on dependent variables. The qualitative procedures extended the scope of the study to include what could not be evaluated quantitatively. Qualitative techniques were applied to probe the level of concept development and to identify students' patterns of thought related to writing.

\section{Research Design and Hypotheses}

As applied classroom research, this study had a pretest-posttest experimental design coupled with selected qualitative procedures (Campbell \& Stanley, 1963). Four different teachers in four different second-grade classrooms participated in the study. Pairs of teachers were matched for experience. One from each pair was randomly assigned to the experimental and control group so that 
each group had one first-year teacher and one teacher with two to three years of experience. Note that the term comparison group is used throughout the study in place of control because of the non-equivalent control group design (intact classrooms were assigned treatments). This assignment of treatments follows the example of Gordon's (1988) research.

\section{Quantitative Phase}

For this study, reading achievement and writing achievement were measured and analyzed quantitatively. The hypotheses involved the independent variable, treatments at two levels, story grammar treatment (experimental) and modified directed reading lesson treatment (comparison). The dependent variable measuring reading achievement was the change from pretest to posttest on the Gates-MacGinitie Reading Tests (GMRT), third edition, Level 2, Forms $K$ and $L$. The dependent variables for writing were three primary trait scores from the adaptedGlazer Narrative Composition Scale (aGNCS) and a score from an holistic scale by R. J. Pritchard. The three primary trait variables consisted of (a) the three aspects of story grammar (the characters, the setting, and the plot): (b) style; and (c) total score. The holistic score consisted of one score. Primary trait scores and holistic scores were taken from pretest and posttest writing samples on a topic of each student's choice. 


\section{Hypotheses:}

\section{Reading:}

1. Nul1: The population mean posttest reading achievement scores adjusted for the pretest are equal for both methods of instruction.

Alternate: The population mean posttest reading achievement scores adjusted for the pretest are higher for the experimental group than those for the comparison group.

\section{Writing:}

2. NuI1: The population mean posttest writing achievement scores adjusted for the pretest are equal for both methods of instruction.

Alternate: The population mean posttest writing achievement scores adjusted for the pretest are higher for the experimental group than those for the comparison group.

\section{Qualitative Phase}

This portion of the study used planned pretest and posttest interviews. The questions were designed to tap what students had been thinking during prewriting planning and while writing and to determine the level of development of the concepts of story grammar (character, setting, and plot). Frequency counts were expressed as ratios of those students who had attained varying levels of story grammar concepts from simple acquisition (able to 
identify) to a developed level (able to manipulate) for each group. Comparisons from pretest to posttest were made within the two treatment groups.

\section{Procedures and Methods}

\section{Pilot studies}

A literature-based program for second grade entitled Mythology: Science and spirit in Story was written and implemented over a period of two years, in four elementary schools (Fine, 1989, 1990). A variety of techniques were used to improve students' comprehension. For example, students drew pictures (visualizations) and wrote sentences (verbalizations) to go with the text of rewritten myths. Then students shared their work to help each other check the accuracy of their comprehension (similar to research by Linden and wittrock, 1981). Later, students wrote stories paralleling myths that had been read aloud to them. The pictures and stories showed that emotions and physical sensations were a part of the response the children made. The current study was based on observations of the positive effects these previous activities had on the reading and writing achievement of second-grade students.

\section{Sample Population}

This study took place in one school (987 students) selected from a large multi-ethnic metropolitan school 
district $(150,000$ students) in a southeastern city. The school is approximately one-third Black, one-third Hispanic, and one-third Caucasian. This study targeted second graders $(N=77)$ because observations from the pilot study showed they seemed to be at a point at which their comprehension and composition could benefit from direct instruction. Deep processing (a concept development technique) was added to help students grasp the concepts of character, setting, and plot.

of the 77 students who completed the study, there were 38 males and 39 females. Ninety-five students started the study, but, due to an outbreak of chicken pox and other illnesses, fewer students completed the instructional unit. Completion meant students missed no more than one day of the instructional program. Parents signed a release giving permission for participation in the study. One hundred percent of the permission slips were returned. Students were preassigned by the principal to four different classrooms with four different teachers each of whose highest degree was a Bachelor of science. The students selected for interviews were chosen by their classroom teacher on the basis of perceived achievement (high, middle, or low). These students' ability levels were then identified according to their performance on the GatesMacGinitie Reading Tests to ensure that students from all levels of performance were included in the analysis. 
Teachers also selected extra students for each group in case some students did not complete the treatment.

\section{Quantitative Phase}

Reading achievement: Instrument. The GatesMacGinitie Reading Tests (GMRT), third edition, Level 2, Forms $\mathrm{K}$ (pretest) and $\mathrm{L}$ (posttest) were used for the assessment of achievement. There were three reasons why this test was chosen. First, students were going to take the Stanford Achievement Test in a few weeks so it was not appropriate to use that test. Second, since Reutzel and Cooter (1990) used the GMRT to compare students' achievement in a whole language approach contrasted with a basal reader approach and were able to detect significant differences, the GMRT seemed appropriate for this study. Third, the GMRT was generalizable, a standard measure that other researchers could transfer to other contexts. The GMRT consisted of a 45-item vocabulary and a 46-item comprehension test. The vocabulary subtest is primarily a test of decoding skills and takes 20 minutes of actual test time. The comprehension subtest involves understanding passages and selecting one of three pictures that illustrates each passage. It takes 35 minutes of actual test time.

Reading and writing achievement: Training of teachers. For the standardized reading test, the teachers were 
given GMRT manuals and all materials. The very explicit directions were reviewed and any questions concerning the administration were answered according to the instructions in the teacher's manual. The teachers were instructed to administer the tests according to the directions in the manual. For the writing samples, teachers were instructed to tell their students to plan a story and then to write it. They were also told to tell the students they could change or edit their stories as much as they wanted during the writing session.

Writing achievement: Samples. Each student generated a pretest and posttest story on a topic of his or her choice. The decision to allow the students to write on topics of their choice was based on work by calkins (1986) and Golden (1984). The writing sessions varied in length but were approximately 45 minutes.

Writing achievement: Assessment scales. Two scales were used to assess writing achievement: (a) the adaptedGlazer Narrative Composition scale, a primary trait scoring scale for writing, that focuses on specific aspects of story grammar (see Appendix A, p. 123); and (b) an holistic scoring scale by R. J. Pritchard that focuses on general aspects of the writing task (see Appendix B, p. 129). 
The Glazer Narrative Composition Scale (1971, cited in Fagan et al., 1975) was norm-referenced using children in grades four through six. However, the National Council of Teachers of English recommends its use for primary students' composition as well. For this study the scale was adapted to include the specific elements of story grammar taught in the experimental treatment (see Appendix c, p. 132). From the instrument three scores were derived, the story grammar score, the style score, and a score consisting of the story grammar score plus the score from the style section. The original instrument was developed to evaluate the writing of intermediate or junior high students.

The holistic scoring scale was developed by Pritchard (1987) based on A Procedure for Writing Assessment (Myers, 1980). It was used by pritchard (1987) as part of an evaluation of the National Writing Project Model and is recommended by an elementary language arts authority, Norton (1989), for evaluating elementary students' writing. This scale was used as a comparison for the adaptedGlazer Narrative Composition Scale which was not developed for use at primary grade levels.

Writing achievement: Training of raters. Two raters (experienced teachers other than those teaching the treatments) scored the writing samples using both scales. One rater taught preschool and primary classes for nine years 
while the other taught preschool and primary for seventeen years. Neither rater had taught at the school used in the study. The raters were trained in a two-hour workshop. They were given an explanation of all terms, examples of how students' work had been graded, and anchor papers which were used to be sure that scoring procedures were understood. Anchor papers were papers graded by both raters and discussed to help clarify criteria. Training resulted in an inter-rater correlation of $r=.945$.

\section{Qualitative Phase}

Metacognitive assessment: Instrument. The interviews were introspective self-reports (evidence of declarative knowledge) and requests for performance (evidence of procedural knowledge). The self-reported performance request allowed the researcher to understand the tasks involved in writing from the students' perspectives, permitting the researcher to gain insight about students' levels of concept development and patterns of metacognitive strategies.

An interview with four different types of questions was developed. The first question was designed to separate feelings from metacognitive functioning. Because children tend to answer that they feel happy or sad when asked what they are "thinking," by asking how they felt the researcher hoped to help the student differentiate between emotion and metacognition. Following this were 
questions posed directly at what the children were thinking while planning and writing. Next, the questions were pointed at children's manipulation of the three aspects of story grammar to ascertain if students could identify the character, setting, and plot in their stories, and to determine if the student could manipulate each of the aspects by changing them. Lastly, questions were posed to gain insight indirectly into students metacognitive thinking. These were similar to the type of questions asked by Goodman, Watson, and Burke (1987) about what a good reader would do to help a student read better. Instead, these questions asked what a good writer would do to help a student write better. These questions allowed the researcher to tap the student's perception of the writing process. To begin, the interviewer gave a statement of purpose, respondent protection, and researcher intent as suggested by Goetz and Lecompte (1984). The following statement and questions were used:

Interviewer's statement:

I am writing a book about what second-graders do when they write. The book is for teachers. Your answers to questions I am going to ask will help teachers. No one will hear this tape except you and me. In the book, all the children will be disguised so no one will know which answers are yours. We'll take about 15 minutes probably, but your teacher will 
let us have more time. Do you want to ask me about any of this before we start?

Then the following questions were asked:

1. a. How did you feel while you were writing your story?

b. Why did you feel that way?

2. a. What did you think about when you were planning to write your story?

b. Why were you thinking of that?

3. a. What were you thinking of when you were writing your story?

b. Why were you thinking of that?

4. a. Who were the characters in your story?

b. Tell me something you could change about the characters of your story.

5. a. What was the setting of your story?

b. Tell me something you could change about the setting of your story.

6. a. What was the plot of your story?

b. Tell me something you could change about the plot of your story.

7. Who do you know that is a good writer?

8. What would (good writer) do to write a story?

9. What would (good writer) do to help someone who was having trouble writing a story? 
Metacognitive assessment: Training and administra-

tion. Training was provided for the two elementary education majors who interviewed subjects. Techniques to help the students feel comfortable with the interview situation, to probe by restating questions along with cautions to stay close to the script of the interview, and to record data were discussed. The interviewers as well as the researcher interviewed a selected sample of students in each treatment group on the same days they had written their pretest and posttest writing samples. The interviews were written and taped while each student answered the questions orally. Taping the interviews was a precaution in case students spoke too fast for the interviewer to note what they had said and was a means of verifying the interview data.

\section{Classroom Treatments}

Experimental group materials: stories. The stories chosen were three fables and a folktale. The decision to use this type of literature was the result of experiences using myths during the pilot study. The parents of some children in the pilot study refused to give permission for their children to participate in the project on the grounds that the content of myths interfered with their religious beliefs. The stories used in this study were "The Goose and the Golden Egg," "The Shepherd Boy and the 
Wolf," and "The Hare and the Tortoise," all in Tales from Aesop by J. P. Miller (1976), and King Midas and the Golden Touch, retold by Freya Littledale from the tale by Nathaniel Hawthorne (1989). Unadapted versions of the stories were used. Unadapted trade books were used based on Eckhoff's finding (1983) that children write at the same level of complexity of language patterns they read.

Experimental group materials: Lessons. The process lessons developed for the experimental group were adapted from the Modified Directed Reading Lesson (MDRL) suggested by Duffy and Roehler (1989) in which:

1. The teacher introduces the selection as a focus for a strategy to be learned.

2. The teacher introduces the concept (character, setting, or plot) to be taught.

3. The teacher provides direct instruction including modeling, giving examples, guided practice, and independent practice of target concept (character, setting, or plot).

4. The teacher reads aloud while students visually follow in a pair-shared text (first reading of story).

5. The teacher and students discuss the content of the story and targeted concepts.

6. The students reread the story silently from pairshared text (second reading of story). 
7. The students draw a picture of targeted concepts in the context of the focus story for that day (visualization).

8. The students write sentences related to the target concepts in the context of the focus story for that day (verbalization).

9. The students orally express feelings relevant to the targeted concepts in the context of the focus story for that day (emotion).

10. The students orally express physical sensations associated with the targeted concepts in the context of the focus story for that day (physical sensation).

11. The teacher and students summarize the content and strategies.

See Appendix D, p. 137, for lessons delivered to the experimental group.

Experimental group: Teacher training. The experimental group teachers participated in a two-hour training session conducted by the researcher on March 7, 1991, after school. The content of the training was as follows:

1. Overview of the research project

2. Overview of concepts being used

a. Modified Directed Reading Lesson (MDRL)

b. Rationale for teacher reading stories first

c. Story grammar

1) defined 
2) Iimited to three aspects (character, setting, and plot)

3) labeled pictures with the targeted concepts

d. Process writing classroom

1) steps in process

2) nurturing classroom climate

3) social interaction

4) invented spelling

5) revision--checklist displayed in classroom (for example: [a] check that your work makes sense, [b] check capitals, [c] check punctuation, and [d] check spelling)

6) peer conferences and teacher conferences (only during the treatment, not during the testing)

e. Direct instruction

1) definition and example

2) brief literature review of related studies

f. Deep processing--definition and demonstration

3. Testing

a. Testing materials, procedures, and schedules for quantitative reading tests 
b. Testing materials, procedures, and schedules for quantitative writing measures

c. Interviewing questions, procedures, and schedules for qualitative research

4. Treatment schedules--times, dates, clarification that the lessons supplant the regular reading lessons they usually use

5. Population information that the teacher must supply to the researcher--class list, names of teacher-selected students for interviewing, parent permission slips, attendance

6. Scoring--accomplished by the researcher and the raters

Experimental group: Application. The teachers taught the lessons each day for a block of one hour and fifty minutes. The first two and last two days were testing and interviewing days. Including the testing, the treatment lasted eleven days. Teachers gave direct instruction about three aspects of story grammar via the process lessons. Some of the lessons carried over to the following day because the process approach to reading and writing allows students to continue with their work. This approach allowed students time to plan, write, revise, edit, and share their writing. First, students learned about characters. Next they studied character in setting. When planning their stories, they drew pictures of characters 
in a setting on one sheet of paper, labeled them, and wrote sentences about the characters in the settings. Students used their imagination to think of physical sensations and emotions that went with the aspect of story grammar they were developing. Lastly, plot was introduced. On the bottom half of another paper folded into eighths, the students drew pictures showing the characters' problems, the responses or feelings, the actions taken, and the outcomes for the plot. Each of these was labeled. A sentence for each of the parts of the plot was written in the sections of the top half. This process was then repeated for whole stories. Thus, the three concepts of story grammar were multiple-encoded with visualization, verbalization, attachment of physical sensations, and emotions. From their pictures and sentences, the students proceeded to the drafting stage of writing as part of the treatment. After drafting, the students revised, edited, and shared their stories.

Comparison group materials: stories. The same stories were used in the same format as for the experimental group. For each story, the researcher provided multilevel questions to which the students responded in writing. Following discussion, the students played tictac-toe with selected vocabulary from the stories. 
Comparison group materials: Lessons. The comparison group reading lessons consisted of seven steps:

1. The teacher introduces vocabulary.

2. The teacher builds background information.

3. The teacher sets the purpose for reading.

4. The teacher reads aloud while students follow from a buddy pair-shared text (first story reading).

5. The students read a second time silently from buddy pair-shared text (second story reading).

6. The students write answers to written multi-level comprehension questions.

7. The teacher leads a discussion of story questions.

8. The students participate in whole class follow-up activities (tic-tac-toe vocabulary).

See Appendix E, p. 155, for comparison group reading lessons.

Comparison group: Teacher training. The comparison group teachers participated in a two-hour training session on March 4, 1991, after school. The content of the training was as follows:

1. Overview of the research project

2. Overview of concepts being used

a. Directed Reading Lesson, modified 
b. Rationale for teacher reading stories first

c. Revision--checklists displayed in classroom (for example: [a] check that your work makes sense, [b] check capitals, [c] check punctuation, and [d] check spelling)

3. Testing

a. Testing materials, procedures, and schedules for quantitative reading tests

b. Testing materials, procedures, and schedules for writing samples

c. Interviewing questions, procedures, and schedules for qualitative research

4. Treatment schedules--times, dates, clarification that the lessons supplant the regular basal lessons they usually use

5. Population information that the teacher must supply to the researcher--class list, names of teacher-selected students for interviewing, parent permission slips, attendance

6. Scoring--accomplished by the researcher and the raters

Comparison group: Application. The teachers taught the lessons each day for a block of one hour and fifty minutes. The first two and last two days were testing and interviewing days. Including the testing, the treatment continued for eleven days. 


\section{Data collection and Analysis}

\section{Quantitative Phase}

Gathering data. Reading and writing pretests were administered on March 14 and 15, 1991. The treatment began the week of March 18, 1991, and continued through April 2, 1991. Reading and writing posttests were administered following the treatments on April 3 and 4, 1991. Interviews were conducted on the same day the pre- and post-writing samples were written.

Scoring. The reading scores were from the vocabulary and the comprehension subtests of the Gates-MacGinitie Reading Tests, third edition, Level 2 , Forms $K$ and $L$. After scoring these tests, the researcher interpolated for the dates of testing according to the directions in the manual and converted the vocabulary, comprehension, and total scores to normal curve equivalents.

Reliability coefficients on the reading tests as reported in Gates-MacGinitie Reading Tests: Technical Reports (1989), using the Kuder-Richardson Formula 20 (KR20) were: .92 for vocabulary, .93 for comprehension, and .96 total for Level 2 , Forms $K$ and $L$.

The researcher coded each pretest and posttest composition to make evaluation blind. To avoid bias, the names were obliterated with marker, but all the student-written 
papers were read with all their physical attributes, including mechanical errors.

The writing scores were generated from two sources:

(a) the adapted-Glazer Narrative composition scale as a story grammar subscore, a style subscore, and a total; and (b) an holistic grading scale by Pritchard (1987).

Analysis. To test the research questions, reading and writing performances for the experimental group and the comparison group were compared using an analysis of covariance (ANCOVA) with the respective pretests as covariates. In addition, t-tests on the pretest measures checked whether the groups differed initially. Analysis of covariance were carried out on each of the dependent variables: three scores from the adapted-Glazer Narrative Composition scale, one holistic score, and three reading scores (vocabulary, comprehension, and total) which had been converted to normal curve equivalents.

The analysis of covariance is a statistical technique used to assess differences between groups in dependent variable means after adjusting each group's mean performance to be equal on a covariate measure. This is particularly important if covariate means differ between groups. However, the technique adjusts dependent variable means for individual variation on the covariates as well. The primary test in an ANCOVA analysis tests for differences between adjusted dependent variable means using an F-test. 
Two other preliminary $F$-tests are used to determine if the coefficients of the covariates are equal for the groups (homogeneity of slopes test) and if the covariate aids in predicting the dependent variables. For the primary ANCOVA test to be valid, the homogeneity test should not be rejected and the test of covariate should be rejected. Each group's mean improvement from pretest to posttest was measured on all reading and writing measures and was tested using a t-test. A significant t-test statistic indicated that, on the average, there was an improvement from pretest to posttest for the group on the measure. In addition, a correlational analysis was used for the adapted-Glazer Narrative Composition Scale and the holistic scale scores at the pretest, posttest, and on differences to verify that they were consistent measures of the same underlying elements. Since both scores were numerical, Pearson's correlation coefficients were calculated and tested to determine if the correlations differed from zero, i.e., if the two scores were linearly related. The inter-rater reliability between the two raters grading the composition using the adapted-Glazer Narrative Composition scale was high and statistically significant ( $r=$ $.95, \mathrm{p}<.05)$. 


\section{Qualitative Phase}

Gathering data. Interviews were conducted and tape recorded in rooms close to the classrooms or at picnic tables outside the classrooms by the researcher and two senior education major students from the university. This was done as conveniently as was possible so that the time between the posttest sample writing and the interview could be minimized.

Analysis. The answers to student's interviews were read and rewritten on one evaluation sheet. See form in Appendix F, p. 165. These were then coded by the researcher as to acquisition level of story grammar target concepts and metacognitive patterns.

\section{Summary}

This classroom-applied research studied the effects of direct instruction in story grammar using deep processing on the reading and writing achievement of second graders. Analysis of covariance tests using the pretest scores as a covariate were used to analyze reading and writing achievement. The reading scores were normal curve equivalents which came from the Gates-MacGinitie Reading Tests. The writing scores came from the adapted-Glazer Narrative Composition scale and an holistic scale by R. J. Pritchard. Interview data were gathered. These were qualitatively analyzed to see if students could identify 
and manipulate concepts of story grammar (character, setting, and plot) and to determine the types of metacognative strategies the students used. 


\section{Results and Discussion}

The purpose of this chapter is to present the results of the study. The findings and discussions are presented under the following headings: (a) results related to improvement in reading achievement, (b) results related to improvement in writing achievement, (c) results related to qualitative analysis of the interviews for the experimental group, (d) results related to qualitative analysis of the comparison group, (e) summary of the findings, and (f) discussion of the findings.

Results Related to the Improvement in Reading Achievement The effect on reading achievement after an experimental treatment of direct instruction in story grammar using deep processing was compared to a modified directed reading lesson with multi-level questions, and an emphasis on vocabulary. Results were interpreted on the dependent variables, vocabulary, comprehension, and a total reading score. To establish that there were no statistically significant differences between the groups on dependent variables at the beginning of the study, statistical analyses of the pretest scores between groups were carried out. Pretest means, standard deviations, t-test statistics and p-values for the three reading measures are shown in Table 1, p. 61 . 


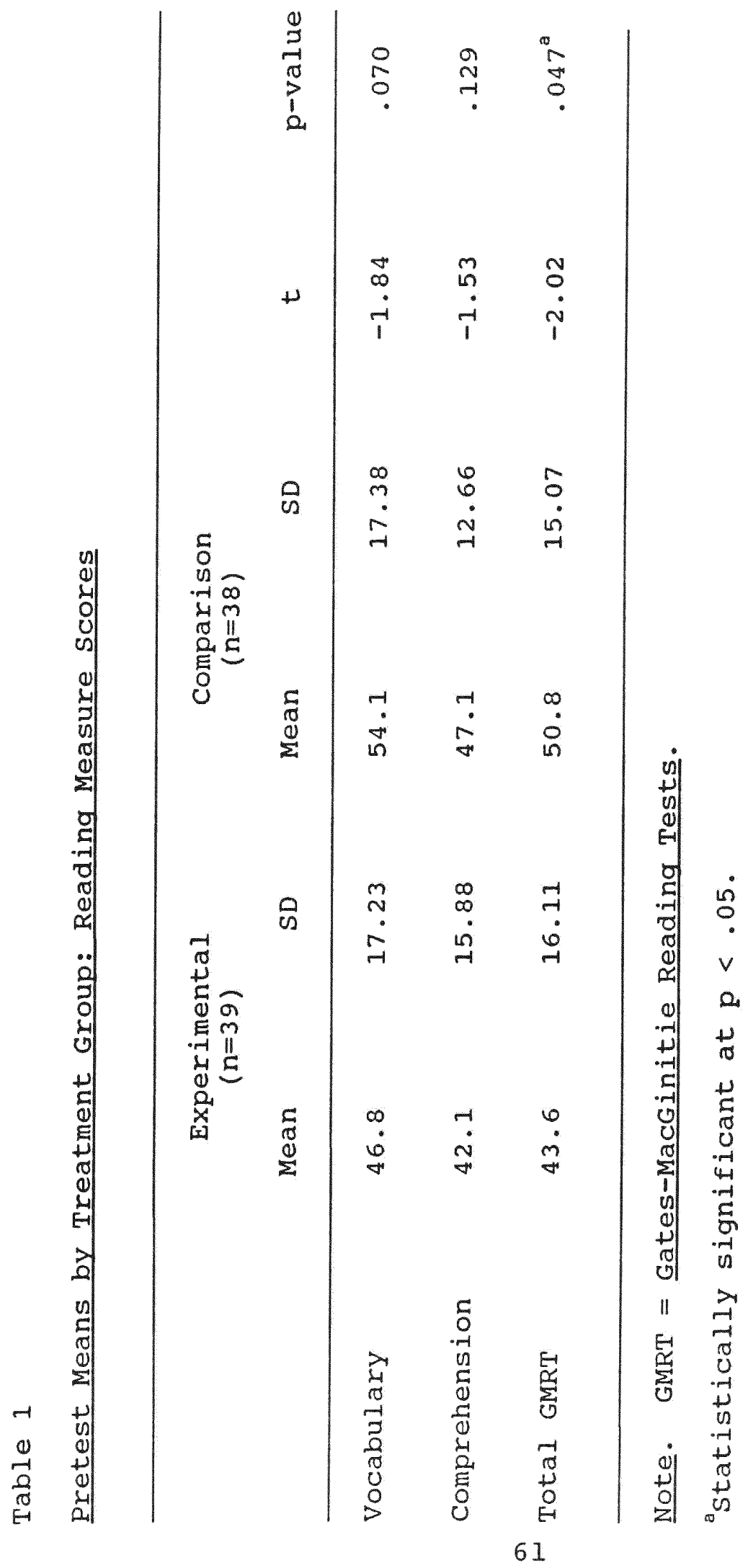


There were no significant differences in the mean pretest reading vocabulary and comprehension scores between the two groups. However, there was a significant difference between the mean total scores $(p<.05)$ with the comparison group scoring 7.2 points higher. Because of this significant difference and the smaller differences between groups in vocabulary and comprehension, ANCOVAs covarying for the pretest were carried out to test for differences between the group means for each of the posttests. Table 2, p. 63 , shows means for the pretest, the raw posttest, and the posttest adjusted for the pretest for each group with $F$ statistic and $p$-values. The hypotheses of homogeneity of slopes for vocabulary, comprehension, and total GMRT for the experimental and comparison groups were not rejected $(p>.05)$. The coefficient for the respective covariates did not differ between groups. The pretests were statistically significant covariates for all three posttest variables respectively $(p<.001)$. The ANCOVA results showed there were no significant differences in adjusted posttest means between the two groups for vocabulary, comprehension, or total scores. The null hypothesis was not rejected. Thus, for the two groups, no difference in any reading measures occurred due to the difference in treatments. 


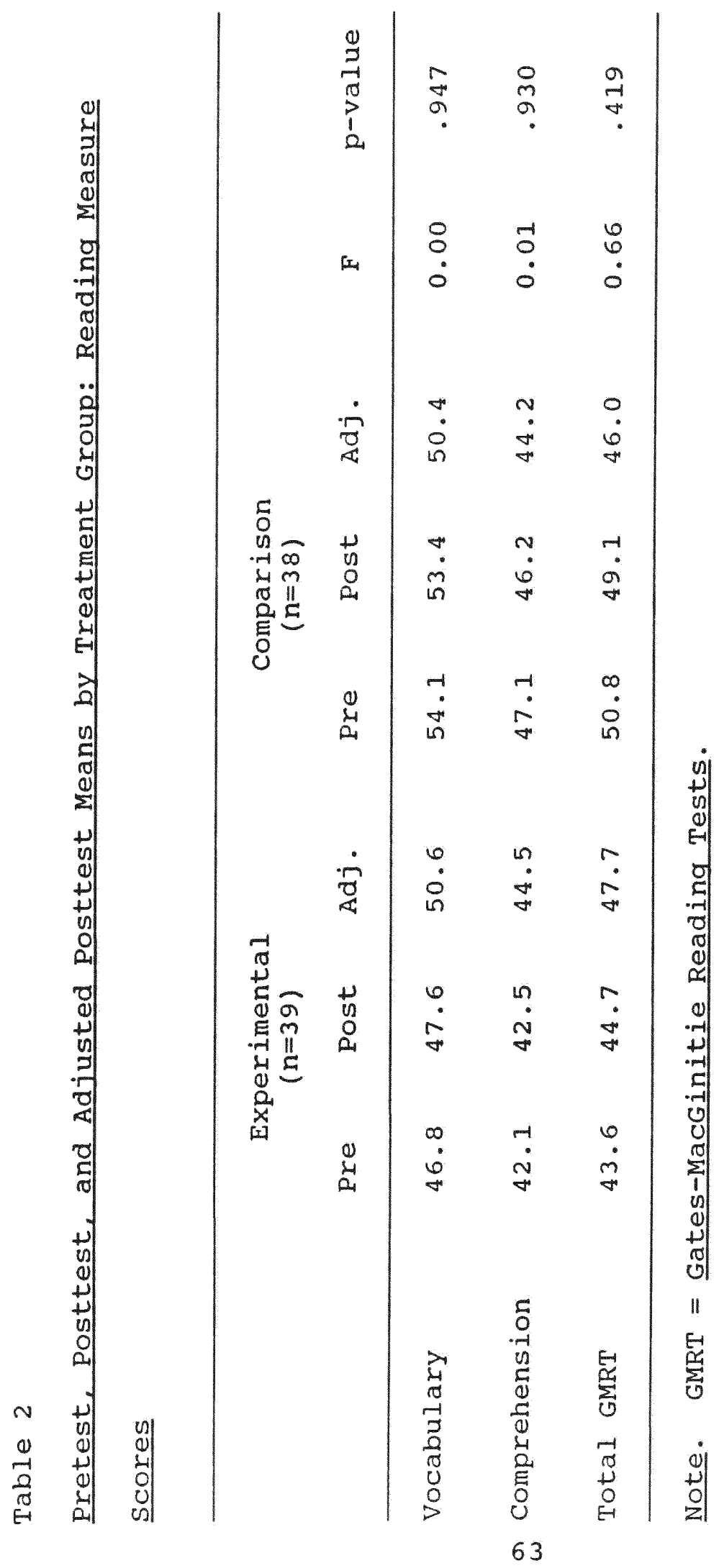


In addition to testing hypothesis one, the two groups were examined separately to determine whether there was an improvement on any of the three reading measures over the treatment period. The differences between pretest and posttest mean scores were analyzed with t-tests. For each group, pretest, posttest, and difference means are given in Table 3, p. 65, along with $t$ statistics and p-values. As a result of the treatment, there were no significant improvements in either of the groups on any of the mean reading scores.

\section{Discussion}

The results of the ANCOVA showed no statistically significant differences in the adjusted mean posttest scores for reading achievement. This meant that the null hypothesis was not rejected.

The Gates-MacGinitie Reading Tests (GMRT) was chosen based on the following criteria: (a) it was not the standardized test the students were supposed to take shortly after the experimental period, (b) it was the same test other researchers had chosen to use to evaluate the performance of students after an holistic reading treatment, and (c) it was generalizable to other situations. However, there were reservations about the inferences made using the GMRT. This was because the standardized test 


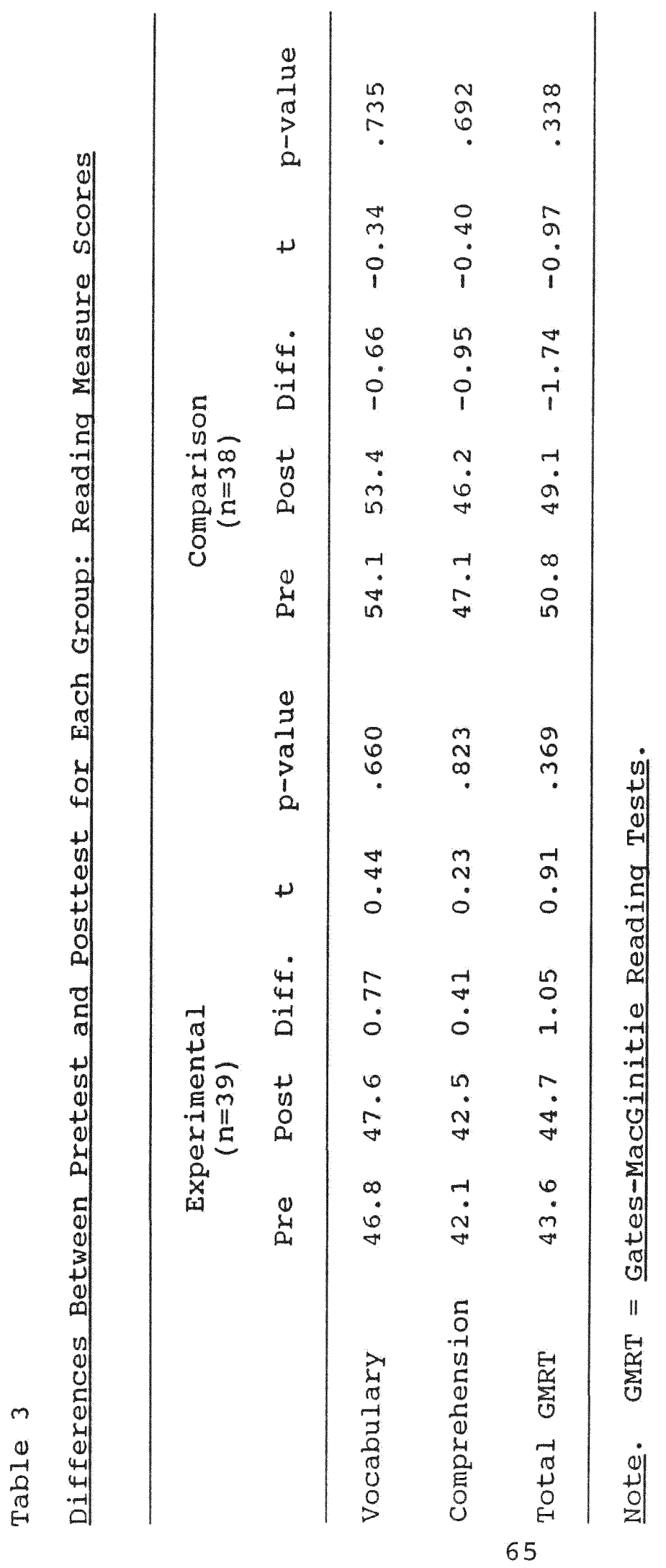


may not be the best fit as a measure of reading achievement of narratives. According to the Gates-MacGinitie Reading Tests: Technical Report, less than half (48\%) of the passages were classified as narratives. Of those, there was still a question as to their evaluative usefulness. Test items were not questions based on developed stories but were short vignettes that had to be matched with a picture showing all the correct circumstances described in the few sentences of text. What the GMRT measured was how closely the student read, made sense of the text, and could differentiate between three pictures. Although imaging the salient parts of story grammar is important for comprehending a story, an ability to pay attention to every little detail is not necessary. One example of the degree of attention that was demanded was the item that speaks about a dancer:

The dancer ended her dance by raising her arms. She held them straight out on each side. Then she raised one leg behind her. (MacGinitie \& MacGinitie, 1989, form L, p. 15.)

The choices showed a dancer with (a) her leg back and her arms raised over her head, (b) her leg back and her arms raised out to the sides, and (c) her leg raised in the front and her arms raised to the side. The focus on such detail was in excess of what might be needed to get meaning in a story. It may give students the idea that it 
would be important to focus on relatively unimportant details rather than the salient features of story grammar (character, setting, and plot).

other questions required specific prior knowledge and measured how well a student could apply it in passages dealing with content area subject matter. For instance, one question involved knowing the role bees play in pollinating pear trees. Some of the experiences, such as making block prints, were probably not part of the experiential background of the children being tested. For this reason, the test was not measuring solely if the students could construct meaning from the text, but rather the degree to which the students paid attention to detail, were familiar with certain experiences, or had prior knowledge of content information. As others have noted (Au, Scheu, \& Kawakami, 1990; Summers, 1980) standardized tests are often not a good match for evaluating students for instructional purposes.

Therefore, the mismatch of the measuring device to either the students or the intended task being measured may have interfered with finding a significant difference between the experimental and comparison groups in reading. Additionally, the mean difference between the pretest and posttest for the comparison group showed that this group's achievement scores were lower than the pretest scores 
while the experimental group's mean difference score was higher than the pretest score.

Results Related to the Improvement in Writing Achievement

The effect on writing achievement after an experimental treatment of direct instruction in story grammar using deep processing was compared to a modified directed reading lesson using the same literature with multi-level questions and an emphasis on vocabulary. The dependent variables with regard to writing were the subscores of story grammar, style, and a total score for the primary trait scoring scale, the adapted-Glazer Narrative Composition scale (aGNCS), and an holistic scoring scale. pretest means, standard deviations, t statistics, and pvalues for the four writing measures are shown in Table 4, p. 69 .

There were no significant pretest mean differences between groups on story grammar, the total aGNCS score, or the holistic score. The groups were essentially at the same level of writing ability at the pretest. There was a significant difference in the pretest score for style with the comparison group's mean $(\bar{x}=10.8)$ being higher than the experimental group's mean $(\bar{x}=8.6, p<.01)$. Since individuals varied and the style means differed, the pretest variables were used respectively as covariates on ANCOVAs of the posttest scores. The pretest, posttest, 


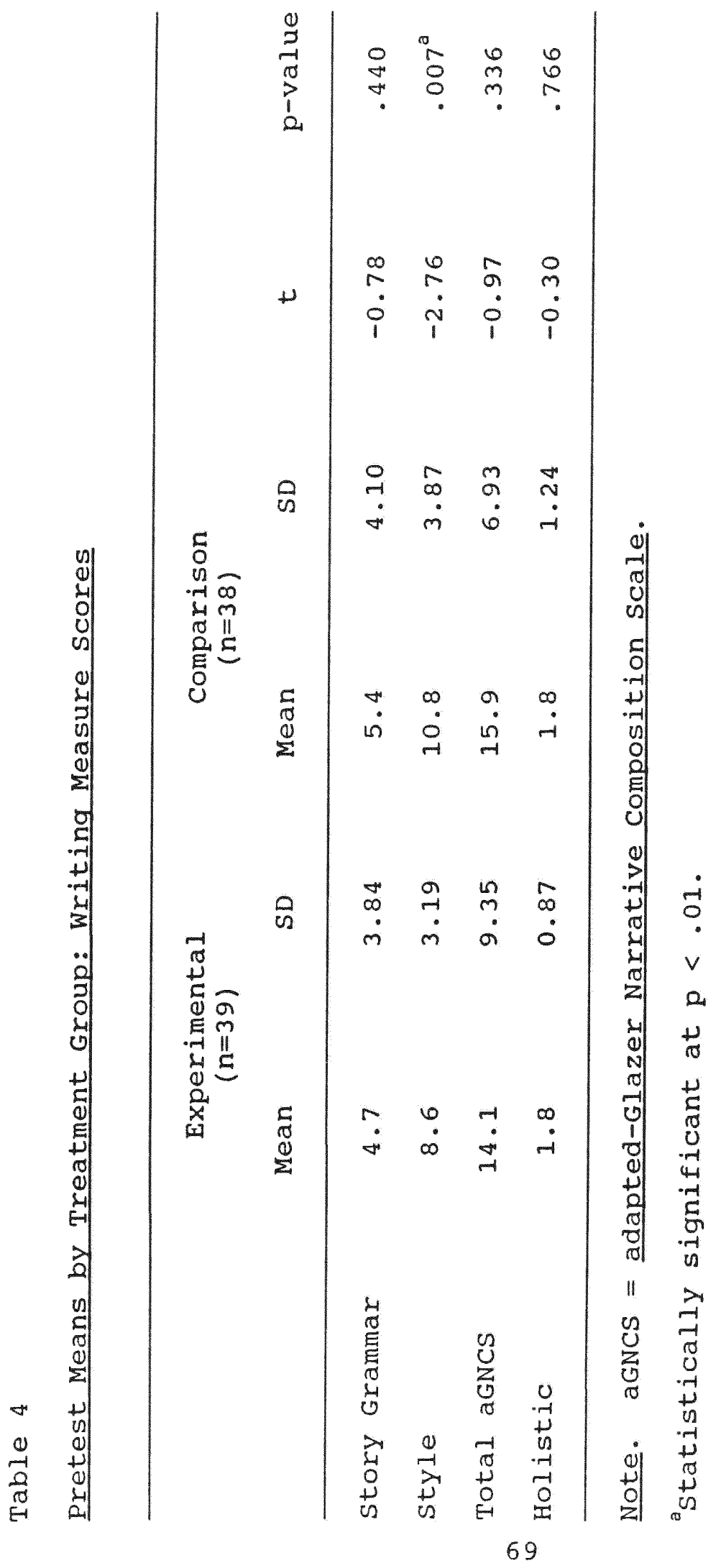


adjusted posttest mean scores, F statistics, and p-values are listed in Table 5, p. 71. Posttest adjusted means for story grammar and total aGNCS, are shown graphically in Figures 1 and 2 , pp. 72 and 73 , respectively.

The hypotheses of homogeneity of slopes for story grammar, style, total aGNCS, and the holistic scale between the experimental and control groups were not rejected $(p>.05)$. So the coefficients for the respective covariates did not differ between groups. The pretest scores were significant covariates for the posttest story grammar, total aGNCS, and the holistic scale respectively $(p<.01)$. However, the pretest style score did not help to predict the posttest style score $(p>.05)$. The ANCOVA results showed a highly significant difference between groups for the mean story grammar score $(p<.001)$. There were also significant differences between the two groups for the total aGNCS and for the holistic scales. Statistically no difference was shown between the two groups with respect to adjusted posttest style score means $(p>.05)$ although the experimental group had a higher adjusted mean than did the comparison group. Therefore, null hypothesis two was rejected and the alternate hypothesis was accepted. The population mean posttest writing achievement scores for all variables measured and adjusted for the pretest were higher for the experimental group than those for the comparison group. 


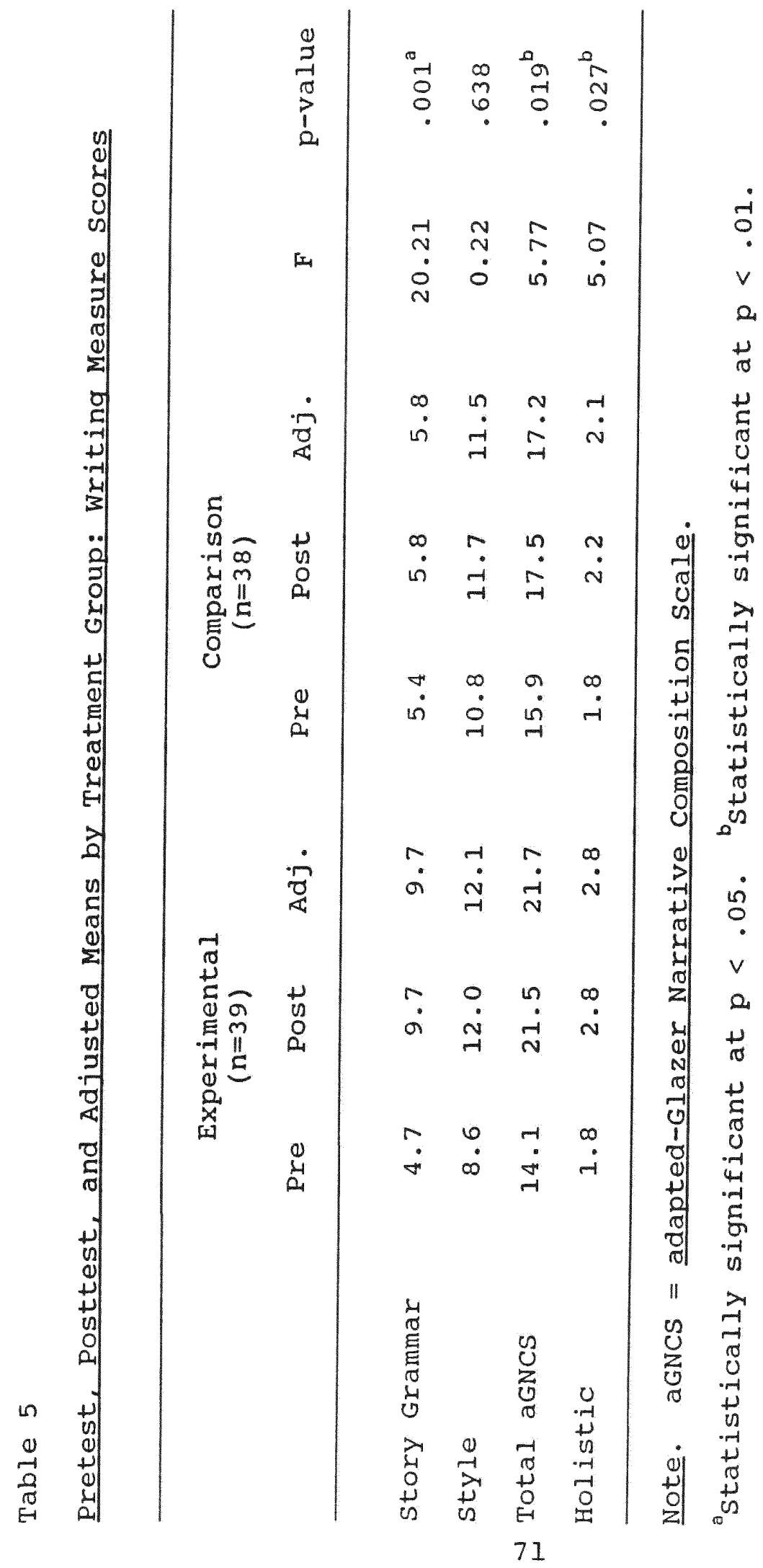




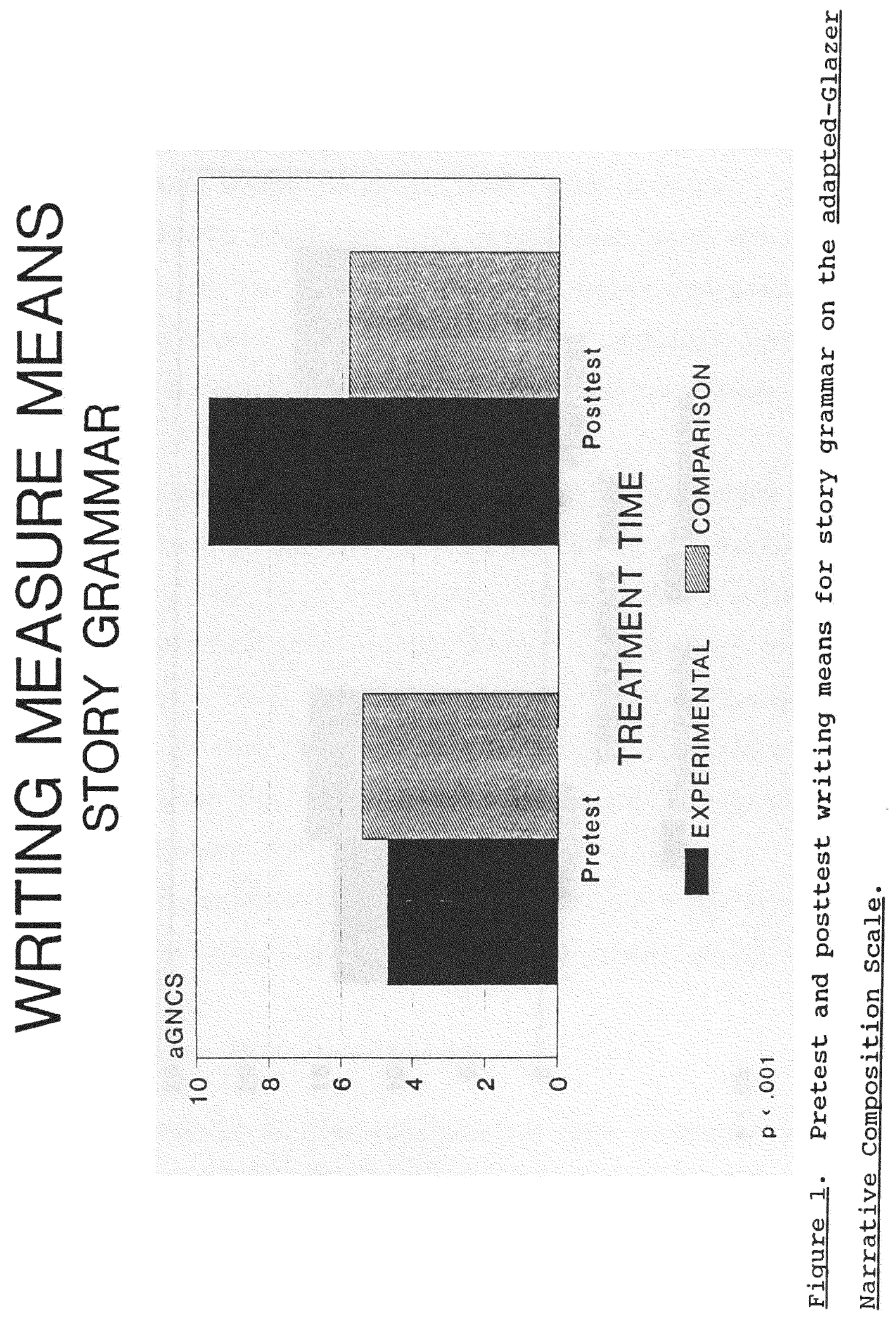




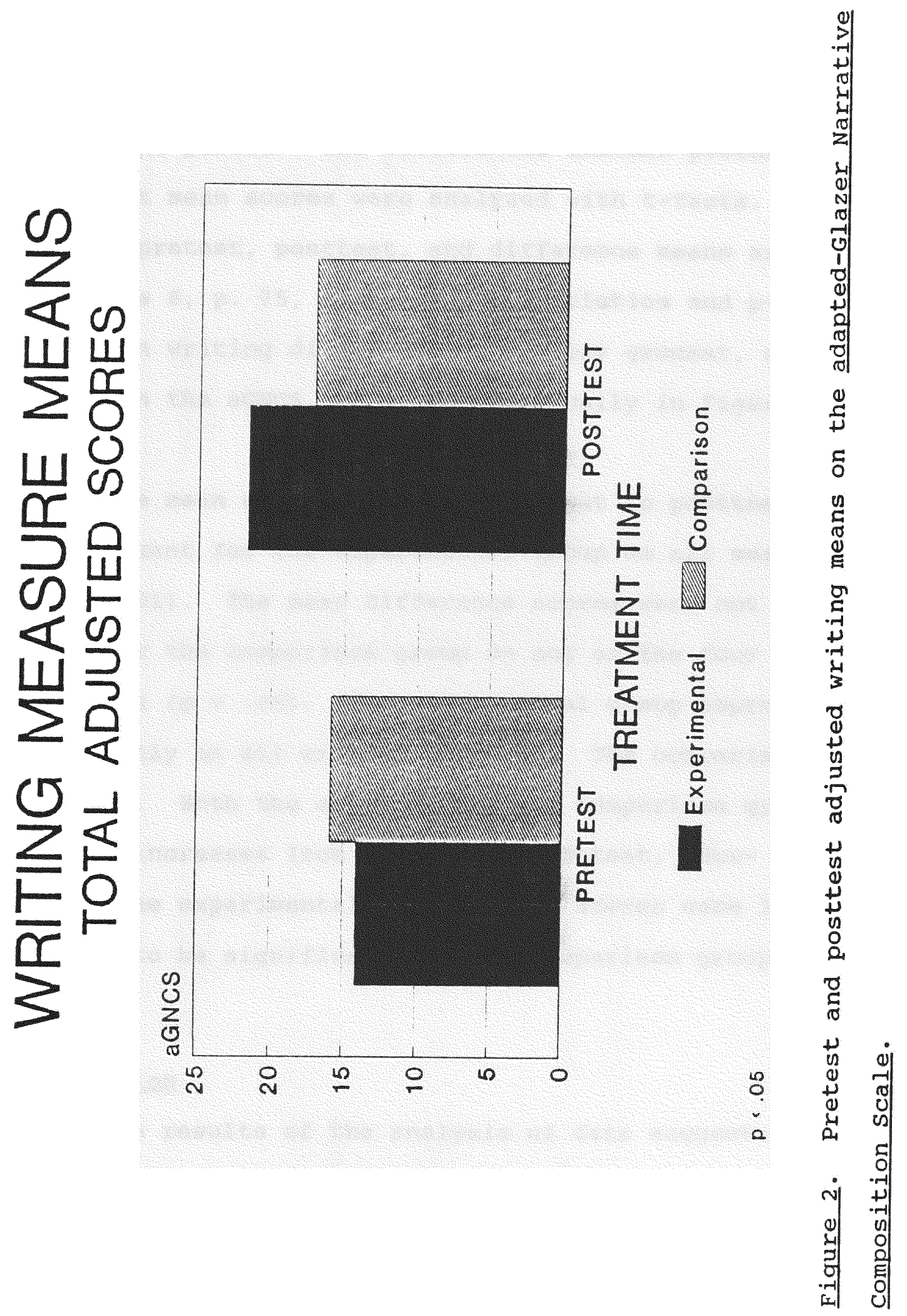


In addition to testing hypothesis two, the two groups were examined separately to determine whether there was an improvement on any of the four writing measures over the treatment period. The differences between pretest and posttest mean scores were analyzed with t-tests. For each group, pretest, posttest, and difference means are given in Table 6, p. 75, along with $t$ statistics and p-values. The mean writing differences for story grammar, style, and total on the aGNCS are shown graphically in Figure 3, p. 76.

The mean gain scores from pretest to posttest were significant for the experimental group on all measures $(p<.001)$. The mean difference scores were not significant for the comparison group on any of the four writing measures $(p>.05)$. The experimental group improved significantly on all writing measures. The comparison group did not. Both the experimental and comparison groups showed increases from pretest to posttest. However, the experimental group's mean scores were large enough to be significant and the comparison groups's were not.

\section{Discussion}

The results of the analysis of data suggested more learning was taking place in the experimental group. The ANCOVAs for three of the four adjusted posttest writing score means showed significant differences between the 


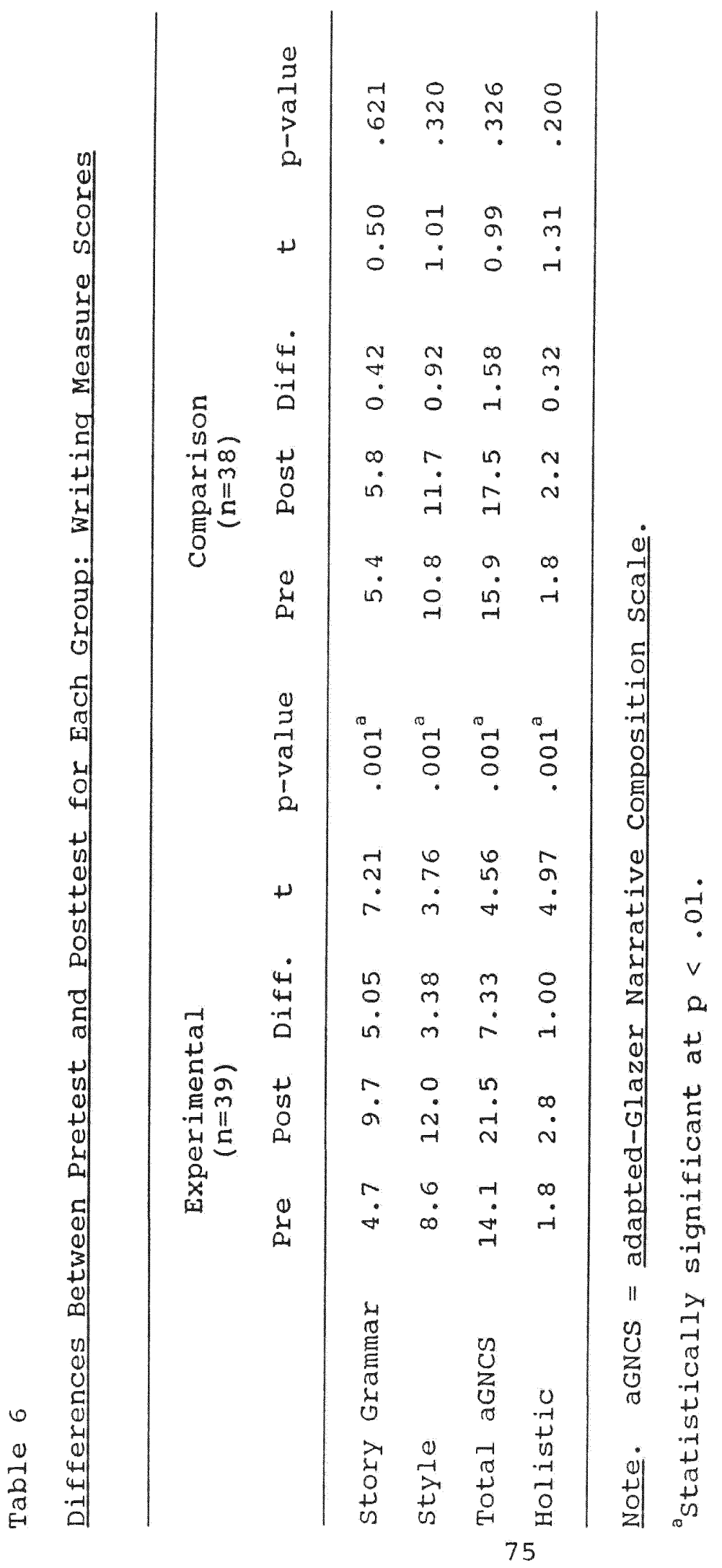




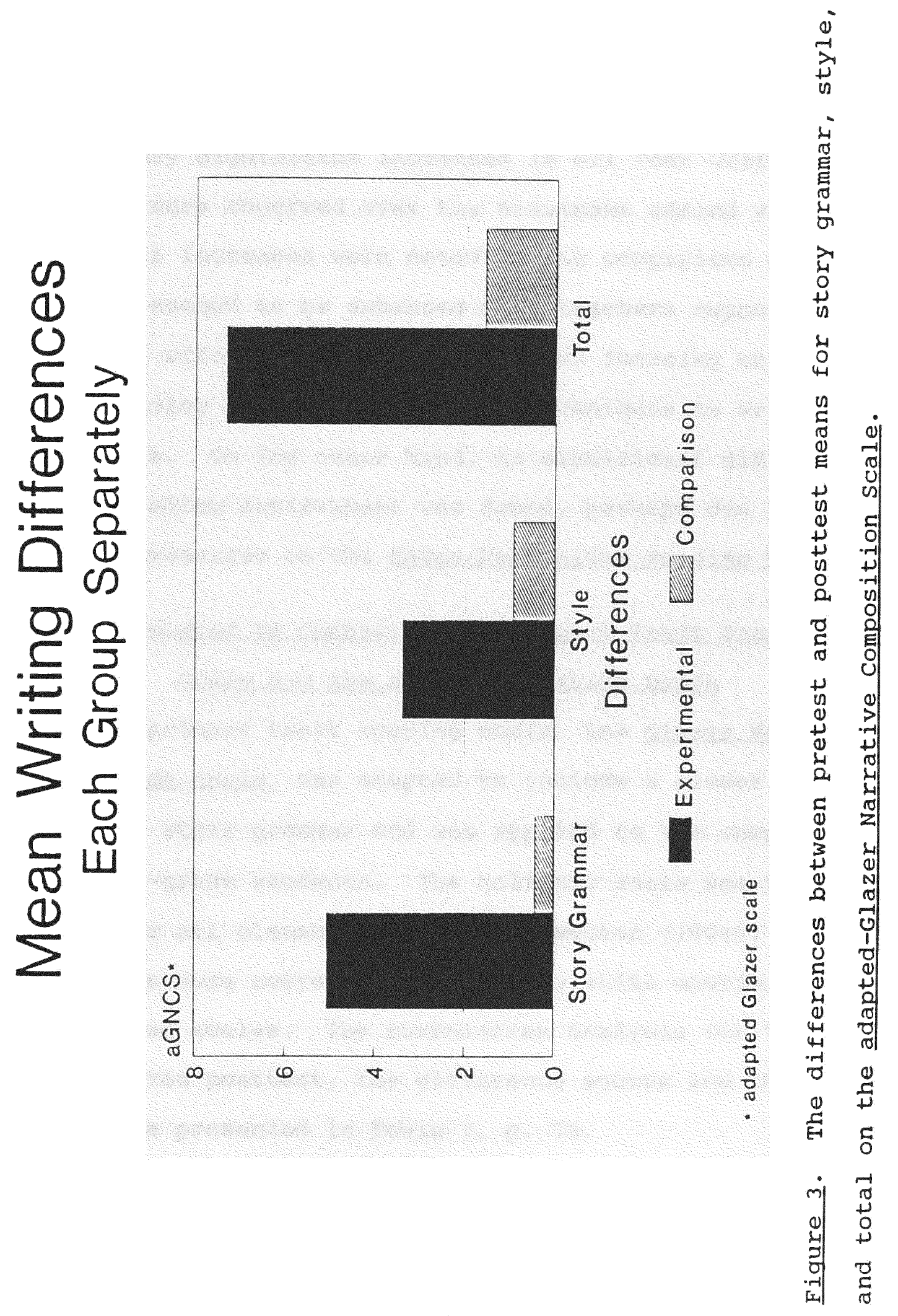


experimental and comparison groups with all of the adjusted means for the experimental group being higher than the comparison group. In addition, for the experimental group, very significant increases in all four writing measures were observed over the treatment period while only small increases were noted in the comparison group. Learning seemed to be enhanced when teachers supported students' efforts to read and write by focusing on story grammar using concept development techniques to write narratives. On the other hand, no significant difference on the reading achievement was found, perhaps due to the concepts measured on the Gates-MacGinitie Reading Tests.

Results Related to comparing the Primary Trait scoring Scale and the Holistic scoring scale

The primary trait scoring scale, the Glazer Narrative composition scale, was adapted to include a closer examination of story grammar and was applied to the composition of second-grade students. The holistic scale was recommended for all elementary grades by Norton (1989). The two scales were correlated to see how alike scoring was for the two scales. The correlation analysis for the pretest, the posttest, the difference scores and the pvalues are presented in Table 7, p. 78 . 
Table 7

Correlations of Primary-Trait scale with Holistic scale

\begin{tabular}{lcc}
\hline \multicolumn{1}{c}{ Score } & Correlation & p-value \\
\hline Pretest & .758 & $<.01$ \\
Posttest & .883 & $<.01$ \\
Difference & .721 & $<.01$ \\
\hline
\end{tabular}

Results showed that the adapted-Glazer Narrative Composition scale scores correlated well with the holistic scale score. At the pretest, the correlation of scores was $.758(\mathrm{p}<.01)$. At the posttest, the correlation was even stronger $(x=.883, p<.01)$. The correlation of difference scores was also good at .721 ( $\mathrm{p}<.01)$.

\section{Discussion}

The high correlations between pretest, posttest, and difference scores indicate that both scales measure writing performance similarly. However, the aGNCs yields not only an overall writing performance measure but also measures elements (story grammar, style) of writing. Since the holistic scale score is valid for all elementary grades and correlates with aGNCS, this analysis indicates that the aGNCS may be successfully extended to lower grades. 
Results Related to the Qualitative Analysis of the Interviews for the Experimental Group

The results of the qualitative analysis of individual interviews of sixteen students in the experimental group are discussed as follows: (a) character, (b) setting, (c) plot, and (d) metacognitive patterns.

Reading Tables: Explanation of Terms and Symbols

on all tables, high, middle, and low groupings refer to the way students performed on the reading pretest. In the table, the label level means the students could identify the concept in their own writing sample. The change level means they could manipulate the concept by changing it in their writing. There are two tables for each group's data on each concept. The first table for each aspect of story grammar shows differences in the number of students in each ability group who attained a concept to a particular level either at pretest or posttest. The second table for each aspect of story grammar shows how individuals performed at pretest or posttest. A plus sign (+) means that the student had attained the particular level of understanding for a concept. A minus sign (-) means the student had not attained the level of understanding or was unable to say an appropriate answer. A superscript "a" means the student was unwilling to change the concept, but was able to demonstrate attainment of that level. In each of the tables showing individuals' 
performances, each column represents a different student, each row a level of understanding at either pretest or posttest. The ratio is the number of students who had attained or not attained the level of the concept compared to the total number in each group.

Character. The analysis of the level of concept development for character is summarized in Tables 8 and 9, pp. 81 and 82 . All students but one could identify at least one character in the pretest writing sample. Ten out of sixteen had the concept of character to the level where they could manipulate the concept of character. All could identify the concept of character on the posttest sample, and all but two could manipulate the concept at the posttest. One student who could manipulate the concept at the pretest could not manipulate it at the posttest. This was perhaps due to the fact that learning is often non-linear in nature. Another student who could change or manipulate the concept of character at the pretest expressed that he would not change the character. After some probing, he was counted as being able to manipulate (change) the concept. The student gave support why the character, an alligator, could not be changed based on the characteristics of the character and why they were important to the story. The expression of an unwillingness to change the character combined with his defensive 


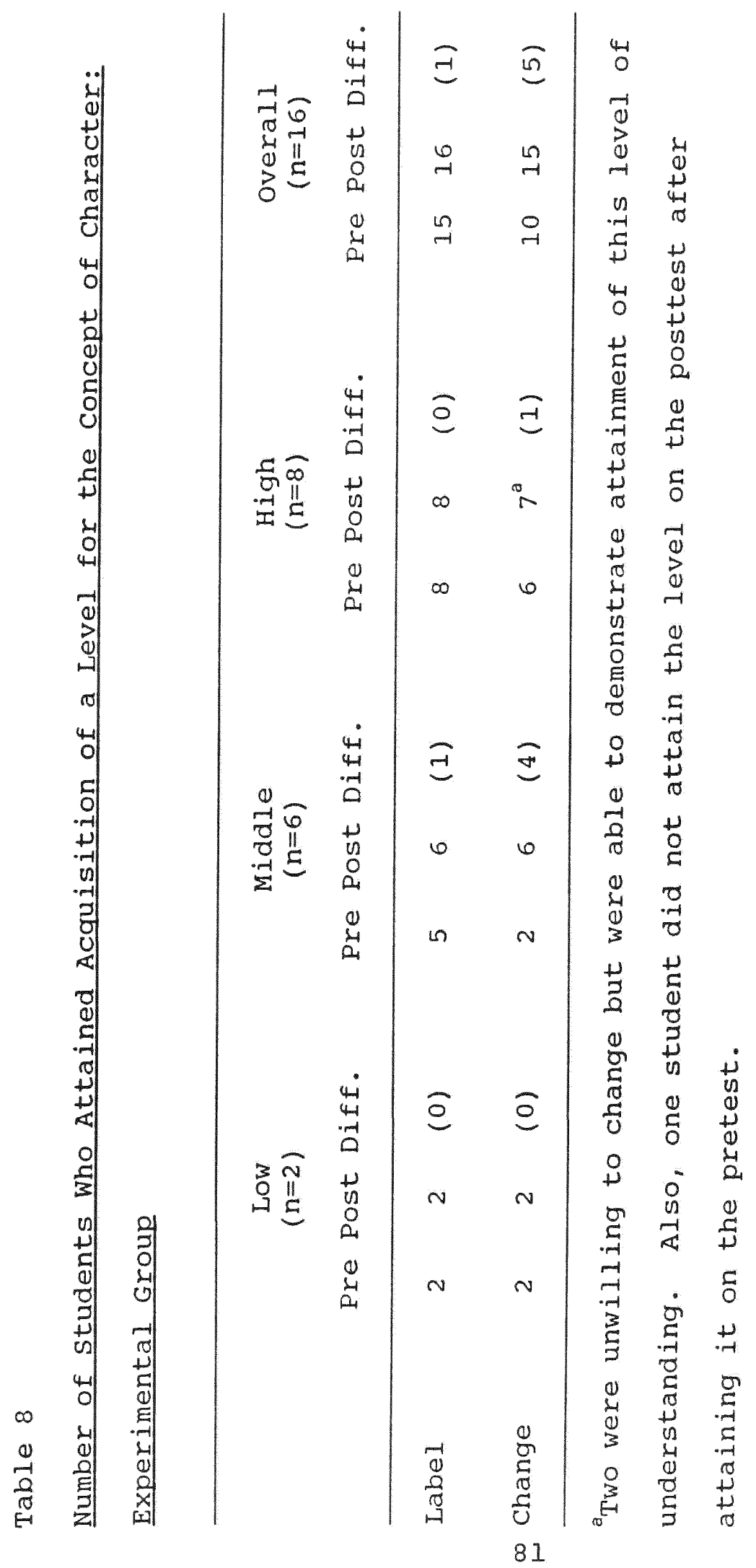




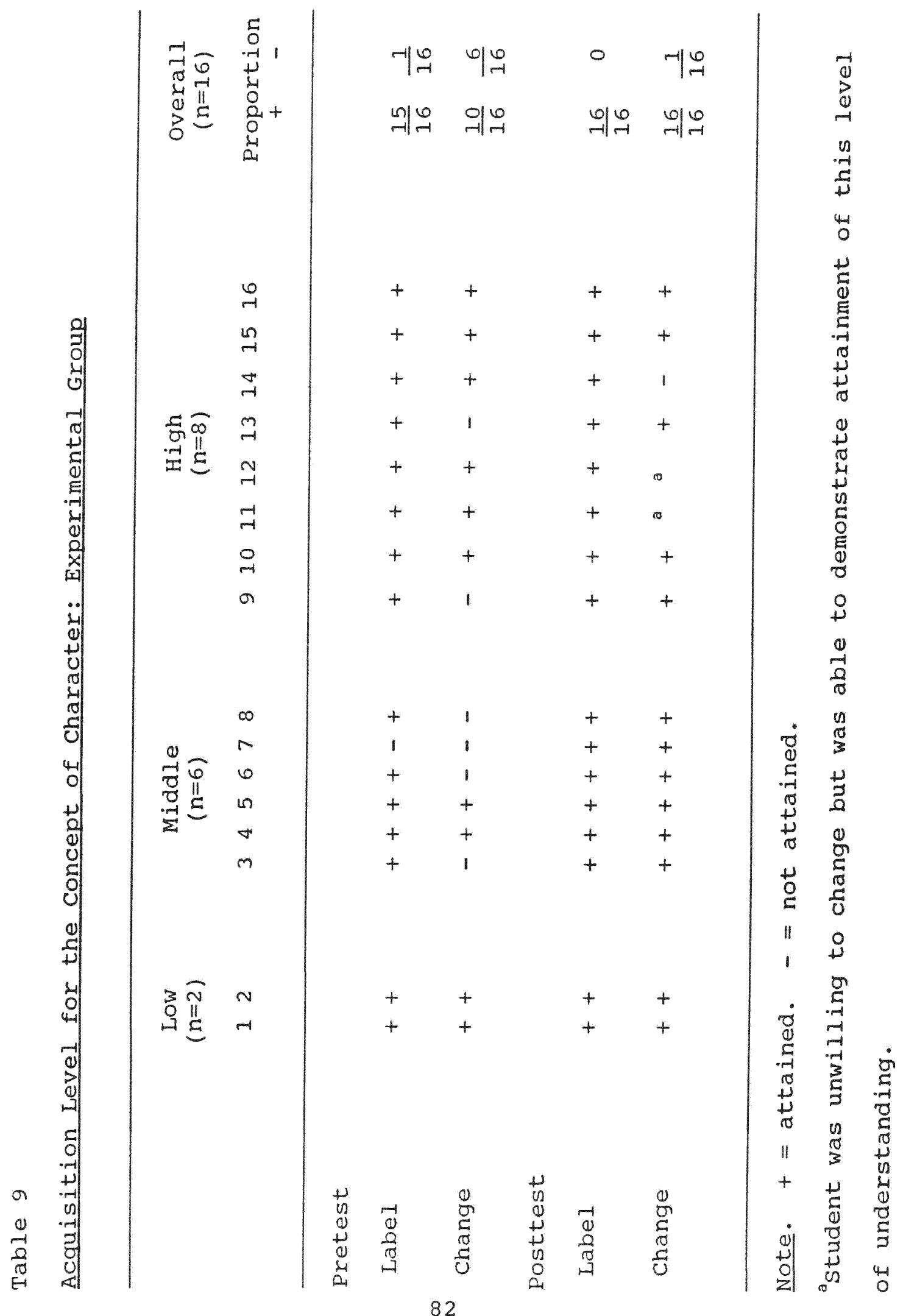


sense was taken as an indication that the student understood the concept at the highest level, the point where character could be manipulated. His sophisticated reasoning may indicate an appreciation of the interconnection between character traits and plot.

Setting. The results of the analysis for the concept of setting are summarized in Tables 10 and $11, \mathrm{pp} .84$ and 85. Nine of sixteen identified the concept of setting in their stories at the pretest. All of those who had a setting in their pretest sample were able to manipulate the concept. Five more students were able to label (identify) and to change (manipulate) the concept on the posttest sample. One student who had the concept at the pretest expressed that he would not change the setting because "there'd be no point to the story." The student's story took place in a desert, and the lack of water was critical to his intended meaning. This suggested a strong feeling of ownership of what he was willing to change or not willing to change in the story. This was the same student who refused to change his characters. Besides his feelings of ownership, he seemed to understand story structure well.

Plot. The results of the analysis of the concept of plot are summarized in Tables 12 and 13, pp. 86 and 87 . The concept of plot seemed to be the least well developed 


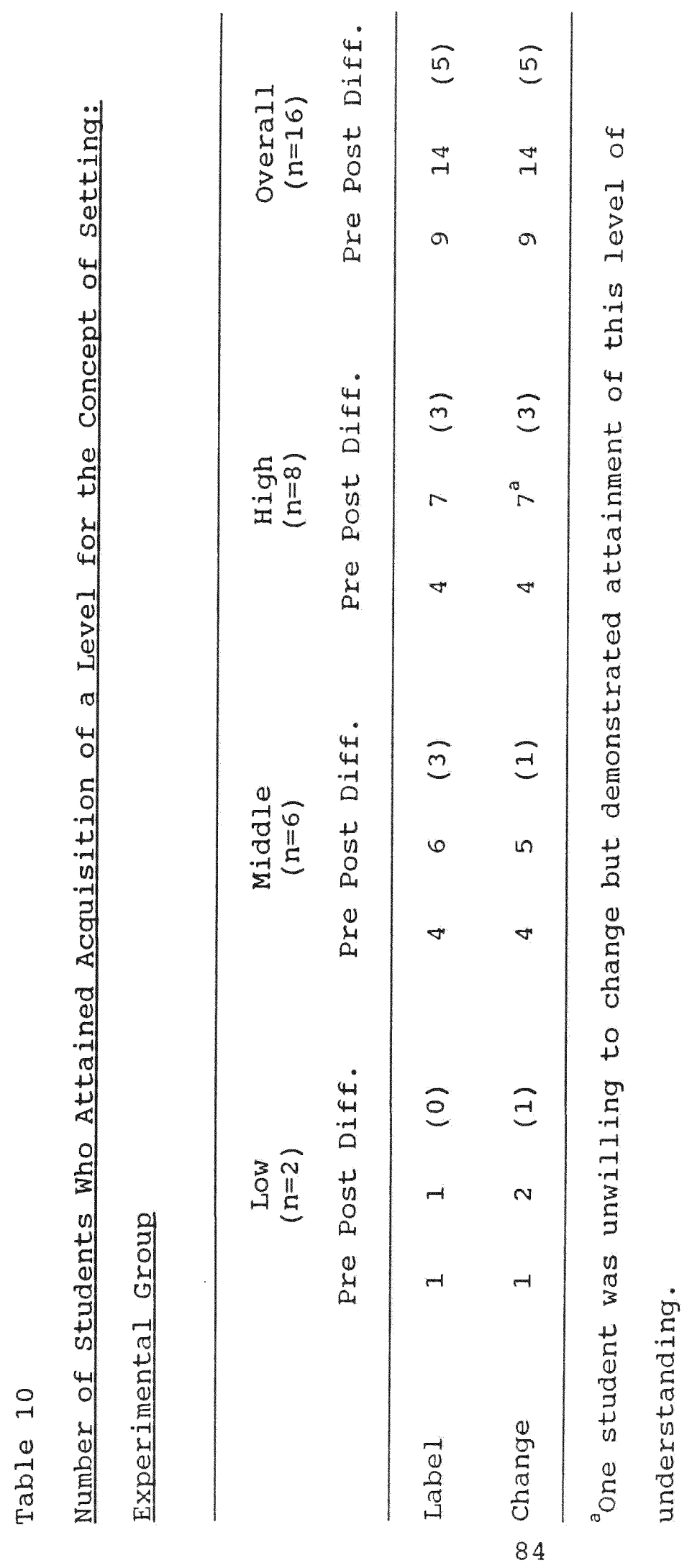




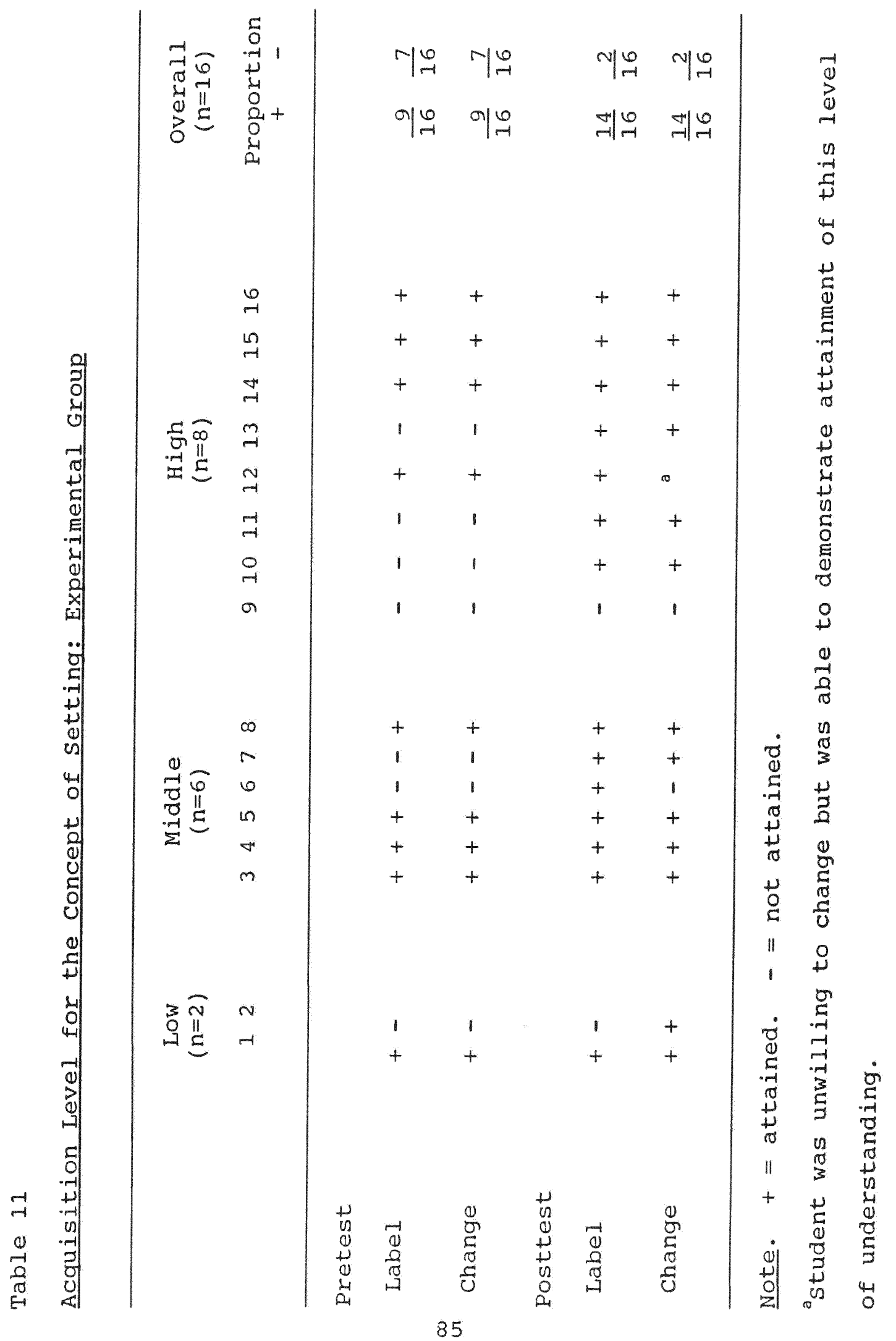




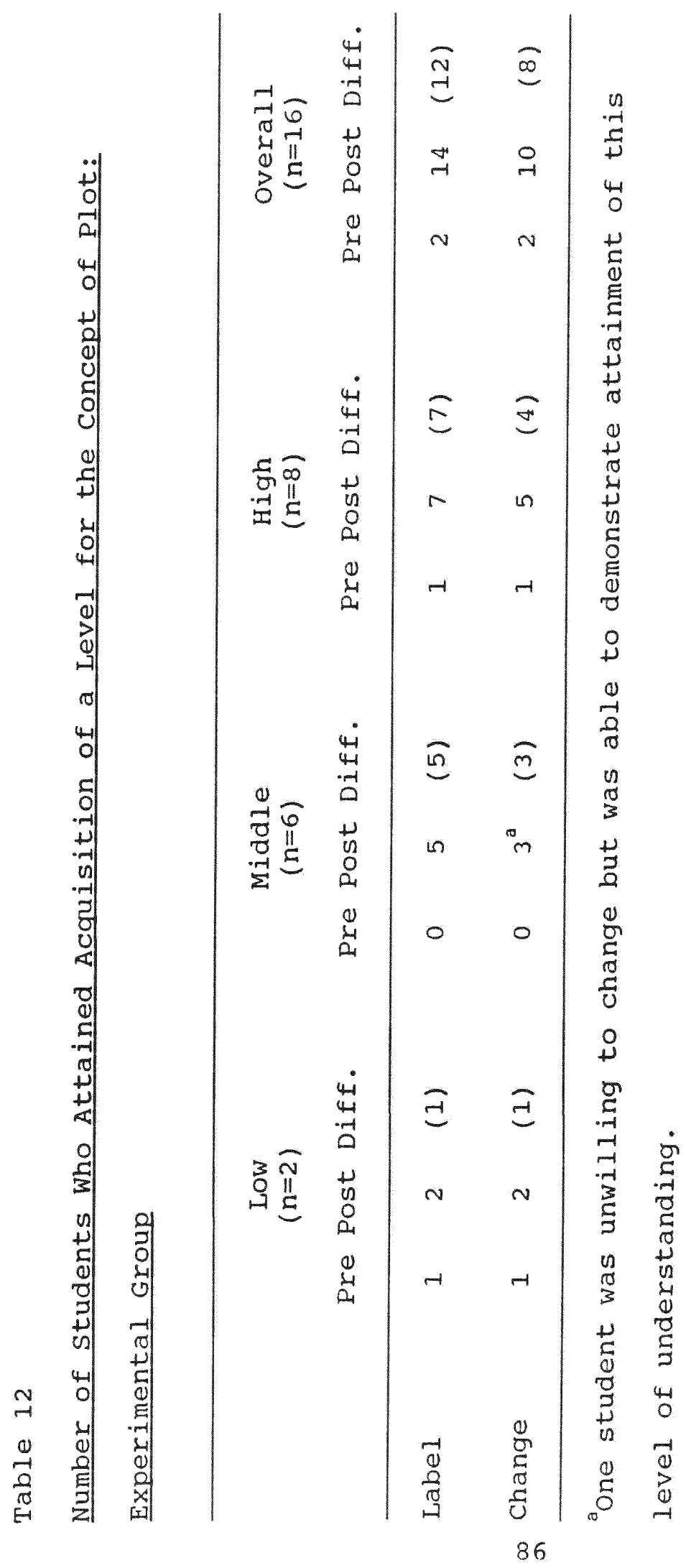




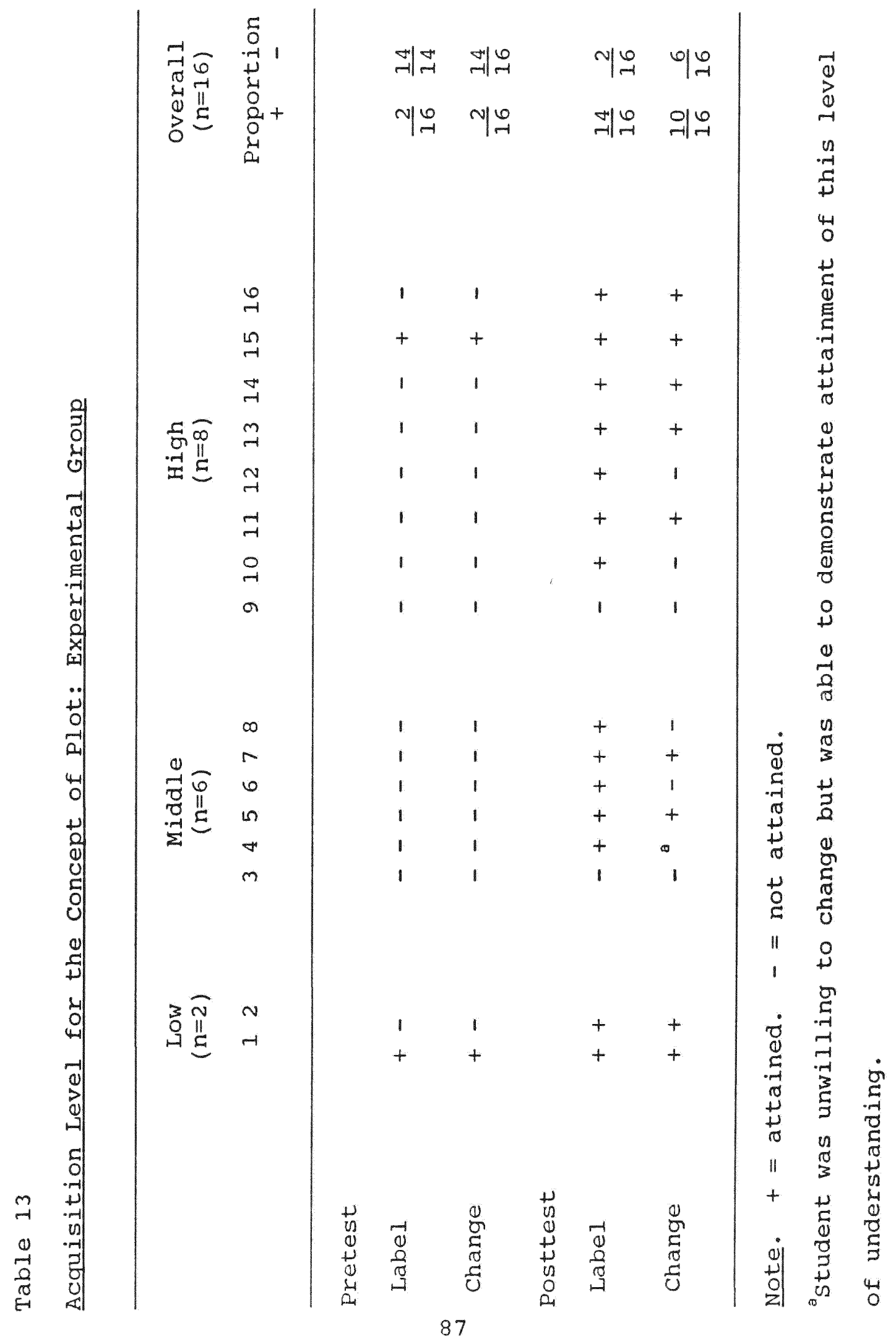


in the pretest samples. Only two of the sixteen students could identify the plot in their story at the pretest. Both of these students were also able to change the plot which was taken as a demonstration of having the concept at the highest level, the level at which it could be manipulated. Eight of the fourteen who did not identify their plot at the pretest were able to identify the plot and to manipulate it in their posttest sample. One student refused to change the plot in any way stating that it would "mess up" his story. Perhaps this child was also demonstrating the strength of the feeling of ownership. His wishes were respected, and he was recognized as having a well-developed concept of plot since he could discuss why the sequence of action in his story was important to the story.

Metacognitive Patterns. From students' responses to questions different patterns of metacognitive thinking emerged. The responses were coded and recorded in Table 14, p. 89. At the pretest, five of the sixteen second graders expressed they were primarily concerned with mechanics. One student said he looked around the room at objects to get ideas which suggests a dependency on his visual field for topics. Three students said they looked to someone else to tell them what to write. Strategies such as making images, making lists, or using another 
Table 14

Metacognitive Patterns: Experimental Group

strategy
Pretest
Posttest
Mechanics

Make sense

objects in view to stimu-

late thought

External locus of control

(good writer would tell

student what to do)

Internal locus of control (good writer would tell

student to think)

Images in their minds

Planning activity such as making a list

Use a story as a model

Use good vocabulary

Use past experience

Use discussion with

classmate

Use story grammar
5

2

0

0

1

0

3

0

0

3

1

1

1

4

1

1

1

0

1

0

0

1

0

story as a model were described which suggest three students had an intuitive sense of what a strategy for writing is. The patterns suggest that the students may have been exposed to skills-based writing instruction. 
The trend at the posttest seemed to be for more independent thinking. Three students said they would think for themselves rather than ask a good writer what to write, four students would use a planning activity such as making a list, and three students said they would plan the characters, setting, and plot.

\section{Discussion}

In summary, there were gains in the understanding of all three aspects of story grammar. While most of the students could identify character in the pretest writing sample, six could not manipulate the concept. By the posttest, all but one student could both identify and manipulate this aspect of story grammar.

The changes in understanding of setting and plot were more dramatic. For the concept of setting, before treatment only 9 out of 16 could identify their story's setting. After treatment 14 out of 16 could identify and manipulate the setting. For the concept of plot, before treatment only 2 out of 16 could identify their story's plot. However, after treatment 14 out of 16 could identify plot. Before treatment only 2 out of 16 could manipulate any part of the plot in their story. After treatment 10 out of the 16 could manipulate the plot in their respective stories. The students seemed to gain much in their understanding of setting and plot. 
Several metacognitive patterns were identified. Before treatment three students said the good writer would tell them what to write (interpreted as the external source of control), after treatment the same three students said the good writer would tell them to think for themselves (internal source of control). Another student's response seemed to give evidence of an awareness of the relationship between reading and writing. She said she would use a story she had read as a model for her story. At the posttest interview, she was the student who then said she would use a story she had read to help herself ask questions about what she needed to include in her story. Her comments seem to exemplify what it means to read as a writer. The students who said they would think of characters, setting, and plot before writing a story provided support for the notion that these concepts had been developed by the experimental treatment to the point at which students could use knowledge of story grammar as a strategy.

\section{Results Related to the Qualitative Analysis of the}

\section{Comparison Group}

The results of the qualitative analysis of individual interviews with eight students in the comparison group are discussed as follows: (a) character, (b) setting, (c) plot, and (d) metacognitive patterns. 


\section{Character}

The results of the analysis of the concept of character for the comparison group are presented in Tables 15 and 16, pp. 93 and 94. All the students could identify at least one character in the pretest and posttest sample. Five were able to change something about the characters at the pretest and posttest. Of the three students who were unable to change something about the character on the posttest interview, one changed where the characters were, which suggested some confusion between character and setting and was thus not counted as being able to manipulate the concept of character.

\section{Setting}

The results of the analysis of the interviews for the comparison treatment group were recorded in Tables 17 and 18, pp. 95 and 96. Four students had the concept of setting to the level at which they could identify it in their own work, and two could manipulate it by changing it. At the posttest the situation was about the same. One more student was able to identify and manipulate the concept, but one other simply said she did not know. Results may have been influenced by the fact that the interviews were held on the last day before spring vacation. 


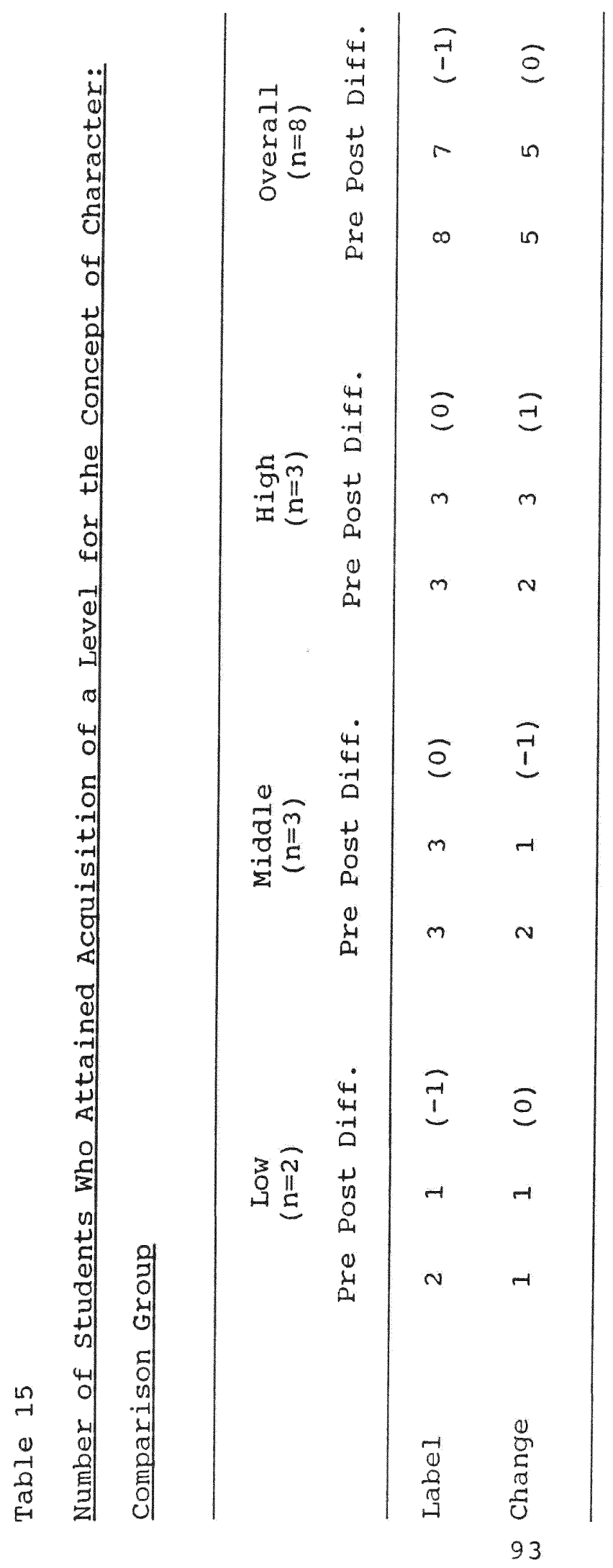




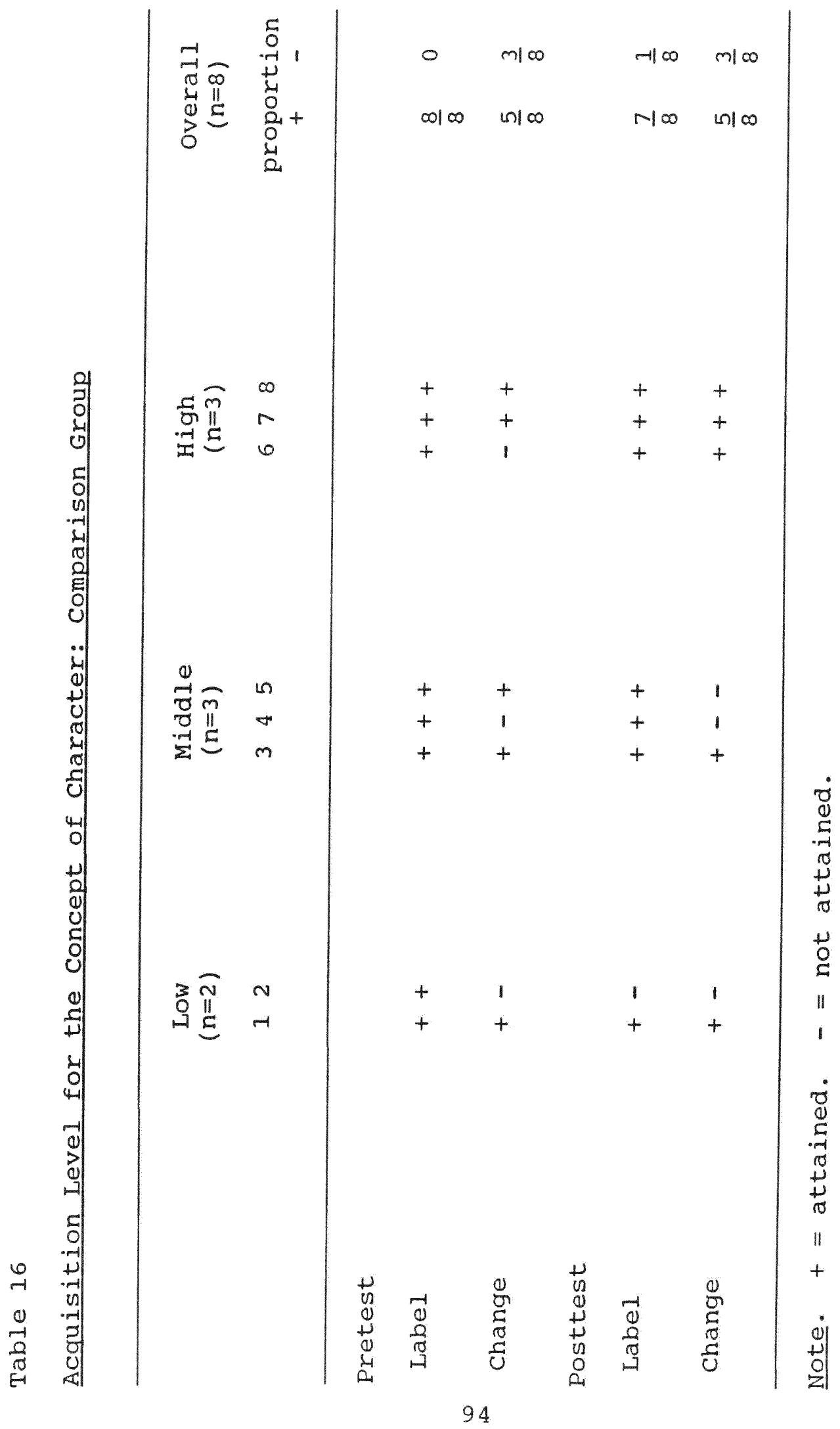




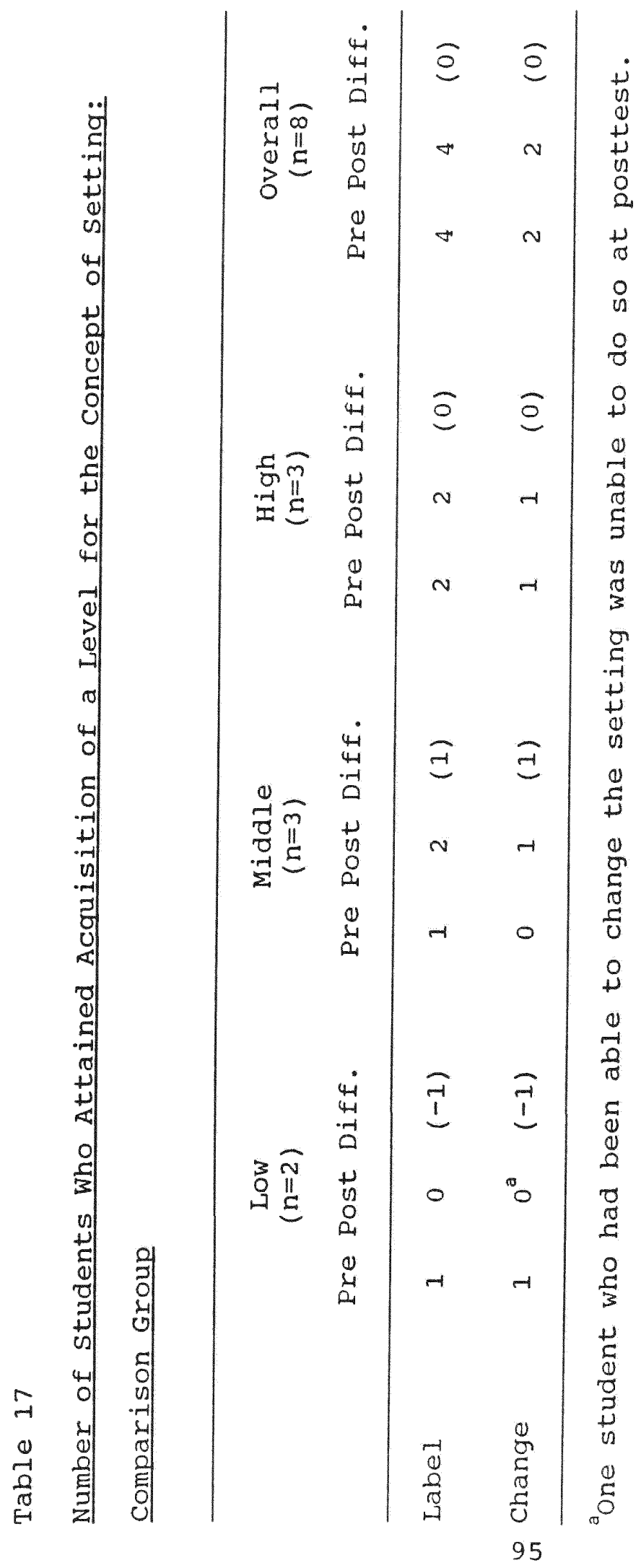




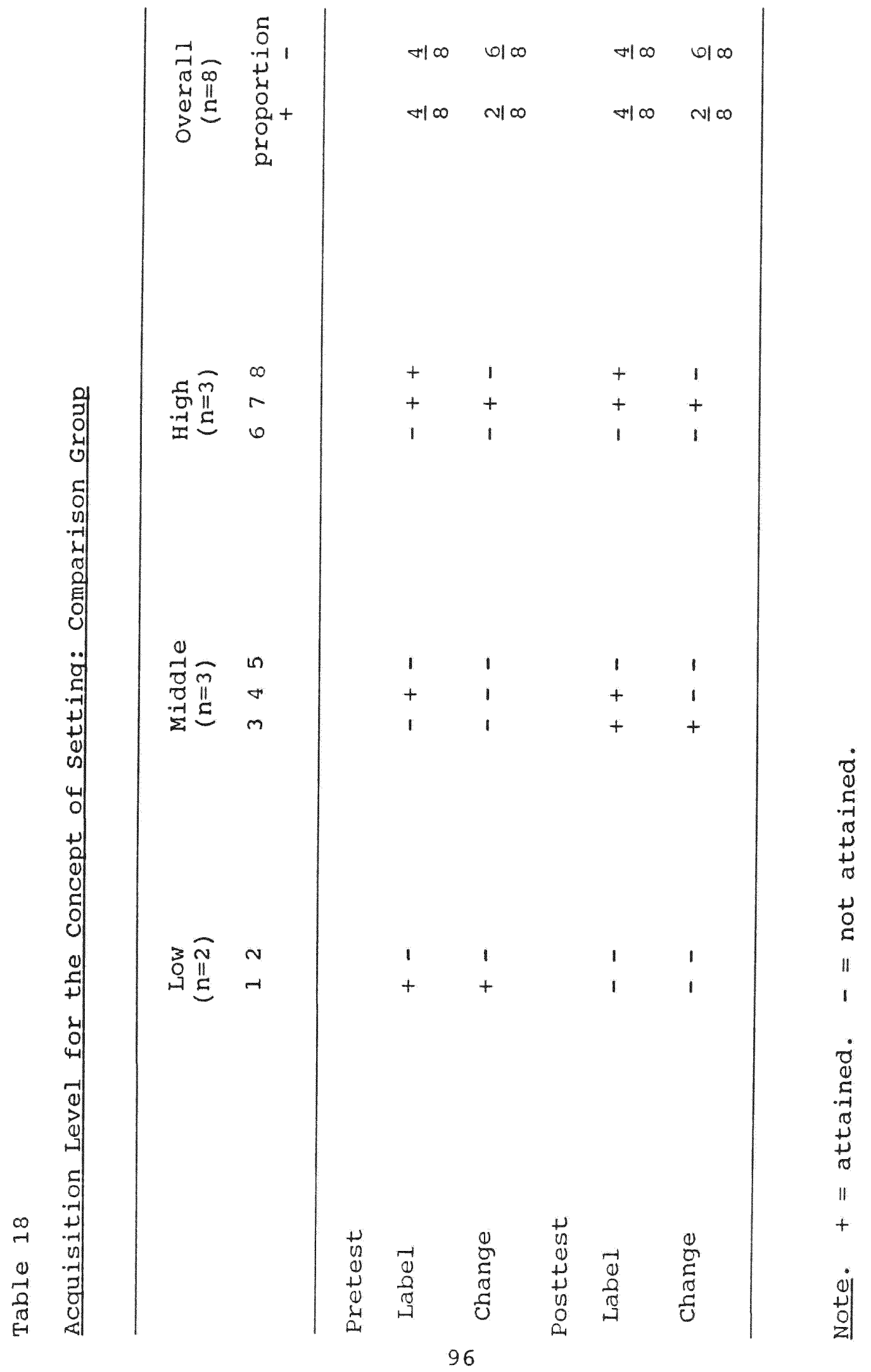


Plot

The responses to the individual interviews were analyzed and recorded in Tables 19 and 20, pp. 98 and 99. The plot seemed to be the least known aspect of story grammar. Only one student could identify and none could change the plot in his or her own story. None of the students appeared to gain knowledge of plot from the comparison treatment.

\section{Metacognitive Patterns}

Students' responses were analyzed and recorded in Table 21, p. 100. Students in the comparison group used a variety of patterns of metacognitive thinking when planning and writing narratives. At pretesting, four of the eight students were concerned with mechanics. One student said he would look to someone else to tell him what to write and three said they would think for themselves. One student was concerned about his story making sense. Another said he would use a story as a model for writing. At the posttest, three students were concerned about mechanics and another three said they would ask someone to tell them what to write. Only two students mentioned they would think of ideas themselves, and one said he would use his experiences for ideas. 


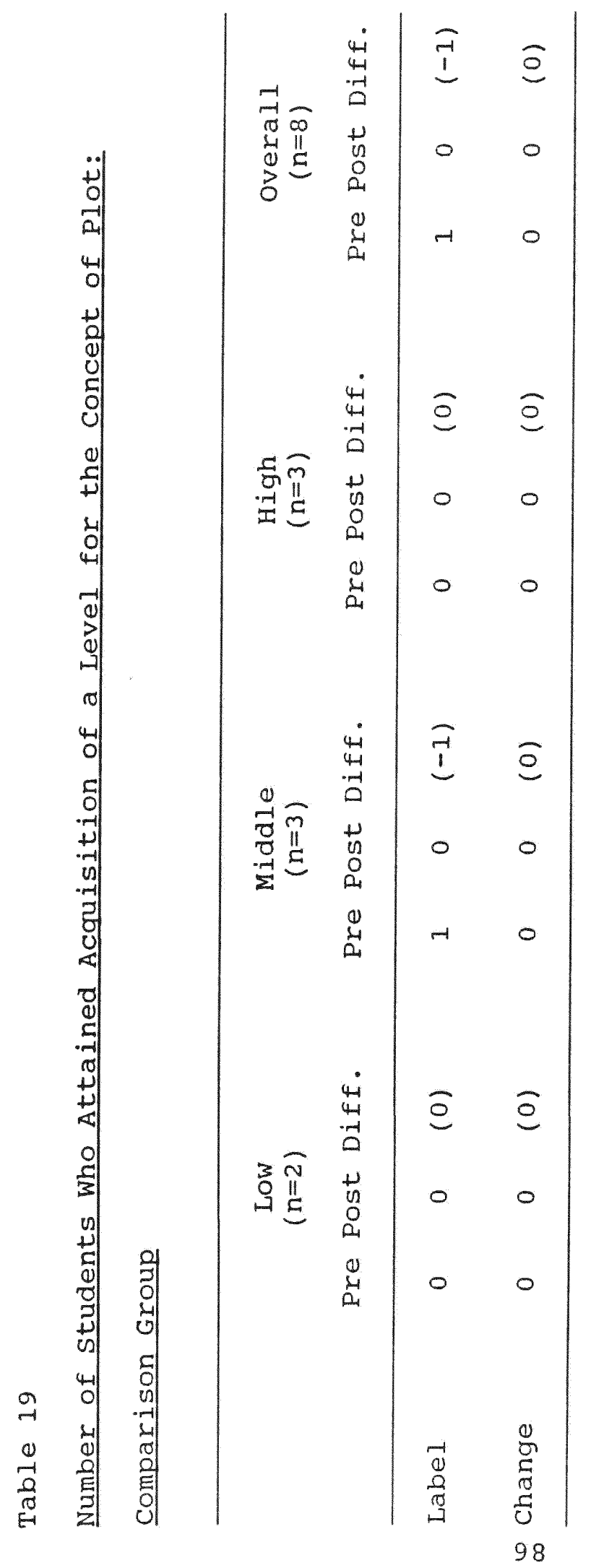




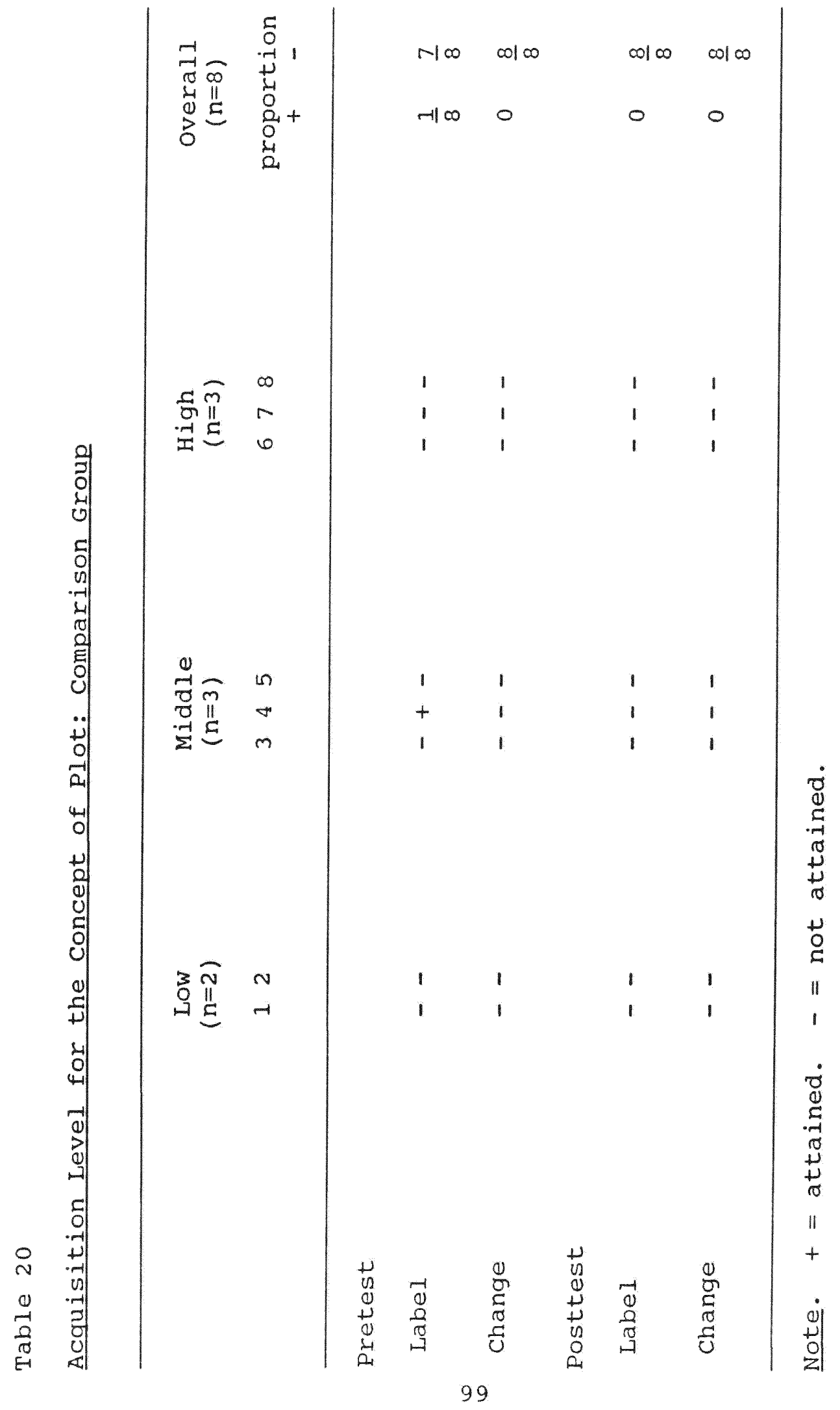


Table 21

Metacognitive Patterns: Comparison Group

Mechanics

4

Make sense

objects in view to stimu-

late thought

External locus of control

(good writer would tell

student what to do)

Internal locus of control (good writer would tell student to think)

Images in their minds

Planning activity such as making a list

Use a story as a model

Use good vocabulary

Use past experience

Use discussion with

0

0

classmate

Use story grammar

0

0

\section{Discussion}

A majority of students in both the experimental and comparison groups had the concept of character at the pretest and posttest. In the experimental group, students seemed to gain in the ability to identify and manipulate 
setting and plot. In the comparison group, there was only one student who seemed to gain in the ability to manipulate and change the concept of setting, while no students seemed to be able to identify or manipulate plot. Some of the students in the experimental group were able to use story grammar as a strategy. Students in both groups used metacognitive patterns involving plans for writing which varied in complexity and usefulness.

\section{Summary of the Findings}

Results of the study of the effect of direct instruction in story grammar using deep processing compared with modified directed reading lessons with an emphasis on answering multi-level questions and vocabulary development showed that there were no differences in adjusted posttest mean reading scores using ANCOVAs. The results of ANCOVAs on the means for the posttest story grammar scores, total adapted-Glazer Narrative Composition Scale scores and holistic scale scores showed significant improvement in writing achievement for the experimental group over the comparison group. The adjusted posttest mean score for style for the experimental group was higher than that for the comparison group, although the difference was not statistically significant. The pretest, posttest difference scores for the experimental group taken separately were statistically significant on all writing measures. The adapted-Glazer Narrative Composition scale pretest, 
posttest, and difference scores correlated well with the respective holistic scale scores.

Qualitative analysis showed that both groups seemed to have a good understanding of the concept of character at the pretest and the posttest interview. Five students in the experimental group who were unable to identify or manipulate the setting in their story at the pretest seemed able to do so after direct instruction in story grammar with deep processing. Twelve students in the experimental group who had been unable to identify the plot in their own stories before treatment seemed able to identify it after the experimental treatment. Eight students in the experimental group who seemed unable to manipulate the plot in their own stories before treatment appeared to be able to manipulate it after treatment. In the comparison group, only one additional student seemed to be able to identify and manipulate setting at the posttest interview as compared to the pretest interview, and no students appeared to gain ability to identify and manipulate the concept of plot.

\section{Discussion of the Findings}

\section{An Individual Case}

one student's performance was of particular interest. This second-grade girl had a much higher score on the primary trait scale for the pretest than for the posttest 
after participating in the experimental treatment. In analyzing this situation, the type of story she wrote seemed important. When she wrote her pretest sample on a topic of her choice, she wrote a fairy tale, a narrative format which seemed quite familiar to her. She knew many elements to include and earned a good score, although she was not very original. After the treatment, she tried to write realistic fiction. In changing types of narratives, she may have lost control over some of the aspects of story grammar which she was able to include in the more familiar type of story. Graves spoke about a non-linear progression in learning to write (cited in Newman, 1985). He hypothesizes that when a student tries to write a different type of story, the shift in focus might cause a lapse in control over previously mastered abilities. The change in preference from fairy tale to realistic fiction, according to Favot (cited in Norton, 1991), is common. He explained that children often change from their preference for folktale to realistic fiction at around the second grade. This child's writing samples seemed to support these observations and underscore the value of looking at the writing sample data both qualitatively and quantitatively to gain insight for instructional planning and student evaluation. 
Summary, Conclusions, and Recommendations The purpose of this chapter is to present: (a) a restatement of the problem, (b) a summary of related research, (c) an overview of design and procedures, (d) the findings of the study, (e) conclusions, (f) implications, (g) recommendations for further research, and (h) discussion.

\section{Restatement of the Problem}

Educators have recognized the need to improve students' reading and writing achievement. This has resulted in a re-evaluation of reading and writing processes, their relationship, and how these processes may be most effectively taught. The immediate problem is whether reading and writing achievement of young children can be improved by building concepts of story grammar using direct instruction with deep processing.

\section{Related Research}

The exact nature of the relationship between reading and writing is not known. Similarities and differences in the processes have been discussed. For example, Sommers (1988) suggested that ability in one area may not necessarily transfer because different strategies may be involved. However, Wittrock (1983) proposes there is a 
symbiotic relationship which suggests that integrating reading and writing instruction may be beneficial.

Particularly relevant to the current study was research involving direct instruction in story grammar. While the effects of direct instruction in story grammar with older students had been found to be positive (Ballard, 1988; Carnine and Kinder, 1985; Idol and Croll, 1987; Singer \& Donlon, 1982; Spiegel and Fitzgerald, 1986), no studies were found which examined benefits of this type of teaching on the reading and writing achievement of primary-grade students. Additionally, no studies were found dealing with the level of awareness primary students have of the concepts of story grammar.

\section{Design and Procedures}

The seventy-seven students in the study were members of four previously established classrooms. The teachers of the classes were matched for years of experience and randomly assigned to the treatment and comparison groups. Scores on the Gates-MacGinitie Reading Tests (GMRT), third edition, Level 2, Forms $\mathrm{K}$ and $\mathrm{L}$ were taken as pretest and posttest measures of reading achievement. To assess writing achievement, students' pretest and posttest writing samples were analyzed using the adapted-Glazer Narrative composition scale (aGNCS) and an holistic scale by $R$. J. Pritchard. Statistical analyses of posttest scores were performed using ANCOVAs adjusted for pretest scores. 
Differences between pretest and posttest scores were also examined within each group separately. The aGNCS and the holistic scores were correlated using pretest, posttest, and difference scores.

To explore the extent of student concept development of story grammar, a subgroup of sixteen experimental group and eight comparison group students were selectively chosen to be interviewed. Students' interviews were stratified by category of performances on the Gates-MacGinitie Reading Tests (high [7-9 stanines], middle [4-6 stanines], and low [1-3 stanines]), so all levels were represented; however, the qualitative data were analyzed by treatment group. Interview data were qualitatively analyzed to determine levels of concept development, i.e., labeling (identifying) and changing (manipulating) the target concepts.

The study was conducted over a period of three weeks (eleven days total) prior to spring vacation. The first two and last two days were devoted to testing and interviewing students. Each treatment and comparison group lesson lasted approximately one hour and fifty minutes. Both the experimental and control groups had access to the text selections and listened as the teacher read selected stories aloud. Then students read the selections themselves. The experimental group received direct instruction in story grammar using the research selections. The 
experimental group also applied deep processing techniques to develop the target concepts (character, setting, and plot) and then were provided opportunities through guided and independent practice to apply the newly developed concepts. The comparison group received modified reading lessons in which students wrote answers to multi-level questions (which were later discussed) and developed vocabulary knowledge. Students were provided with opportunities to use newly-learned vocabulary in the following three ways: within their written answers to the multilevel questions, the discussion of the answers, and a vocabulary game.

\section{Findings of the study}

\section{Quantitative}

The results of the data analyses indicated no significant difference in the reading achievement of students taught with direct instruction using deep processing of story grammar as compared with students taught with directed reading lessons answering multi-level questions and focusing on vocabulary development. There was significant improvement in the writing achievement of the experimental group over the comparison group. In addition, when writing gain scores were examined, the experimental group had made large significant gains on all writing measures from pretest to posttest, whereas the comparison group's small 
positive gains were not statistically significant. The adapted-Glazer Narrative Composition Scale and holistic measures were significantly correlated at the pretest and posttest indicating they measured writing similarly. They measured improvement similarly since the difference scores were significantly correlated as well. These correlations suggest that the aGNCS would be appropriate to use when evaluating the writing of second graders.

\section{Qualitative}

For the experimental group, at the pretest interview, all but one student demonstrated control of the concept of character. However, this student gained control of this concept by the posttreatment interview. Another student had control of all three concepts prior to treatment. The fifteen remaining students gained at least one level of control over the remaining concepts (setting and plot) after the experimental treatment. Three students said they would think about story grammar elements as a strategy for planning or revising their writing. Other metacognitive strategies were also identified: e.g., planning by making a list of events to include, thinking for oneself rather than listening to the suggestions of others.

The comparison treatment group showed minimal gains as expected given they received no direct instruction on story grammar elements using deep processing. All of the students could identify at least one character, and all 
but three could manipulate the concept at the pretest interview. There were no changes at the posttest interview in ability to identify or manipulate character. After treatment, only one student gained the ability to identify and manipulate the concept of setting, and no students gained the ability to identify or manipulate the concept of plot.

\section{Conclusions}

The following conclusions were based on the findings of this study:

1. Reading achievement was not improved as a result of direct instruction in story grammar using deep processing.

2. Writing achievement was improved as a result of direct instruction in story grammar using deep processing.

3. After the experimental treatment, students were able to identify and manipulate the concepts of story grammar in their own narratives.

4. After the experimental treatment, a higher incidence of metacognitive patterns was present and more were identified.

\section{Implications}

1. Teachers of young children can be more direct in the teaching of writing using the techniques of direct instruction and deep processing. 
2. With direct instruction using deep processing, teachers can help students strengthen their intuitive sense of story to more developed levels of metacognitive control. This may enable students to create, change, and revise compositions.

3. Teachers may encourage students to explore metacognitive patterns (strategies) related to writing through discussion techniques prompted by questions such as those used in the interviews in this study.

\section{Recommendations for Future Research}

1. Replicate the study to determine if direct instruction on story grammar using deep processing improves students' reading achievement under the following conditions:

a. Reading is assessed using an instrument that includes narratives containing story grammar elements.

b. Treatments are conducted for a longer period of time.

c. Longitudinal effects are examined.

2. Examine direct instruction using deep processing for teaching other writing concepts related to narratives and text structures related to expository materials.

3. Examine use of concepts:

a. Will students who have discussed strategies write passages using other students' strategies? 
b. How do strategies evolve over time in regards to appropriateness, effectiveness, and complexity?

4. Investigate how direct instruction with deep processing when teaching reading and writing affects students' attitudes toward these processes.

5. Investigate if direct instruction using deep processing improves the achievement of various populations of readers and writers.

\section{Discussion}

There are two additional ideas that came out of this study that merit discussion: (a) improvement in style, and (b) the use of the adapted-Glazer Narrative Composition scale. Although style was not directly investigated, the treatment had an effect on style of writing. When the experimental group students' style score was analyzed separately, students gained significantly $(p<.001)$. Since this one area was not explicitly taught, it is important to note this additional transfer effect of the treatment. Style may be so integral to story grammar that teaching some aspects of story grammar improves style.

Another noteworthy outcome of this study was the adaptation of the Glazer Narrative composition scale to effectively evaluate the writing of second-grade students. Detailed information can be generated from this scale that could help teachers in planning instruction and student conferences. Because the adapted-Glazer Narrative 
Composition scale takes more time to use, it remains to be seen if, with practice, teachers could apply it with facility. 


\section{BIBLIOGRAPHY}

Alvermann, D. E., \& Boothby, P. R. (1982). Text differences: Children' perceptions at the transition stage in reading. The Reading Teacher, 36, 298-302.

Anderson, P. S., \& Lapp, D. (1988). Language skil is in elementary education (4th ed.). New York: Macmillan.

Anderson, R. C., Hiebert, E. H., Scott, J. A., \& Wilkinson, I. A. G. (1985). Becoming a nation of readers. Washington, DC: National Institute of Education, National Academy of Education, Commission on Reading.

Applebee, A. N. (1978). The child's concept of story. Chicago: University of Chicago Press.

Atwell, N. (1987). In the middle: Writing, reading, and learning with adolescents. Portsmouth, NH: Boynton/ cook, Heinemann.

Au, K. H., Scheu, J. A., \& Kawakami, A. J. (1900). Assessment: Assessment of students' ownership of literacy. The Reading Teacher, 44, 154-156.

Ballard, P. J. Q. (1988). The effects of narrative instruction on the comprehension abilities of eighth grade students (Doctoral dissertation, Purdue University, 1988). Dissertation Abstracts International, 50, 106 .

Barnes, D. (1987). Is this a story? Preschool children's responses to written vignettes (schema) (Doctoral dissertation, University of Oregon, 1987). Dissertation Abstracts International, 48, 2803.

Bromley, K. D. (1988). Language arts: Exploring connections. Boston: Allyn \& Bacon.

Bruner, J. S. (1975). The ontogenesis of speech acts. Journal of Child Language, $2,1-40$.

Britton, J., Burgess, T., Martin, N., Mcleod, A., \& Rosen, H. (1975). The development of writing abilities, 11 18. London: Macmillan. 
Bryant, S. M. (1986). The effects of visualization and verbalization as study strategies on middle school students' retention of defined concepts learned from expository text (Doctoral dissertation, The Florida State University, 1986). Dissertation Abstracts International, 47, 4274A.

Caine, R. N., \& Caine, G. (1990). Understanding a brainbased approach to learning and teaching. Educational Leadership, 48, 66-70.

Calkins, L. M. (1986). The art of teaching writing. Portsmouth, NH: Heinemann.

Campbell, D. T., \& Stanley, J. C. (1963). Experimental and quasi-experimental designs for research. Boston: Houghton Mifflin.

Carnine, D., \& Kinder, D. (1985). Teaching low-performing students to apply generative and schema strategies to narrative and expository material. Remedial and Special Education, $6,20-30$.

Cooper, C. R., \& Petrosky, A. R. (1976). A psycholinguistic view of the fluent reading process. Journal of Reading, 19, 184-207.

Davis, Z. T., \& McPherson, M. D. (1990). Story map instruction: A road map for reading comprehension. Reading Teacher, $43,232-240$.

Deci, E. L., \& Ryan, R. M. (1987). The support of autonomy and the control of behavior. Journal of Personality and Social Psychology, 53, 1024-1037.

Drake, B. M. (1988). A factor analytic examination of the learning styles paradigm and brain hemisphere research (Doctoral dissertation, Indiana University, 1988). Dissertation Abstracts International, 49 , $1737 \AA$.

Duffy, G. G. \& Roehler, L. R. (1986). Improving classroom reading instruction. New York: Random House.

Durkin, D. (1989). Teaching them to read. Boston: Allyn $\&$ Bacon.

Eckhoff, B. (1983). How reading affects children's writing. Language Arts, 60, 5, 607-616. 
Fagan, W. T., Cooper C. R., \& Jensen, J. M. (1975). Measures for research and evaluation in English language arts: A reading-and-writing approach for children. Urbana, IL: National Council of Teachers of English.

Feldmen, M. J. (1983). Evaluating pre-primer basal readers using story grammar (Doctoral dissertation, state University of New York at Buffalo, 1983). Dissertation Abstracts International, 44, 3024A.

Fine, J. C. (1989). Mythology: Science and spirit in story. (Available from Joyce Fine, Florida International University, Broward Center, 3501 S. W. Davie Road, Davie, Florida 33314.)

Fine, J. C., Kossack, S. W., \& Johnson, P. (1986, December). Learning bridges falling down: Basal progression and transfer called to question. Paper presented at the meeting of the American Reading Forum, Sarasota, FL.

Fitzgerald, J., \& Spiegel, D. L. (1983). Enhancing children's reading comprehension through instruction in narrative structure. Journal of Reading Behavior, 15, $1-17$.

Freeman, E. B., Samuelson, J., \& Sanders, T. (1986). Writing instruction: New insights from ethnographic research. Journal of Research and Development in Education, 19, 10-15.

Franklin, E. A. (1988). Reading and writing stories: Children creating meaning. The Reading Teacher, 41 , 184-189.

Gage, N. L., \& Berliner, D. C. (1988). Educational psychology (4th ed.). Dallas: Houghton Mifflin.

Gersten, R., \& Dimino J. (1989). Teaching literature to at-risk students. Educational Leadership, 46, 5, 5357.

Goetz, J. P., \& Lecompte, M. D. (1984). Ethnographic and gualitative design in educational research. Orlando, FL: Academic Press.

Golden, J. M. (1984). Children's concept of story in reading and writing. The Reading Teacher, 37, 578584 . 
Goodlad, J. I. (1984). A place called school: Prospects for the future. New York: McGraw-Hill.

Goodman, K. (1986). What's whole in whole language? Portsmouth, NH: Heinemann.

Goodman, K. S., Shannon, P., Freeman, X., \& Murphy, S. (1988). Report card on basal readers. New York: Richard C. Owen Publishers.

Goodman, Y. M., Watson, D. J., \& Burke, C. L. (1987). Reading miscue inventory. New York: Richard $C$. Owen Publishers.

Gordon, C. J. (1988). Contexts for narrative text structure use: What do the kids say? English Quarterly, 21, 3, 148-163.

Gordon, C. J. (1989). Teaching narrative text structure: A process approach to reading and writing. In $K$. D. Muth (Ed.), Children's comprehension of text: Research into practice (pp. 79-102). Newark, DE: IRA.

Graves, D. (1983). Writing: Teachers and children at work. Portsmouth, $\mathrm{NH}$ : Heinemann.

Hillocks, G. (1986). Research on written composition: New directions for teaching. Urbana, IL: ERIC Clearinghouse on Reading and Communication skills and the National Conference on Research in English.

Holdaway, D. (1979). The foundations of literacy. Portsmouth, NH: Heinemann.

Hudson, S. A. (1986). Contest and children's writing. Research and the Teaching of English, 20, 294-317.

Huey, E. B. (1908). The psychology and pedagogy of reading. Boston: MIT Press. (Republished in 1968.)

Idol, I., \& Croll, V. (1987). Story mapping: Training as a means of improving reading comprehension. Learning Disabilities Quarterly, 10, 214-230.

Jaggar, A. M., Carrara, D. H., \& Weiss, S. E. (1986). Research currents: The influence of reading on children's narrative writing (and vice versa). Language Arts, 63, 292-300. 
Johnson, M. R. (1987). Effects of a cloze story map strategy on reading comprehension (Doctoral dissertation, Auburn University, 1987), Dissertation Abstracts International, 49, 02A.

Kliebard, H. M. (1982). The struggle for the American curriculum 1893-1958. New York: Routledge \& Kegan Paul.

Littledale, F. (1989). King Midas and the golden touch. New York: Scholastic.

MacGinitie, W. H. \& MacGinitie, R. K. (1989). GatesMacGinitie Reading Tests. Chicago: Riverside.

Mandler, J. M., \& Johnson, N. S. (1977). Remembrance of things parsed: Story structure and recall. Cognitive Psychology, 2, 111-151.

Marshall, N. (1984). Discourse analysis as guide to informal assessment of comprehension. In J. Flood (Ed.), Promoting reading comprehension (pp. 79-96). Newark, DE: IRA.

Marzano, R. J. (1991). Cultivating thinking in English and the lanquage arts. Urbana, IL: National Council of Teachers of English.

Marzano, R. J., \& Arredondo, D. E. (1986). Tactics for thinking. Alexandria, VA: ASCD.

Miller, J. P. (1976). Tales from Aesop. New York: Random House.

Myers, M. (1980). A procedure for writing assessment and holistic scoring. Newark, DE: IRA.

National Commission on Excellence in Education. (1983). A nation at risk: The imperative for educational reform (Stock No. 065-000-00177-2). Washington, DC: U.S. Government Printing office.

Newman, J. M. (Ed.). (1985). Whole language: Theory in use. Portsmouth, NH: Heinemann.

Norton, D. E. (1989). The effective teaching of language arts ( $3 \mathrm{rd}$ ed.). Columbus, OH: Merrill.

Norton, D. E. (1991). Through the eyes of a child (3rd ed.). New York: Merrill. 
Palinscar, A. S. (1986). The role of dialogue in providing scaffolded instruction. Educational Psychologist, 21, 1-2, 73-98.

Pearson, P. D. (1985). Changing the face of comprehension instruction. The Reading Teacher, 38, 724-738.

Paris, S. G., Lipson, M. Y. \& \&ixson K. K. (1983). Becoming a strategic reader. Contemporary Educational Psychology, $8,293-316$.

Pritchard, R. J. (1987). Effects on student writing of teacher training in the National writing Project Model. Written Communication, 4, 51-67.

Raphael, T. E. (1984). The context of school-based literacy. New York: Random House.

Ratliff, J. L. (1986). Explicit instruction in story structure: Effects on preschoolers' listening comprehension (story grammar) (Doctoral dissertation, The Louisiana State University and Agricultural and Mechanical College, 1986). Dissertation Abstracts International, 47, 3972 .

Reutzel, D. R., \& Cooter, R. B. (1990). Whole language: Comparative effects on first-grade reading achievement. Journal of Educational Research, 83, 252-257.

Richardson, A. (1969). Mental imagery. New York: springer.

Richardson, A. (1983). Imagery: Definition and types. In A. A. Sheikh (Ed.), Imagery: Current theory, research and application (pp. 3-32). New York: Springer.

Rose, M. L. R. (1983). The relationship between children's concept of story and reading comprehension of narrative prose (Doctoral dissertation, North Carolina State University, 1983). Dissertation Abstracts International, 44, 3025.

Rosenblatt, L. (1976). Literature as exploration. New York: Springer.

Routman, R. (1988). Transitions: From literature to literacy. Portsmouth, NH: Heinemann. 
Samuels, S. J., \& Kamil M. L. (1984). Models of the read ing process. In P. D. Pearson (Ed.), Handbook of reading research. (pp. 185-224). New York: Longman.

Shanahan, T. (1988). The reading-writing relationship: Seven instructional principles. The Reading Teacher, 42, $636-647$.

Singer, H., \& Donlon, D. (1982). Active comprehension: Problem solving-schema with question generation for comprehension of complex short stories. Reading Research Quarterly, 17, 166-185.

Smith, F. (1973). Psycholinguistics and reading. New York: Holt, Rinehart \& Winston.

Smith, F. M. (1986). The effects of story structure training upon first graders' memory and comprehension of wordless picture books (Doctoral dissertation, University of Maryland, 1986). Dissertation Abstracts International, 47, 3722 .

Sommers, A. (1988). Research in whole language: Implications for teachers. In U. H. Hardt (Ed.), oregon English (pp. 10-13). Lake Oswego, OR: Lake Grove.

Spiegel, D. L., \& Fitzgerald, (1986). Improving reading comprehension through instruction about story parts. The Reading Teacher, 39, 676-82?

Squire, J. R. (1983). Composing and comprehending: Two sides of the same basic process. Language Arts, 60 , 581-589.

stein, N., \& Glenn C. (1979). An analysis of story comprehension in elementary school children. In $R$. Freedle (Ed.), New directions in discourse processing: Vol. 2 (pp. 53-120). Norwood, NJ.: Ablex.

Stoll, J. P. (1983). The effects of imagery training and istening to fairy tales on reading comprehension and creativity of third graders (Doctoral dissertation, Rutgers University, The state University of New Jersey [New Brunswick], 1983). Dissertation Abstracts International, 44, 2039A.

Stotsky, S. (1983). Research on reading/writing: A synthesis and suggested directions. Language Arts, 60, $5,627-642$. 
Summers, P. F. (1980). The relationship between demonstrated story grammar usage by third graders and their score on selected reading comprehension test (Doctoral dissertation, Boston University, School of Education, 1980). Dissertation Abstracts International, 41, 2039.

Taylor, B. M. (1980). Children's memory for text after reading. Reading Research Quarterly, 15, 399-411.

Taylor B. M. \& Beach, R. W. (1984). The effects of text structure instruction on middle-grade student's comprehension and production of expository text. Reading Research Quarterly, 19, 134-146.

Tierney, R. J., \& Leys, M. (1984). What is the value of connecting reading and writing? (Report No. 55). Urbana, IL: University of Illinois center for the Study of Reading. (ERIC Document Reproduction Service No. ED 251810 )

Tierney, R. J., \& Pearson, P. D. (1983). Toward a composing model of reading. Language Arts, $60,568-$ 589.

Tompkins, G. E., \& McGee, L. M. (1989). Teaching repetition as a story structure. In K. D. Muth (Ed.), Children's comprehension of text: Research into practice (pp. 59-78). Newark, DE: IRA.

Turnbill, J. (1984). Now we want to write. Portsmouth, $\mathrm{NH}:$ Heinemann.

Vygotsky, L. S. (1962). Thought and language (E. Hanfmann \& G. Vakar, Trans.). Cambridge: Harvard University Press.

Vygotsky, L. S. (1978). Mind in society: The development of higher psychological processes (M. Cole, V. Johnsteiner, S. Scribner, \& E. Souberman, Eds. and rans.). Cambridge: Harvard University Press.

Way, C. (1988). The effects of story grammar and story interestingness on children's recall and preference of narratives in standardized reading comprehension tests (Doctoral dissertation, University of colorado at Boulder, 1988). Dissertation Abstracts International, 50, 678A.

Wells, G. (1980). Learning through interaction. Cambridge: Cambridge University Press. 
Westbrooks, S. (1987). The comparative effects of two instructional strategies on second-graders' reading comprehension and writing ability (story mapping, sumary) (Doctoral dissertation, Indiana state University, 1987). Dissertation Abstracts International, 48,2808 .

Winzenz, M. A. (1988). Comprehension of extended narrative text: The role of spontaneous mental imagery while reading or listening (Doctoral dissertation, University of the Pacific, 1988). Dissertation Abstract International, 49, $1744 \mathrm{~A}$.

wittrock, M. C. (1983). Writing and the teaching of reading. Language Arts, 60, 568-606.

Wittrock, M. C. (1986). Student's thought processes. In M. C. Wittrock (Ed.), Hand book of research in teaching (pp. 297-314). New York: Macmillan.

Zarnowski, M. (1990). Learning about biographies. Urbana, IL: National Council of Teachers of English. 


\section{APPENDICES}


APPENDIX A

ADAPTED-GLAZER NARRATIVE COMPOSITION SCALE 


\section{ADAPTED-GLAZER NARRATIVE COMPOSITION SCALE}

I. CHARACTERIZATION

- No characters are mentioned.

1 Characters are identified by a name, noun, or pronoun, with no further description.

2 Characters are described physically, emotionally, or both.

3 Characters are described physically, emotionally, or both, and act in accordance with description.

II. SETTING

0 No setting is mentioned or indicated.

1 Time and/or place are indicated in general.

2 Time and/or place are given specifically.

3 Time and/or place are given in descriptive, sensory terms.

III. PLOT

A. Problem/goal

0 No problem or goal is mentioned or indicated.

1 A problem or goal is mentioned or indicated indirectly.

2 A problem or goal is mentioned and related to action.

3 A problem or goal is mentioned and is stated as the cause of action to solve the problem.

\section{B. Feelings}

- No emotion is mentioned or indicated.

1 A single word denotes emotion.

2 Emotion is stated and related to the problem.

3 Emotion is a basic part of the story, perhaps affecting the plot. 
C. Action

- No action is mentioned or indicated.

1 Action is stated or indicated indirectly.

2 Action is stated directly and is related to the problem.

3 Action is developed as a solution to the problem or an attempt to gain goal.

D. Outcome/Ending

0 There is no ending. Closure or concluding remark but in the story sense.

1 Ending is stated, but there is no reason for ending or it is a trite ending.

2 Ending follows logically from the story.

3 Ending follows logically from the story and is clever, or well stated. May be a surprise ending.

IV. THEME

o Story does not have a theme.

1 Theme could be inferred.

2 Theme is stated as a moral at the end of the story, or is summarized in the concluding statements.

3 Theme is an integral part of the story.

V. STYLE

A. Title

0 There is no title.

1 The story and title do not match.

2 The title is very general and tells little about the story.

3 The title is interesting or clever, builds desire to read the story.

B. Sentence structure

Sentence structure--Fluency, Variety

1 Sentences are short or choppy or run-on. The same pattern may be repeated. Lacks fluency.

2 Sentences read without noticeable breaks, and there is some variety in pattern.

3 There is a great variety in sentence patterns, some rather complex. The composition flows freely. 
Sentence Structure--Use of Connectives

o No connectives.

1 "And" is used to create run-on sentences. one connective, such as "then" or "so" is used extensively and with little intrinsic meaning.

2 The same connective is used repeatedly, but with meaning. The transitions are not particularly smooth.

3 Connectives are used logically and create a smooth transition.

C. Word Usage

Word Usage--Vocabulary

1 Common, fairly general words are used. The same words may be used repeatedly.

2 Accurate, precise, but not unusual words are used.

3 Vivid, descriptive words are used.

Word Usage--Figurative Language

0 There is no figurative language at all.

1 Common idioms or often-used figures of speech are used.

2 Original figures of speech, appropriate to the situation, are used. New expressions are introduced. Unique language is used.

Word Usage--Names

1 Characters are not named, are referred to by a common noun.

2 At least one character is named, using actual names.

3 Names are created for an imaginary creature, or to match a character. Unusual names are used.

Word Usage--Pronouns, Verb Tense

1 Two different pronouns are used to refer to the same antecedent. There is a confusing change of verb tense.

2 For the most part, pronoun usage and verb tense are consistent with the meaning of the passage. Some verb inflections may be omitted. 
3 For the entire story pronoun usage and verb tense are consistent with the meaning of the passage.

D. Dialogue

1 No dialogue is used. The dialogue is stilted or unnatural.

2 The dialogue advances the plot, is natural, and is appropriate to the character speaking.

3 The dialogue advances the plot, is natural, and is appropriate to the character speaking, and is particularly clever or effective.

E. Emotional Quality

1 No emotion is mentioned or indicated. A single word denotes emotion.

2 Emotion and reaction to emotion are shown.

3 Emotion is a basic part of the story, perhaps affecting the plot. An unusual depth of understanding of emotion is shown.

F. Unusual Elements

1 The story is told in direct narrative.

2 The story employs some literary device which increases its effectiveness. Examples are:

An unexpected element

Special punctuation or capitalization for emphasis

Repetition of words or phrases

Unusual point of view

Special format or form

Aside to reader

Humor, exaggeration, sarcasm 
I. CHARACTERIZATION

II. SETTING

III. PLOT

Problem

Feelings

Action

Outcome / Ending

SCORE

SUBTOTAL

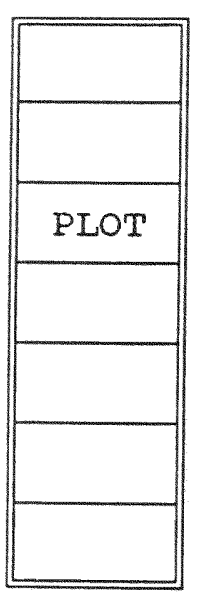

IV. THEME

V. STYLE

A. Title

B. Sentence structure--fluency, variety Sentence structure--use of connectives

c. Work Usage--vocabulary

Word Usage--figurative language

Word Usage--names

Word Usage--pronouns, verb tense

D. Dialogue

E. Emotional quality

F. Unusual Elements

SUBTOTAL

TOTAL SCORE

Paper No.

Rater

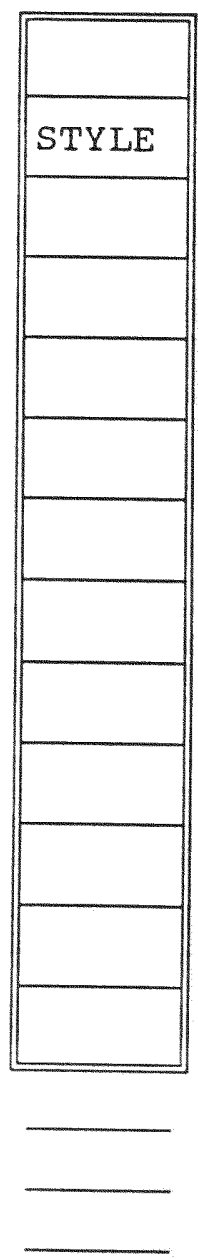


APPENDIX B

PRITCHARD HOLISTIC SCORING SCALE 
HOLISTIC SCORING SCALE FOR WRITING

by R. J. Pritchard

Point score

6

5

4

3

2

\section{Characteristics}

Has a thesis

Concrete details effectively used

Fluent in words and ideas

Varied sentence structure

Satisfactory closing statement

Generally clear mechanics

Has a central idea

specific facts, details, or reasons

consistent development

Less insightful, imaginative, concrete, or developed than a 6

Generally clear mechanics, errors do not

interfere with overall effectiveness

Has several clear ideas

Relevant and specific details

Evidence of fluency, but not of unified

development

May be overly general or trite

May have simple sentence structure or vocabulary

Mechanical errors do not affect readability

Has at least one idea, few, if any supporting details

Less fluent, developed, or detailed than a 4

Sentences, vocabulary, and thought may be simplistic

Mechanical errors do not affect readability

No thesis

Has a sense of order, but order may be only that of plot summary

Fluency and thought are minimal

Has at least one relevant idea

May have many mechanical errors but paper is readable 
No thesis and, of course, no support for thesis

No sense of organization Simplistic or vague language

May be unreadable due to spelling, handwriting, or other mechanical problems 
APPENDIX C

GLAZER NARRATIVE COMPOSITION SCALE 


\section{GLAZER NARRATIVE COMPOSITION SCALE}

I. PLOT

A. Originality

1 - The story is a retelling of a known story, or has obviously been copied.

2 - The basic idea and development of the story might be expected from intermediate grade children.

3 - The basic idea and development of the story show a new outlook, original thought.

B. Beginning

1 - Beginning is not particularly interesting, gets the story off to a slow start.

2 - Beginning is interesting, may be a stereotyped format.

3 - Beginning is intriguing, gets the reader into the story immediately.

c. Internal Logic

1 - Story lacks coherence. Story does not have a plot. Events are told in sequence, but without a cause and effect relationship. There is an unexplained conflict in the logic of the story.

2 - Events of the story are related logically, with some cause and effect.

3 - Events of the story are clearly interconnected by a cause and effect relationship.

D. Inclusion of Detail

1 - Very little detail included.

2 - Fair amount of detail.

3 - Much detail, adding to the development of the plot.

E. Ending

1 - Lack of closure. Lack of reasoning for specific ending. Trite ending.

2 - Ending follows logically from the story.

3 - Ending follows logically from the story, is clever, succinctly stated. May be a surprise ending. 
II. THEME

1 - story does not have a theme.

2 - Theme is stated as a moral at the end of the story, or is summarized in the concluding statements.

3 - Theme is an integral part of the story.

III. SETTING

1 - Time and place are indicated in general.

2 - Time and place are given specifically.

3 - Time and place are given in descriptive, sensory terms.

IV. CHARACTERIZATION

1 - Characters are identified by a name, noun, or pronoun with no further description.

2 - Characters are described physically, psychologically, or both.

3 - Characters are described physically, psychologically, or both, and act in accordance with the description given.

V. STYLE

A. Title

1 - There is no title. The story and title do not match.

2 - The title is very general and tells little about the story.

3 - The title is interesting or clever, builds desire to read the story.

B. Sentence structure

Sentence structure--Fluency, Variety

1 - Sentences are short or choppy. The same pattern may be repeated. Lack fluency.

2 - Sentences read without noticeable breaks, and there is some variety in pattern.

3 - There is a great variety of sentence patterns, some rather complex. The composition flows freely. 
Sentence Structure--Use of Connectives

1 - "And" is used to create run-on sentences. one connective, such as "then" or "so" is used extensively and with little intrinsic meaning.

2 - The same connective is used repeatedly, but with meaning. The transitions are not particularly smooth.

3 - Connectives are used logically and create a smooth transition.

c. Word Usage

Word Usage--Vocabulary

1 - Common, fairly general words are used. The same words may be used repeatediy.

2 - Accurate, precise, but not unusual words are used.

3 - Vivid, descriptive words are used.

Word Usage--Figurative Language

1 - There is no figurative language at al1.

2 - Common idioms or often-used figures of speech are used.

3 - Original figures of speech, appropriate to the situation, are used. New expressions are introduced.

Word Usage--Names

1 - Characters are not named, are referred to by a common noun.

2 - At least one character is named, using actual names.

3 - Names are created for an imaginary creature, or to match a character. Unusual names are used.

Word Usage--Pronouns, Verb Tense

1 - Two different pronouns are used to refer to the same antecedent. There is a confusing change of verb tense.

2 - For the most part, pronoun usage and verb tense are consistent with the meaning of the passage. Some verb inflections may be omitted. 
3 - For the entire story pronoun usage and verb tense are consistent with the meaning of the passage.

D. Dialogue

1 - No dialogue is used. The dialogue is stilted or unnatural.

2 - The dialogue advances the plot, is natural, and is appropriate to the character speaking.

3 - The dialogue advances the plot, is natural, is appropriate to the character speaking, and is particularly clever or effective.

E. Emotional Quality

1 - No emotion is mentioned or indicated. A single word denotes emotion.

2 - Emotion and reaction to emotion are shown.

3 - Emotion is a basic part of the story, perhaps affecting the plot. An unusual depth of understanding of emotion is shown.

F. Unusual Elements

1 - The story is told in direct narrative.

2 - The story employs some literary device which increases its effectiveness. Examples are:

An unexpected element

Special punctuation or capitalization for emphasis

Repetition of words or phrases

Unusual point of view

Special format or form

Aside to reader

Humor, exaggeration, sarcasm 


\section{APPENDIX D \\ DIRECT INSTRUCTION LESSONS \\ DEEP PROCESSING STORY GRAMMAR:}

EXPERIMENTAL GROUP 


\section{DIRECT INSTRUCTION LESSON}

\section{GENERAL FORMAT}

Step 1: Introduce the selection as a focus for a
strategy to be learned.

Step 2: Introduce strategy to be taught. (Which strategy, where to use it, what is the key to learning the strategy, how using it will make the student a better reader/writer.)

Step 3: Direct instruction: Model how to use the strategy, give examples, give guided practice, and provide opportunity for independent student application.

Step 4: Students 1 isten and/or read silently while the teacher reads the story aloud.

Step 5: Discuss the story content and use of strategy application.

Step 6: Reread the story silently.

Step 7: (Visualization) Draw a picture. Label the picture "characters in a setting" across the top.

Step 8: (Verbalization) Write a sentence for the picture. 
Step 9: (Emotional and Physical Attachment) Ask the student to express feelings and think about physical sensations that go with the element of story grammar being emphasized.

Step 10: Closure: Summarize content and strategy. 


\section{DIRECT INSTRUCTION LESSON \\ Deep Processing Story Grammar}

\section{Lesson 1: The Goose and the Golden Egg}

Step 1: Today we are going to read the story The Goose and the Golden Egg to be able to talk about the characters.

Step 2: The characters are the people or animals who do the action in the story. Characters are part of story grammar. You can use story grammar when you read and write stories. Story grammar names the parts all stories have in common. All stories have certain parts, just as all people have arms, legs, a body, and a head. When you know these parts, you will be able to better understand stories. You will also be able to write better because you will see how authors use these parts to create their stories.

Step 3: When you read, you should try to picture the way the characters look according to how the author, the person who wrote the story, describes them. What the characters do tells us about the kind of person they are. You will get a chance to draw a picture of each character to help you 
remember what the character looks like and what the character does in the story.

Sometimes the characters' names are in the title.

Who are the characters in Goldilocks and the Three Bears? (Goldilocks, three bears) who are the characters in Little Red Riding Hood? (Little Red Riding Hood, wolf, Grandmother, Little Red Riding Hood's mother, hunter) Sometimes all the characters are not mentioned in the title.

Who do you think are the characters in The Goose and the Golden Eggs? Let's read to see if we can say who they are.

Step 4: Read the story aloud. Students may read silently while the teachers reads aloud.

Step 5: Who are the characters? (man, goose) Did you picture in your mind what they look like? Close your eyes and picture them.

Step 6: Reread the story silently. Look at the story now. Find where the characters' names are underlined. Look for words that will help you picture the characters. 
Step 7: (Visualization) Draw a picture of each of the characters.

Step 8: (Verbalizations) Write the word "character" across the top of paper to remind you that the characters are who are in the story. Write a sentence about each character, the man and the goose.

Step 9: (Feelings and sensations) What do you think of this man? Do you like him? Why or why not? It is good to think about your feelings towards the characters.

If you touched the goose, what would he feel like? What kind of man was the main character? (Greedy) What did you make him look like in your picture?

Step 10: You can use this type of drawing to help you learn story grammar for any story. 


\section{DIRECT INSTRUCTION}

Deep Processing story Grammar

\section{Lesson 2: The shepherd Boy and the wolf}

Step 1: Today we are going to read The Shepherd Boy and the wolf to be able to talk about the setting.

Step 2: Setting is another part of story grammar. We talked about story grammar yesterday. What is story grammar? story grammar is what we call the parts that all stories have. We talked about the characters yesterday. Who are the characters? (People or animals in the story.)

Step 3: Today we will focus on the setting. That is the time, when, the story happens and the place, where, the story happens. The story usually has key words that tell when or where the story takes place. Sometimes we know when and where a story takes place from our own experiences.

Let's think about the setting in yesterday's story, The Goose and the Golden Egg. Where do you think it took place? It did not say, but we know it could have been on a farm. We think that because we know that is where someone might live who has a goose. Do you remember when it took place? It said long ago. If it did not 
say, it might be any time because there could be a foolish person today or any time who would think the way the man did.

Where did Goldilocks and the Three Bears take place? (Woods) When did Goldilocks go into the bear's house? (She went in while the bears were taking a walk.)

Where do you think The shepherd Boy and the wolf takes place? (Any prediction is acceptable. They may say the woods.) Listen to see where and when the story takes place.

Step 4: Read the story to group.

Step 5: Where did the story take place? (It took place beside the woods on a hillside overlooking the village.)

Step 6: Reread the story. Picture where and when it took place.

Step 7: Draw a picture of the setting. Put in the characters.

Step 8: Write a sentence to go with the story. 
Step 9: How do you think the boy felt when he was on the hill with only the sheep? What sounds would he hear?

Step 10: You can use a drawing of characters in a setting and a sentence to think about any story. 


\section{DIRECT INSTRUCTION \\ Deep Processing Story Grammar}

\section{Lesson 3: Ring Midas and the Golden Touch}

Step 1: Today we are going to read King Midas and the Golden Touch. From the title can you predict who one main character is? (King Midas) What do you think the setting will be if the main character is a king? (Where do kings live? A castle. When do many stories about kings take place? Long ago.)

Step 2: Our story today will help us to talk about the problem or goal in stories and how we learn something from reading how others solve problems.

Step 3: The problem or goal is something the character wants to do or become. Usually the character has some strong feeling that makes the character do something. What is done is the action. There is a result or outcome from the action. (Draw a map for display on the board.) 


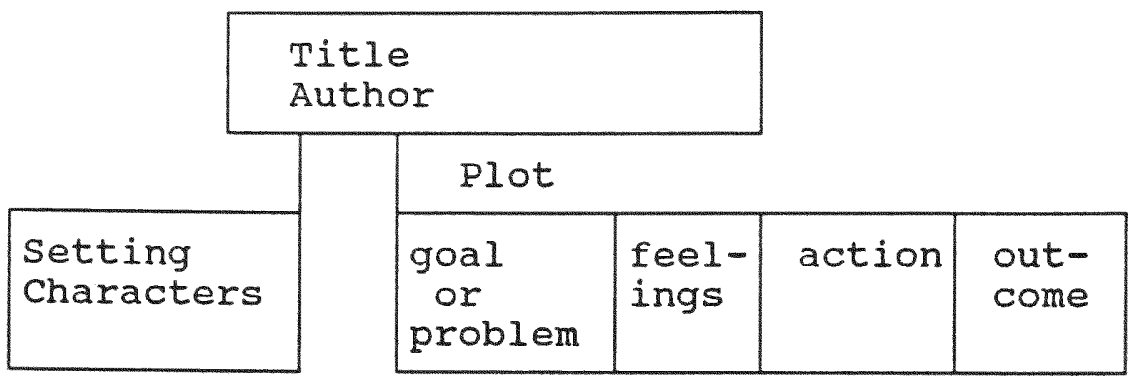

When you listen to a story, the feelings, actions, and outcomes are important parts of story grammar that help us understand the story. There is a relationship between the actions and the other parts we have discussed. The characters are who do the actions. The setting is where and when the actions take place. Think of the characters, where they are, what they feel, what they do and what the outcomes are.

In The shepherd Boy and the wolf, the boy feels lonely with only sheep to keep him company on top of the hill. This feeling makes him decide to trick the townspeople into believing the wolf is after the sheep. When the townspeople see he tricked them, they are angry. Then when he really does need their help, they will not come. We learn that it is wrong to call for help when you do not really need it. 
How did Little Red Riding Hood feel about her grandmother not being well? (Sad) What did Little Red Riding Hood want to do? (Take food to her grandmother so she would feel better.) Who did she meet on the way? The wolf. What did he do? He ran ahead to the grandmother's and ate her. Then he tried to trick Little Red Riding Hood. What did we learn from the story? (Do not talk to strangers.)

Listen to King Midas and the Golden Touch to see what King Midas wants to do or to become. (Very rich man) Think about what feelings make him act the way he does. (Greed)

Step 4: Students listen as teacher reads story.

Step 5: What did King Midas want to become? (A very rich king.) This is his goal or problem. What kinds of feeling are these? (Greedy feelings)

What action did he take? He agreed to letting everything he touched turn to gold.

How did he feel at first? (Happy) Then what happened to cause him to change his feelings? (His daughter turned to gold.) 
Then what did he have to do? (He had to get rid of the special touch.)

What was the outcome? (He decided he was better off having his daughter than the special touch.)

Step 6: Reread the story silently.

Step 7: Model the following procedure: Fold a paper in half length-wise. Fold it in half in the opposite way twice more. Label each block across the top in order on the unfolded paper (1) problem or goal, (2) feelings, (3) action, and (4) outcome.

Draw a picture of each of the parts in the labeled blocks in block below. (Teacher models thought process and does the rest of the lesson with the total group.)

Step 8: Write a sentence to go with each picture in the labeled block.

Step 9: How do you feel about King Midas' decision to give up the golden touch? Do you think you would make the same decision?

Step 10: The problem or goal, the feelings, the action and the outcome are parts of story structure. 
They help us learn from a story as well as help us understand and appreciate it. 


\section{DIRECT INSTRUCTION \\ Deep Processing Story Grammar}

\section{Lesson 4: The Hare and the Tortoise}

Step 1: Today we are going to read The Hare and the Tortoise by Aesop to be able to map a story using pictures for story grammar.

Step 2: We have talked about the parts of story grammar. We have drawn pictures and written sentences explaining the pictures.

What are the parts of story grammar?

How can this help us when we read? (We know the important parts to think about.)

Drawing this can help us plan our own stories too.

Step 3: Let's share your pictures from King Midas and the Golden Touch to create a map. (Teacher models.)

King Midas wants to be very rich. He accepts the special touch. He makes his daughter turn into a golden statue. He must lose the special touch. His daughter is back to being a girl. What was learned? (Money is not everything.) 
Step 4: Listen to The Hare and the Tortoise to see what the story grammar parts are.

Step 5: Discuss the story and all the parts.

Step 6: Reread the story silently.

Step 7: Draw a picture that goes with each part of story grammar. (The hare makes fun of the tortoise.)

What feelings does the tortoise have? (He feels angry.)

What action does he take? (He decided to challenge the hare.)

What is the outcome?

Step 8: Write your sentences to go with each.

Step 9: Ask the students to express feelings they would have, and the physical sensations they would feel if they were living in the story?

Step 10: Story maps can help us understand stories we read and also help us to write our own stories. 


\section{DIRECT INSTRUCTION \\ Deep Processing Story Grammar}

\section{Lesson 5: Writing original stories}

Step 1: Today you are going to plan and write a story using story grammar.

Step 2: What parts do you have to think about? Characters, setting (time and place), problem or goal, feelings, actions, outcomes and what is learned.

Step 3: Draw a picture showing the characters in the setting that you want. Label the paper "characters in a setting." Take another paper and fold it the way we did when we talked about the plot. Decide what you want for your goal or problem, the feelings, the action and the outcome. Label the sections of the paper: problem, (2) feelings, (3) action, and (4) outcome.

Step 4: Write a sentence to go with each.

Step 5: With a partner check to see that each of you has included the parts of story grammar. Teacher conferences.

Step 6: Write your story linking all the parts of story grammar. Give students time to make changes. 
Step 7: Revise your story. Teacher conferences.

Step 8: Edit your story.

Step 9: Share your stories.

Step 10: This technique can be used to plan other stories. 
APPENDIX E

MODIFIED DIRECTED READING LESSON:

COMPARISON GROUP 


\section{GENERAL FORMAT}

Step 1: Skill: Vocabulary

Step 2: Background information

Step 3: Set purpose for reading

Step 4: Story reading: Teacher reads aloud while students follow. Students read a second time silently.

Step 5: Questions: Students write answers

Step 6: Discussion

Step 7: Follow-up activities: Tic-tac-toe vocabulary 


\section{Lesson 1: The Goose and the Golden Egg}

Step 1: Vocabulary: Frame the underlined word in each sentence. Read the sentence silently. Think of a word that begins with the same letter as the underlined word that would make sense in the sentence.

1. The goose did lay an egg.

2. The farmer was satisfied with the number of eggs.

3. The man was the richest person in town.

4. Good fortune is when things go well.

5. There was a heap of eggs in the nest.

6. The man owned a goose.

7. The United States is a free country.

8. The prize was hidden near the tree.

9. There was nothing to do.

Step 2: Background: What kind of animal do you see in the illustration? (a goose) Who is the man in the picture? (a farmer) What is he holding? (a golden egg)

Step 3: Set purpose: Read to find out what happens when the farmer finds a golden egg. 
Step 4: Story reading: Teacher reads aloud while students follow. Students read the story a second time silently.

Step 5: Questions: students write answers.

1. Who found the golden eggs? (the farmer)

2. Why did the farmer get rich? (He sold the eggs.)

3. Why do you think the farmer wanted more eggs? (He was not satisfied, and he wanted to get rich faster.)

4. What did the farmer think he would find in the goose? (many eggs) What did he find? (nothing)

5. How did the farmer feel when he did not find eggs in the goose? (Answers will vary•)

Step 6: Discussion: Discuss answers to the above questions.

Step 7: Follow-up activities: Play tic-tac-toe vocabulary activity. 


\section{Lesson 2: The shepherd Boy and the wolf}

Step 1: Vocabulary: Frame the underlined word in each sentence. Read the sentence silently. Think of a word that begins with the same letter as the underlined word that would make sense in the sentence.

1. The shepherd watched the sheep.

2. The sheep eat the grass in the pasture.

3. The shepherd longed for company.

4. With much excitement, everyone came running to the hill.

5. The people live together in a village.

6. The sheep were grazing in the pasture.

7. The wolf frightened the boy.

8. The wolf was feasting on the boy.

9. When the wolf vanished the boy came out of hiding.

10. The boy was ashamed of what he had done.

Step 2: Background: A shepherd is someone who watches over the sheep to make sure that they are safe.

Step 3: Set purpose: Read to see what happens when the shepherd boy plays a trick on the men of the village. 
Step 4: Story reading: Teacher reads aloud while students follow. Students read the story a second time silently.

Step 5: Questions: Students write answers.

1. Where did the boy take the sheep?

2. Why did the boy cry wolf when there was no wolf?

3. What did the men do when they heard the boy's cry?

4. Why did the men not come when they heard the boy cry a second time?

5. Why did the boy feel ashamed?

Step 6: Discussion: Discuss answers to the above questions.

Step 7: Follow-up activities: Play tic-tac-toe vocabulary activity. 


\section{Lesson 3: King Midas and the Golden Touch}

Step 1: Vocabulary: Frame the underlined word in each sentence. Read the sentence silently. Think of a word that begins with the same letter as the underlined word that would make sense in the sentence.

1. King Midas lived in a splendid palace.

2. The king kept treasures in a secret room.

3. A stranger came to the secret room.

4. The stranger disappeared.

5. The Golden Touch was a wish come true.

6. The king needed his spectacles to read.

7. Marigold thought real roses were worth a lot.

8. Soon Marigold became a golden statue.

9. The king was miserable when he lost Marigold.

10. He had to sprinkle water to change the touch.

Step 2: Background: Sometimes people wish for things they can not have or should not have.

Step 3: Set purpose: Read to find out what King Midas wanted and what happened when he got his wish. 
Step 4: Story reading: Teacher reads aloud while students follow. Students read the story a second time silently.

Step 5: Questions:

1. What did King Midas like best of all?

2. What was the king's wish?

3. Who granted the king's wish?

4. How did King Midas feel when he first got the golden touch?

5. What made the king change his feelings about the golden touch?

6. Why did the king hate gold at the end?

Step 6: Discussion: Discuss the answers to the above questions.

Step 7: Follow-up activities: Play tic-tac-toe vocabulary activity. 


\section{Lesson : The Hare and the Tortoise}

Step 1: Vocabulary: Frame the underlined word in each sentence. Read the sentence silently. Think of a word that begins with the same letter as the underlined word that would make sense in the sentence.

1. The hare has very long legs.

2. A tortoise has a shell and very short legs.

3. The animals gathered together to see the race.

4. The owl gave the starting signal.

5. The tortoise would plod slowly down the path.

6. The tired animals finished the race.

step 2: Background: The tortoise is a slow-moving turtle. The hare is a fast-moving rabbit.

Step 3: Set purposes: Read to find out what happens when the hare makes fun of the tortoise.

step 4: Story reading: Teacher reads aloud while students follow. Students read the story a second time silently. 
Step 5: Questions: Students write answers.

1. Who made fun of the tortoise? (the hare)

2. What did the tortoise want the hare to do? (race the hare)

3. Why did the tortoise win the race? (He never stopped while the hare stopped to rest.)

Step 6: Discussion: Discuss answers to the above questions.

Step 7: Follow-up activities: Play tic-tac-toe vocabulary activity with all the vocabulary introduced thus far. 
APPENDIX F

QUALITATIVE ANALYSIS FORM

165 
Name

Id.\#

Researcher

Treatment

Pretest

QUALITATIVE ANALYSIS

\begin{tabular}{|l|c|c|c|}
\hline CHARACTER & $\begin{array}{l}\text { SETTING } \\
\text { ANALYSIS }\end{array}$ & $\begin{array}{c}\text { PLOT } \\
\text { ANALYSIS }\end{array}$ & $\begin{array}{c}\text { METACOGNITIVE } \\
\text { CONTROL }\end{array}$ \\
\hline CHARACTER & $\begin{array}{c}\text { SETTING } \\
\text { SYNTHESIS }\end{array}$ & SYNTHESIS & PYNTHES \\
& & & $\begin{array}{c}\text { METS } \\
\text { CONTROL }\end{array}$ \\
& & & \\
\hline
\end{tabular}

Name

Id. \#

Researcher

Treatment

Pretest

QUALITATIVE ANALYSIS

\begin{tabular}{|c|c|c|c|}
\hline $\begin{array}{l}\text { CHARACTER } \\
\text { ANALYSIS }\end{array}$ & $\begin{array}{l}\text { SETTING } \\
\text { ANALYSIS }\end{array}$ & $\begin{array}{c}\text { PLOT } \\
\text { ANALYSIS }\end{array}$ & $\begin{array}{c}\text { METACOGNITIVE } \\
\text { CONTROL }\end{array}$ \\
\hline $\begin{array}{l}\text { CHARACTER } \\
\text { SYNTHESIS }\end{array}$ & $\begin{array}{l}\text { SETTING } \\
\text { SYNTHESIS }\end{array}$ & $\begin{array}{c}\text { PLOT } \\
\text { SYNTHESIS }\end{array}$ & $\begin{array}{c}\text { METACOGNITIVE } \\
\text { CONTROL }\end{array}$ \\
\hline
\end{tabular}

